
AIR ENTRAINMENT

\title{
P.G. Aleiferis*
}

Department of Mechanical Engineering, Imperial College London, UK

\section{N. Papadopoulos}

Department of Mechanical Engineering, University College London, UK

*Author for Correspondence:

Prof. Pavlos Aleiferis

Imperial College London

Department of Mechanical Engineering

Exhibition Road, London SW7 2AZ, UK

Tel: +44-(0)20-75947032

E-mail: p.aleiferis@imperial.ac.uk

Full length article accepted for publication by the International Journal of Heat and Mass Transfer. 


\begin{abstract}
The design of fuel injectors is key to achieving high-efficiency engine combustion with low tailpipe emissions. The small dimensions of injector nozzle holes make the manufacturing of real-size optical injectors aimed at fundamental understanding of in-nozzle processes at design stage very challenging, especially for operation under realistic incylinder thermodynamic conditions. Therefore, faithful numerical predictions based on complete multiphase flow simulations upstream and downstream of the nozzle exit of a real injector geometry are highly sought after. In this paper, numerical studies of a Diesel injector nozzle with moving needle were performed using transient Reynolds Averaged Navier-Stokes (RANS) modelling with compressibility of all phases accounted for. A Volume of Fluid (VOF) method was employed, coupled to cavitation and evaporation submodels, along with a complete set of pressure and temperature dependent thermophysical fuel properties. The aim was to understand the flow inside the nozzle both during injection and after the end of injection, including fuel dribble and air backfilling effects. A range of fuel injection and air chamber pressures and temperatures were simulated, namely 400 and 900 bar upstream and 1, 35 and 60 bar downstream. Fuel, air and wall temperatures were varied in the range $300 \mathrm{~K}$ to $550 \mathrm{~K}$. The results showed that the flow during injection carried hysteresis effects. After the end of injection, the state of the nozzle varied from being filled with a large amount of liquid to being filled mostly with air. Some form of immediate fuel dribble existed in all test cases, whilst late liquid fuel mass expulsion was also predicted under certain conditions. The latter prediction highlighted sensitivity to the models enabled. The use of a transient pressure outlet based on an engine's expansion stroke pressure trace affected the process of late fuel expulsion by pulling fuel out of the nozzle in multiphase form faster. These processes are of particular importance as they can contribute directly to unburned hydrocarbon emissions and/or the formation of deposits inside the holes. Starting a second injection from the resulting state of the nozzle at the end of the original injection resulted in a deformed liquid jet tip without the classic mushroom shape and a temporarily lower liquid jet penetration.
\end{abstract}




\section{INTRODUCTION}

\subsection{Background}

Concerns over global warming and public health, as well as international obligations to focus on sustainability, constantly call for higher engine efficiency and stricter tailpipe emission regulations. Diesel engines are a source of pollutants, including unburnt hydrocarbons and particulate matter that are both particularly toxic. Their formation is related to non-optimum fuel atomisation, mixing and combustion, including pool fires that originate from fuel spray impingement onto the liner walls and piston crown, or poorly atomised fuel that enters the chamber late in the combustion process. A source of the latter can be low-velocity fuel dripping from nozzle holes after the end of injection that does not mix sufficiently with in-cylinder air [1,2]. After the end of combustion, increased temperatures may also cause fuel that has been left in the injector nozzle sac and orifice to evaporate and move into the cylinder. The lighter compounds evaporate first, leaving back the heavier ones, which can then create nozzle deposits that affect the spray and efficiency of the engine [3]. Although an injector can be designed with a smaller sac volume to reduce $\mathrm{HC}$ emissions, the presence of a sac is typically important to equalize the pressure of the fuel at nozzle hole inlets and produce good quality sprays with low hole-to-hole flow variations and low respective variations in individual spray plume penetration, cone angle, etc. $[4,5]$. At real engine conditions, to promote atomisation, Diesel fuel is injected with very high pressures that lead to cavitation inside the nozzle [6-8]. In the case of consecutive injections, gas bubbles have been observed inside the nozzle before the start of injection $[9,10]$. These can be of a random pattern distribution in the nozzle, with bubbles coalescing and forming one large gas pocket that fills most of the hole, reaching as far back as the sac's volume. Such pockets are thought to be created by cavitation in the last stages of the previous injection event, as well as by air entrained inside the nozzle orifice from the outlet [10].

Some of the first comprehensive experimental studies in the literature provided basic visualisation of scaled-up optical injector model geometries at steady-state conditions, some of which allowed even quantitative flow field information to be extracted by Particle Image Velocimetry [11, 12]. Real-size optical injector nozzles, manufactured as faithfully as possible (but still with various limitations) [9, 13-16], enabled more relevant research studies. For example, the existence of vapour bubbles at the end of injection has been noticed in [17] and attributed to the inertia of the flow while the needle was still open. This caused the pressure inside the nozzle to drop abruptly when the needle closed, promoting cavitation. The end of injection has also been associated with bubbles forming in the sac of the injector, composed of fuel vapour and undissolved gas [18]. Although such elaborate optical studies on realsize nozzles have been very informative, they mostly allowed interpretation of events on the basis of mere observation, not by truly quantitative information of the flow field, amount of in-nozzle vapour, pressure, temperature, etc., neither by providing conclusive evidence on the exact mechanism of nozzle emptying and air backfilling $[19,20]$. In recent years, X-ray techniques of real all metal injectors have provided further insights into these complex multiphase flow problems [21, 22], including some interpretation of needle motion effects on the in-nozzle flow during injection and at the end of injection with quantification of fuel dripping (e.g. $[23,24])$. The challenge of dealing experimentally with very small real-size nozzle holes (of the order $100 \mu \mathrm{m}$ or less in diameter) at high injection pressures (in the thousands of bar) with high flow velocities (many hundreds of $\mathrm{m} / \mathrm{s}$ ) at elevated fuel and air temperatures is still an on-going research topic and it expected that more useful quantitative experimental data will emerge in the future.

In the context of such challenges, Computational Fluid Dynamics (CFD) simulations have provided useful quantification that has not been possible by typical in-situ experimentation. Simulations with finer meshes, smaller time steps and more detailed multiphase modelling methods enabled further interpretation of in-nozzle phenomena, assisting the design of new injector nozzles. However, considering computational power and memory requirements, despite the transient flow and motion of the needle, it has been common practice to simulate the flow as steady state at different fixed needle lifts [25-28], or only at full needle lift [29], at isothermal flow conditions with constant fuel properties, and with computational domains that extended only up to the nozzle exit. Some researchers have included 
a small part of the combustion chamber in their simulations, e.g. [30-32]. This was done specifically to understand in-nozzle cavitation effects on the near-nozzle atomisation process, as well as air entrainment effects. Most often the Volume Of Fluid (VOF) model is used for in-nozzle modelling [30, 33, 34], which provides liquid-gas interface tracking. In combination with Large Eddy Simulation (LES) on a sufficiently dense grid, this method may also be able to predict the primary breakup [32, 35]. Alternative multiphase flow simulation methods include the Homogeneous Relaxation Model (HRM) [36, 37]. Other gases can be included in the calculation, such as air. In [33] it was noticed that during the injection event, air entered the orifices through flow recirculation at the nozzle exit. Some work has been done on the effect of the needle's motion on the flow. For example [38] used a single-hole injector and simulated a $90^{\circ}$ sector of the real geometry due to symmetry, whilst $[39,40]$ employed multi-hole injectors but also only modelled one orifice due to symmetry. Moving needle simulations that included a part of the injection chamber have also been performed. In [41] the injection chamber was modelled as full of liquid fuel, whilst in $[42,43]$ an injection chamber full of air was used for single-hole injectors. It has been shown that the flow during the opening and closing stages of the needle's motion leads to hysteresis effects [38, 40, 41]. Hysteresis effects may be less evident with high inlet pressures in comparison to more significant effects related to needle off-axis motion [44]. The flow at the end of injection has also been given more computational attention recently. Multiphase effects have been noticed after the closing of the needle, along with fuel dribble and nozzle back-filling by ambient gas [45, $46,47]$. Effects of bulk cavitation at the end of injection, as well as air bubbles present in the nozzle affecting subsequent injection events have recently been studied both experimentally and computationally, e.g. see [19, 20, 48-52]. These highlighted the complexity of such phenomena and their diverse behaviour between single-hole and multi-hole injectors, with multi-hole nozzles associated with larger amount of fuel dribble and ingested air at the end of injection.

\subsection{Present Contribution}

A large amount of research has been carried out on the flow inside fuel injectors and the subsequent spray formation process in order to understand the complex multiphase flow physics involved and the coupling between in-nozzle and outside-nozzle phenomena. However, the effect of in-nozzle multiphase flow conditions during injection on the status of the fuel nozzle just after the end of injection (i.e. after the needle has gone back down onto its seat), and all subsequent effects on the remaining liquid fuel inside the nozzle holes and sac upon interaction with the air downstream the nozzle exit, are still mostly unknown from a quantitative perspective, particularly for a combination of realistic fuel and in-cylinder air temperatures and pressures. This is particularly true in terms quantifying the heat, mass and momentum transfer mechanisms that may induce fuel dribble or nozzle emptying between injections, contributing to engine unburnt $\mathrm{HC}$ and affecting the spray's initial formation at the next injection event, or leading to fuel film formation inside the nozzle that may gradually lead to nozzle coking. With these aims in mind, particular effort was put into setting objectives on various levels for this paper, covering the necessity for as a complete modelling approach of the whole injection process as possible, from start of injection to after the end of injection, over a useful range of temperature and pressure conditions, as summarised below:

- Devise a computational procedure with all necessary validated submodels and thermophysical fuel properties to enable multiphase simulations of a real-size multi-hole injector nozzle with moving needle and with an air chamber coupled to the exit of the injector's nozzle to allow liquid fuel, fuel vapour and air to be all tracked simultaneously on the solution domain during injection and well after the end of injection.

- Study the mechanism of injection and 'immediate' fuel dribble/expulsion after the end of injection over a range of realistic fuel injection and air back pressures, including nozzle-emptying and air-backfilling effects, focusing on differences when applying various temperatures to fuel, air and nozzle walls.

- Extend the study using a transient pressure boundary on the air chamber side, mimicking the gradual pressure decrease during the expansion stroke of an engine and identifying 'late-cycle' fuel dribble phenomena. 
- Investigate the effect of the state of the in-nozzle multiphase fluid after the end of injection on the next injection event, e.g. typical effects of pilot-main injection sequence or of injection from one cycle to the next.

Analysis of the results involved comparison with relevant experimental data, both qualitatively and quantitatively where possible, to provide validation and physical understanding of the multitude of phenomena involved. It is noted that the paper makes an attempt to bring together in a single document a wide range of conditions. It was the authors' intention from the outset to publish and discuss these data in one entity rather than in a series of separate smaller papers. Therefore, it is acknowledged that this paper may be longer than usual. However, it is believed that this approach can be more useful to the relevant research community, as it contributes notably towards a coherent database of observations which are essential for developing our knowledge of the underlying fundamental mechanisms to underpin the development of cleaner thermal propulsion systems.

\section{METHODOLOGY}

\subsection{Modelling Formulation}

The set of modelling equations consisted of the continuity equation, the momentum equations and the energy equation. The Reynolds Averaged Navier-Stokes (RANS) approach was used with compressibility of all phases accounted for. RANS solves only for the 'mean' velocity. The second-order correlations of the instantaneous fluctuating terms in the RANS equations, so-called Reynolds stresses, are modelled typically by the eddy viscosity concept. The $k-\varepsilon$ turbulence model [53-55] and the $k$ - $\omega$ model [56] are the most common models in RANS, where $k$ is the turbulent kinetic energy, $\varepsilon$ the dissipation of turbulent kinetic energy and $\omega$ is the specific dissipation rate of turbulence. The Shear Stress Transport (SST) version of the $k$ - $\omega$ model, developed by [57] was employed for most of the current study. This model combines the $k-\omega$ with the $k-\varepsilon$ model. In the free stream it uses the $k-\varepsilon$ because it is considered to perform better. However, for near wall regions, or at high pressure gradients, and in cases of flow separation and reattachment, it uses the $k$ - $\omega$ formulation which has generally better performance. The $k-\varepsilon$ model was only employed for some initial sensitivity analysis of the predicted flow rate of the injector, as detailed later.

\subsection{Multiphase Flow Modelling \& Species Transport}

The Volume of Fluid (VOF) method was employed. VOF was originally mentioned by [58], however the first publication was by [59]. With this methodology, when cavitation occurs, vapour areas are not quantified by a distinct bubble population but as an average vapour volume fraction inside the cell. The VOF conservation equation is:

$$
\frac{\partial}{\partial t}\left(\alpha_{q} \rho_{q}\right)+\nabla \cdot\left(\alpha_{q} \rho_{q} \boldsymbol{U}_{q}\right)=S_{\alpha_{q}}+\sum_{p=1}^{n}\left(\dot{m}_{p q}-\dot{m}_{q p}\right)
$$

where $\alpha_{q}$ is the volume fraction of phase $q, \rho_{q}$ is the density of phase $q$ and $\dot{m}_{p q}$ is the mass transfer from phase $q$ to phase $p . S_{\alpha_{q}}$ represents any source of phase $q$ that might exist. The phase that is not being solved for will be calculated based on the constraint that the sum of volume fractions in a cell must be equal to 1 . The discretization scheme used was a modified High Resolution Interface Capturing (HRIC) scheme [60, 61].

The VOF method assumes that the liquid and gas phases are immiscible and tracks the interface that separates them. During a typical injection of Diesel two separate gases are present; vapour and air. In some cases these two gases never mix with each other in the nozzle, as the air usually has higher pressure and cavitation bubbles collapse before the nozzle outlet. When super-cavitation is present though, the cavitation region extends to the nozzle exit and vapour originating from cavitation is transferred further downstream and can mix with the in-cylinder air. Also, after the end of injection, air can enter the nozzle and mix with vapour. For such cases, provision should be made so that numerical predictions are realistic by enabling the use of a species transport model. This means that the two gases, vapour and air, are considered to be different species of the same phase. They are defined as active scalars, each of which has its own properties. A scalar transport equation is solved for each one but they share the same interface that separates them from the liquid. Scalar transport is based on a convection-diffusion equation that is solved for $n-1$ species:

$$
\frac{\partial}{\partial t}\left(\rho Y_{i}\right)+\nabla \cdot\left(\rho \boldsymbol{U}_{q} Y_{i}\right)=-\nabla \cdot \boldsymbol{J}_{i}+S_{i}
$$

where $S_{i}$ is any source of the $i^{\text {th }}$ species that might exist. 


\subsection{Cavitation and Evaporation Modelling}

Cavitation is modelled as a mass transfer mechanism which converts liquid to vapour. This happens when specific criteria are met, typically when the pressure drops locally below the saturated vapour pressure. The vapour then is one of the species that is governed by equation (2). When the pressure rises again, vapour turns back into liquid. The cavitation model of Schnerr and Sauer [62] was used in the current study after some initial sensitivity studies that also tested the Zwart-Gerber-Belamri (ZGB) [63], as will be detailed later. In the Schnerr-Sauer model, the vapour source term is given by:

where:

$$
R=\frac{\rho_{v} \rho_{l}}{\rho} \frac{d \alpha}{d t}
$$

$$
\alpha=\frac{n_{b} \frac{4}{3} \pi R_{B}{ }^{3}}{1+n_{b} \frac{4}{3} \pi R_{B}{ }^{3}}
$$

with $n_{b}$ the number of bubbles per volume of liquid (typically set as a constant of the order $10^{13}$ ) and $R_{B}$ the bubble radius calculated by the Rayleigh-Plesset equation [64, 65].

The evaporation process was modelled as another mass transfer mechanism converting mass from liquid to its vapour with a purposely implemented submodel. Evaporation as a process occurs at the surface of a liquid continuously. At the same time, vapour condenses into liquid at the surface at a different rate. The rate at which each process takes place depends on the partial pressure of vapour, as defined by Dalton's law. When the partial pressure of vapour is equal to the vapour pressure, then evaporation and condensation are in equilibrium. If the partial pressure of vapour is lower than the vapour pressure, then evaporation is higher than condensation, leaving a net flux of mass from liquid to vapour. The rate of evaporation for a single component liquid as derived in [66] is equal to:

$$
\dot{\omega}=\frac{\left.\rho_{g} D_{m} \nabla Y_{\vec{N}}\right|_{g} ^{\Gamma}}{1-Y_{\text {vap }}^{\Gamma}}
$$

where $\rho_{g}$ is the density of the gases, $D_{m}$ the mass diffusivity of the gases, $\left.\nabla Y \underset{N}{\overrightarrow{ }}\right|_{g} ^{\Gamma}$ is the gradient of the vapour concentration in direction normal to the interface and:

$$
Y_{v a p}^{\Gamma}=\frac{p_{\text {vap }}^{\Gamma} m_{\text {vap }}}{\left(p_{a t m}-p_{\text {vap }}^{\Gamma}\right) m_{g}+p_{\text {vap }}^{\Gamma} m_{\text {vap }}}
$$

where $p_{v a p}^{\Gamma}$ is the vapour pressure at the interface. The surface area of the interface was calculated by the VOF gradient. As described in $[67,68]$, the magnitude of the VOF gradient is equal to the surface density (i.e. the magnitude of the interfacial area inside a cell) and its direction is normal to the surface. The evaporation model was implemented by user coding into ANSYS Fluent [69] and the code was then used for the solution of the system of transport equations, employing also ideal gas equations of state for vapour and air.

\subsection{Fluid Properties}

Diesel fuel is a mixture of a large number of organic compounds without a strictly fixed unique composition, hence it can come in various types of blends with a range of distillation curves between $150-300{ }^{\circ} \mathrm{C}$. Use of appropriate thermophysical fuel properties with full temperature and pressure dependence is particularly important in modelling high-pressure fuel injectors because of the large gradients that exist in very small spaces. Measuring real Diesel fuel properties over a wide range of temperatures and pressures is a challenging task and no fixed set of properties has been unanimously agreed by researchers as the best for in-nozzle simulations, hence one can find a variety of suggested properties in the literature. Within the objectives of the current paper, it was considered reasonable to select fuel properties that would match the fluid that had been used for injection flow rate measurements of the injector under study. The fluid used in the experiments was a calibration liquid with specifications defined by ISO4113, called "Normafluid". A formulation for the density and viscosity of this fluid that was consistent with the properties provided by the experimentalists was found in [70], whilst other properties like the specific heat, bulk modulus, coefficient of compressibility were found in [71]. For the thermal conductivity and the speed of sound, the formulation suggested by Kolev [72] was selected; most other properties suggested by Kolev [72] were properties of 
$n$-octane and not considered. After intense study, it was found that the properties of $n$-tridecane were a good match for the properties of Normafluid. This approach was followed because according to [70, 71] 25.7\% of the molar mass of Normafluid comes from isomers of tridecane. Also, another $30 \%$ comes from isomers of dodecane and tetradecane which have similar molar masses. Several researchers have used $n$-dodecane in their simulations, e.g. to compare with Spray A, B, D experiments of the Engine Combustion Network (ECN) [46, 48, 49]. However, $n$-dodecane was not considered directly suitable within the scope of the current work due to this not being the best match for Normafluid's properties and due to the high vapour pressure at increased temperatures that could lead to excessive cavitation. The thermophysical properties of $n$-tridecane were obtained from [73] over a wide range of temperatures and pressures and implemented for liquid and gas phases by user-coding respective temperature and pressure dependent correlations (density, viscosity, surface tension, thermal conductivity, heat capacity, latent heat, vapour pressure, diffusion coefficient, bulk modulus, speed of sound).

\subsection{Injector Geometry, Needle Motion and Grid}

The geometry of a real multi-hole Diesel injector with sac volume, designed for vertical installation inside the engine head of a light duty vehicle, was used. The total length of the geometry in the direction of the axis of the needle was $7 \mathrm{~mm}$. The injector carried 7 holes with a length of $0.6 \mathrm{~mm}$ and diameter of approximately $0.12 \mathrm{~mm}$. The inlet curvature radius was $0.02 \mathrm{~mm}$ and the inclination angle of each orifice was $84^{\circ}$. The symmetric geometry allowed the use of only one $1 / 7^{\text {th }}$ sector of the injector for the simulations; periodic boundaries were employed on the sides to save computational time. The geometry is illustrated in Figure 1. In order to allow simulations of the fluid motion after the end of injection, an extra volume of cylindrical shape with length equal to 10 nozzle diameters was attached to the nozzle exit, mimicking a part of the combustion chamber.

A moving mesh strategy was used by adopting a layering technique. The computational domain consisted of two regions. One was the non-moving region, which represented the geometry when the needle was at its fully closed position. The moving region was made out of the volume that was created as the needle lifted. When the needle moved, the layer of cells in touch with the needle changed size in order to account for this motion. When the size of the cells exceeded certain limits, the cells either divided into smaller ones, thus creating a new layer, or combined with the neighbouring layer. The needle was a moving no-slip wall boundary. Practically, for all simulations, the needle never actually touched the needle seat. This is because the code cannot handle two different wall boundaries when two surfaces are in direct contact. Therefore, in order to seal the high-pressure zone from the sac and nozzle area at needle closure, a wall interface was enabled. Specifically, an interface that connected the needle seat area with the needle itself existed throughout the simulation. While the needle was in motion, this interface was considered 'interior', so it had no effect on the flow. Just before the start of the needle's lift motion, or when the needle descended to $0.5 \mu \mathrm{m}$ lift during closure, this interface was switched to 'wall' and resulted in two disconnected domains [45], interrupting the flow passing through and sealing the high-pressure from the low-pressure zone. During the period that this interface was defined as wall, it consisted of 4 cells in thickness.

The needle lift curve is illustrated in Figure 2. This defined how the needle moved with respect to time. The injection duration was $1.86 \mathrm{~ms}$ long, during which the needle was ascending for $0.88 \mathrm{~ms}$ and descending for $0.98 \mathrm{~ms}$. Compared to the maximum lift of $256 \mu \mathrm{m}$, the $0.5 \mu \mathrm{m}$ threshold of needle closure was considered negligible. The measured volumetric flow rate at the injector's inlet has also been included in Figure 2 (total flow rate for all 7 holes). The measurements were obtained with 400 bar injection pressure and 60 bar back pressure at isothermal room temperature conditions using Normafluid. Start Of Injection (SOI) is at $0.72 \mathrm{~ms}$ and corresponds to the start of the hydraulic motion of the needle excluding injector driver and other delays recorded from the start of time. The End Of Injection (EOI) is at $2.58 \mathrm{~ms}$ and corresponds to the time the needle returned back to its seat. The flow exhibited some leakage due to needle bounce past $2.58 \mathrm{~ms}$; these effects were not considered in the simulations. It is also noted that, when the needle starts lifting, a pressure drop is typically noticed on the injector's fuel line, which recovers later in the injection process. Therefore, the measured flowrate exhibits typically an asymmetric profile when comparing pre- 
and post- maximum needle lift periods, clearly indicating a slower rate on the early period. A typical event of this type can also be seen in other publications, e.g. in [10] where the line pressure dropped abruptly at the beginning of the injection by $\sim 13 \%$ of the nominal value and did not recover completely till the end of injection. Comments on the predicted profiles of flow rate shown in Figure 2 with $k-\varepsilon$ and $k$ - $\omega$ models for fixed injection pressure of 400 bar into 60 bar back pressure will be provided in the validation section later.

A block-structured mesh was used for discretising the domain. Details of the mesh have been included in Figure 1. When the needle was closed, the mesh consisted of 611,478 cells. 391,878 of these were part of the nozzle, while the rest were part of the air chamber. At full lift there were 1,130,094 cells in total. 50 cells were typically placed along the nozzle diameter. In the core of the orifice the typical cell size was $\sim 4 \mu \mathrm{m}$, while the first cell at the wall was $\sim 0.15$ $\mu \mathrm{m}$. The average size in the sac area was also $\sim 4 \mu \mathrm{m}$. The achieved wall $y^{+}$was less than 1 in the region of the sac and nozzle orifice. For grid sensitivity analysis, three more meshes were created and tested. A coarse one, with 120,000 cells at minimum needle lift (excluding the air chamber), a medium one with 250,000 cells and a very fine mesh with 1,500,000 cells. Aspects of this analysis were performed at the conditions of the measured flow rate with 400 bar inlet, 60 bar outlet. The $k-\omega$ SST model was used. Second-order discretisation was employed. The core of the grid sensitivity results have been discussed in [74] and are not reproduced here in graphical form for brevity. It is summarised though that the predicted volumetric flow rate throughout the whole injection event showed a maximum difference of just $0.5 \%$ between the coarse and very fine meshes. Velocity profiles of all four meshes were studied inside the orifice where flow separation and recirculation occurred. The length of the recirculation zone showed differences between the fine and the medium mesh of the order of $4-5 \%$, while for the fine and the very fine meshes this was of the order $2 \%$. Therefore, the rest of the simulations in this paper were performed with the fine mesh that provided good balance between grid independence and available computing power.

\subsection{Boundary Conditions and Test Cases}

At the beginning of the injection, the flow field was considered to be at rest. The nozzle was full of liquid fuel, while the injection chamber was full of air. The main vertical sides of the injector geometry were defined to be periodic. A total pressure boundary condition was applied to the inlet where fuel entered the domain and absolute static pressure was applied to the outlet surfaces of the cylindrical air chamber. The test matrix of simulated cases is summarised in

Table 1. The conditions were selected by a systematic approach to examine specific effects as shown in the last column and detailed below.

Three different pressure sets were used. The first one corresponded to the measured flow rate conditions of 400 bar injection pressure into 60 bar chamber pressure. The second one related to a limited data set of optical nozzle injection images captured at 400 bar injection pressure into 1 bar chamber pressure (see [19] for a sample set). The third one referred to the operating conditions of a single-cylinder research engine based on a DI Diesel Puma configuration with a Ford TDCi production multi-cylinder head, run on a dynamometer in-house [75]; this was 900 bar injection into 35 bar chamber pressure.

The temperatures for fuel, air and walls were carefully considered. According to [76], fuel temperatures were measured as high as $363 \mathrm{~K}$ at the common rail and $373 \mathrm{~K}$ at the nozzle tip. However, the nozzle tip itself has been known to reach higher temperatures, which is one of the reasons that injector fouling/coking takes place. The work of [3] refers to typical temperatures of 523-573 $\mathrm{K}$ at the nozzle when firing, whilst [77] measured $473 \mathrm{~K}$ at motoring. The work of [76] referred to 463-473 K which dropped to 363-373 K with cooling and insulation. The work of [78] measured $440-500 \mathrm{~K}$ at the nozzle tip, similar to the ones of $[79,80]$. It was decided to use fuel temperatures in the range 300-353 K. The walls were considered adiabatic for the majority of the simulations but for one case the wall was set to a constant temperature of $473 \mathrm{~K}$. The fluid temperatures were uniform everywhere and equal to the temperature of the inlet, except from one case where a higher temperature of $550 \mathrm{~K}$ at 35 bar was applied to the air chamber region to represent air at compression based on the in-cylinder measured data obtained in-house. The Reynolds numbers were calculated for all simulated test cases when the needle was at maximum lift (using averaged 
quantities at the nozzle exit). These were found to be in the range 10,000-40,000, with the larger values corresponding to higher fuel temperatures with lower fuel viscosities and slightly higher flow rates. The review work of [81] was also considered for comparison with the general literature on cavitating injectors. The discharge coefficient of this nozzle was found in the range $0.7-0.8$ for cavitation parameters $K=\left(p_{i n j}-p_{v}\right) /\left(p_{i n j}-p_{a m b}\right)$ in the range $1-$ 1.4 , following literature trends.

\begin{tabular}{|c|c|c|c|c|c|c|}
\hline $\begin{array}{c}\text { Test } \\
\text { Case }\end{array}$ & $\begin{array}{c}\text { Injection } \\
\text { Pressure } \\
{[\mathbf{b a r}]}\end{array}$ & $\begin{array}{c}\text { Chamber } \\
\text { Pressure } \\
{[\mathbf{b a r}]}\end{array}$ & $\begin{array}{c}\text { Injection } \\
\text { Temperature } \\
{[\mathbf{K}]}\end{array}$ & $\begin{array}{c}\text { Chamber } \\
\text { Temperature } \\
{[\mathbf{K}]}\end{array}$ & $\begin{array}{c}\text { Wall } \\
\text { Temperature } \\
{[\mathbf{K}]}\end{array}$ & Examined Effect \\
\hline 1 & 400 & 60 & 300 & 300 & Adiabatic & Validation case \\
\hline 2 & 400 & 1 & 300 & 300 & Adiabatic & $\begin{array}{c}\text { Reduced back pressure to } \\
\text { study effect on cavitation }\end{array}$ \\
\hline 3 & 900 & 35 & 300 & 300 & Adiabatic & $\begin{array}{c}\text { Increased injection pressure, } \\
\text { intermediate back pressure }\end{array}$ \\
\hline 4 & 900 & 35 & 353 & 353 & Adiabatic & $\begin{array}{c}\text { Increased fuel and air } \\
\text { temperature }\end{array}$ \\
\hline 5 & 900 & 35 & 333 & 550 & Adiabatic & $\begin{array}{c}\text { Highly increased chamber } \\
\text { temperature }\end{array}$ \\
\hline 6 & 900 & 35 & 333 & 333 & 473 & \begin{tabular}{c} 
High wall temperature \\
\hline 7
\end{tabular} \\
\hline 900 & $35 \rightarrow 10$ & 300 & 300 & Adiabatic & $\begin{array}{c}\text { Transient decrease of air } \\
\text { chamber pressure }\end{array}$ \\
\hline 8 & 900 & $35 \rightarrow 10$ & 333 & 550 & Adiabatic & $\begin{array}{c}\text { Transient decrease of air } \\
\text { chamber pressure }\end{array}$ \\
\hline 9 & 400 & 1 & 300 & 300 & Adiabatic & $\begin{array}{c}\text { Needle relift after the end of } \\
\text { injection }\end{array}$ \\
\hline
\end{tabular}

Table 1 Boundary conditions and type of properties for the test cases that were simulated.

It is noted here for completeness that in Diesel engines, depending on operating regime, injection and in-cylinder pressures and temperatures can be higher than the ones investigated within the parameter space of this paper. Certain operating regimes for Diesel engines can approach the critical point on the saturated vapour pressure curve and then the determination of all fluid properties and modelling of thermophysical behaviour has to be reconsidered by using real fluid equations of state. Transcritical and supercritical conditions are under study by the current authors but not included in this paper. Therefore, the conditions in Table $\mathbf{1}$ were selected specifically to stay clear off such issues. Nevertheless, they still cover a quite wide range of engine operation, including typical pilot and main injection events, and are also representative of novel injection strategies targeted at partially premixed charge compression ignition operation with quite advanced injection timings. For example, typical pilot injections start well in advance of the main injection, about $20-40^{\circ}$ crank angle before top dead centre [82-84], or even $90^{\circ}$ crank angle before top dead centre for highly premixed charge operation, e.g. [85], hence in-cylinder pressures in such cases can be significantly lower than the main injection event.

\subsection{Validation}

Validating in-nozzle flow simulations at realistic engine operating conditions can be a quite challenging. This challenge is primarily associated with the lack of available experimental data, particularly of optical nature and of quantitative type from faithful real-size optical injector nozzles at high-pressure high-temperature fuel and air conditions. Several levels of validation processes were performed within the bounds of the current work. The first one aimed at studying the flow rate during the injection process and comparing this against the measured flow rate of this injector for 400 bar injection pressure and 60 bar back pressure at $300 \mathrm{~K}$ to study the effect of turbulence model. The second one was based on published studies of cavitation imaging in optical nozzles obtained from the literature using water fluid at different temperatures and pressures. The third one focused on simulations of evaporating droplets using various test cases in the literature with water and $n$-dodecane over a range of temperatures 
and pressures. Considering the extensive nature of validation, results are not reproduced here in graphical form for brevity but can be found in $[74,86]$. Key validation points are provided below though for the benefit of the reader.

\subsubsection{Injector Flow Rate}

A satisfying agreement with the measured flow rate of Figure 2 was observed at the very early stages of needle opening (0.6-1 ms) with both the $k-\varepsilon$ and $k-\omega$ SST models. The latest stages of closing (2.2-2.6 ms) where predicted very well by the $k-\omega$ SST model. The period of $1-1.5 \mathrm{~ms}$ was predicted better with the $k-\varepsilon$ model whilst the period 1.7-2.2 ms better with the $k$ - $\omega$ SST model. This was associated with the imposed fixed inlet pressure boundary condition of 400 bar that was used in the simulations in contrast to the injector's inlet lowered pressure effect on the measured flow rate upon needle opening during the first half of injection as mentioned earlier. To examine this hypothesis, a test simulation with a pressure inlet of 360 bar, i.e. $10 \%$ lower than the nominal of 400 bar, was performed. The resulting flow rate predicted by the $k-\omega$ SST model was found to match well the flow rate of the experiment in the first half of the injection event. A similar type of behaviour has been noticed in [87, 88]. The $k-\varepsilon$ model that appeared to be in better agreement with the experimental results in the first part of the simulation when the nominal pressure of 400 bar was applied, produced much lower flow rate with 360 bar than that shown in Figure 2. Detailed study of the in-nozzle flow field predicted by the $k-\varepsilon$ model revealed much different recirculation zones than those predicted by the $k-\omega$ SST model, which could be directly linked to the different discharge coefficient of the $k-\varepsilon$ prediction. Therefore, the $k-\omega$ SST was employed for the rest of the simulations reported hereafter.

\subsubsection{Validation of Cavitation Modelling}

The predicted flow rate curve of the $k-\omega$ SST model was independent of cavitation model; both the Schnerr-Sauer and the Zwart-Gerber-Belamri models led to the same flow rates as this case was associated with very minimal presence of cavitation (to be shown in detail later). Therefore, it was decided to identify a couple of optical nozzle geometries with sufficiently wide range of measured data that could be used for validation of the two cavitation models. The experimental work of [89] has been used by some authors to validate simulated cavitating flows. However, conflicting observations have been reported. For example, it was found in [90] that the Schnerr-Sauer model underestimated the size of the cavitation zone but matched better the velocity profiles than the Zwart-GerberBelamri model. After extensive survey, the experimental optical geometries of [91, 92] were finally selected for validation here as they offered all necessary dimensions to faithfully model their relatively simple geometries with water as the working fluid, using cell resolution of similar level to that used in the real injector simulations. The geometry of [91] as a 4-mm-wide quasi-2D optical nozzle operated with fluid temperatures in the range 293-333 K and Reynolds numbers as low as 50,000. The simulations showed that the Schnerr-Sauer predictions were closer overall to the experiments than the Zwart-Gerber-Belamri in terms of cavitation length over the full range of temperatures [74]. Then this cavitation model was selected to model the 3D step optical nozzle configuration of [92] that provided experimental data of cavitation imaging and in-nozzle velocities measured by Laser Doppler anemometry. A range of different inlet pressure boundary conditions were simulated, with cavitating conditions spanning from incipient cavitation to super-cavitation. Good agreement between experiment and simulations was observed for both the length and the width of the cavitation region at most conditions of relevance to the real injector. Moreover, the predictions matched the measured profiles of both mean and standard deviation axial velocities at three different locations downstream the orifice inlet within $5-10 \%$ at most conditions [86]. The main challenge involved capturing highly transient incipient cavitation phenomena observed in the experiments. However, this was expected by RANS. Adoption of LES showed better match with the experiments at such challenging conditions but, considering the much greater running times required with LES, the combination of the selected RANS models was considered sufficient to provide analysis of the cavitation phenomena in the real Diesel injector for the range of conditions of interest in the current study. 


\subsubsection{Validation of Evaporation Modelling}

The evaporation methodology that was implemented by user coding was studied by running several test cases to validate the calculation of the surface area of the liquid and evaporation rate [86]. Initially various geometrical shapes of liquid were studied with dimensions similar to those of the injector's nozzle hole (e.g. in the range 10-100 $\mu \mathrm{m}$ in radius or thickness), using cell densities comparable to those used to resolve features of the in-nozzle flow. For arbitrary shapes the surface area is not known, hence the VOF gradient calculated by the code was employed. The calculation of the overall surface area of the simple shapes was validated to be within fractions of $0.1 \%$ of the nominal. Then the evaporation rate was validated by using as reference cases the studies of [66, 93]. These were selected from the literature to match the range of thermodynamic conditions used in the current study. The case of [66] referred to water droplets of $75 \mu \mathrm{m}$ in initial radius at an initial temperature of $353 \mathrm{~K}$ with the temperature of the gas set to $373 \mathrm{~K}$ or $573 \mathrm{~K}$. The simulated results matched those of [66] in the evaporating mass of the droplet within 1-4\%, with the larger difference recorded for the higher gas temperature. The temperature of the droplet was also predicted sufficiently well, with a maximum difference of $\sim 7 \mathrm{~K}$ recorded on the interface of the droplet. The work of [93] referred to various $n$-Dodecane droplet test cases relevant to Diesel injection, typically with initial droplet radius of $10 \mu \mathrm{m}$ at initial temperature of $300 \mathrm{~K}$ in an environment of air at $650 \mathrm{~K}$, or slightly larger droplets with initial radii in the range $16-18 \mu \mathrm{m}$ at a higher initial temperature of $380 \mathrm{~K}$ with the surrounding air at $707 \mathrm{~K}$ and a pressure of about 60 bar. Good agreement was recorded between the simulations of the current methodology and those presented by [93], typically again within $1-4 \%$ in terms of the droplet's radius reduction during evaporation.

\section{RESULTS - PART I: Flow Behaviour during Injection}

Various plots are shown in the following sections to provide a global view of the state of the nozzle in terms of cavitating flow. Two main views of the geometry have been selected. One is the middle/symmetry plane that cuts through the sac and the orifice, giving a view of the interior flow and the injection chamber so that the state of the liquid jet can be evaluated. The second view is made out of 5 planes vertical to the axis of the orifice, one of these being the orifice exit. During injection the contours are plotted mainly at three different timings: at $25 \mu \mathrm{m}$ ascending needle lift (0.18 ms After the Start Of Injection, ASOI), at maximum lift of $\sim 250 \mu \mathrm{m}(0.88 \mathrm{~ms}$ ASOI), and at $25 \mu \mathrm{m}$ lift during the needle closing period (1.78 ms ASOI). Contours for the period After the End Of Injection (AEOI) till the point where the flow has been brought to a halt were also studied at various timings and are shown in respective parts of results in later sections of this paper.

\subsection{Test Case 1: 400 bar inlet at $300 \mathrm{~K}$ and 60 bar outlet at $300 \mathrm{~K}$}

At this condition cavitation was limited to very small areas in the vicinity of the nozzle orifice inlet, confined to highly transient incipience points and appeared only temporarily, therefore no cavitation can be seen at the orifice entrance or the rest of nozzle area within the resolution of Figure 3. At $0.1 \mathrm{~ms}$ ASOI one can observe the typical 'mushroom' shape forming at the tip of the liquid jet that has been captured experimentally by [9, 94-96] at conditions of nozzle orifice full of liquid at SOI. This flattens out quite quickly by $0.14 \mathrm{~ms}$ ASOI. At $0.18 \mathrm{~ms}$ ASOI, the velocity magnitude inside the orifice had a maximum value of around $175 \mathrm{~m} / \mathrm{s}$. The flow field is not presented here because aspects of this have been discussed by the current authors in [74] and have also been found similar to what reported by other authors, e.g. see $[29,30,36,97,98]$. However, it is noted that the flow has formed a region of separation at the top corner of the orifice inlet by $0.18 \mathrm{~ms}$ ASOI with a vortex pair present in the upper area of the orifice on the circular cross section of the orifice. At full needle lift, $0.88 \mathrm{~ms}$ ASOI in Figure 3, the flow is 'quasi-steady' with minimal disruption of the liquid phase within the resolution of the simulation; velocity levels were as high as 290 $\mathrm{m} / \mathrm{s}$. The flow was linked with a clear system of four vortices inside the orifice forming a helical pattern of motion, similar to those reported by $[27,29,88,99]$ and linked with the sac volume. At $1.78 \mathrm{~ms}$ ASOI with $25 \mu \mathrm{m}$ needle lift before closure, wavy fluctuations are seen on the liquid jet's surface with a size 10-20\% of the nozzle diameter. Such behaviour was not observed at $25 \mu \mathrm{m}$ ascending needle lift, indicating flow hysteresis effects. No vapour from cavitation was predicted at this condition, most probably because of the inability to capture highly transient cavitation 
incipience phenomena that would require an LES framework of prediction. It also noted that string cavitation within helical flow fields cannot be captured properly by existing cavitation models as it is highly unstable and can occur at local 'mean' pressures higher than the vapour pressure [88]. Overall the temperature inside the nozzle increased due to shearing and strain effects. The areas with higher temperature were the wall boundaries, the recirculation or significant secondary flow zones, and at full needle lift the outer edges of the liquid jet. At $25 \mu \mathrm{m}$ ascending and descending needle lift the temperature inside the orifice was about $10-20 \mathrm{~K}$ higher than the inlet. This increase occurred mostly downstream of the needle seat, with higher values just downstream the sharp orifice inlet corner. A word of caution applies here. Although there is no phase change inside the nozzle and no major fluctuations are seen on the surface of the liquid jet outside the nozzle in Figure 3 at full needle lift, some diffusion of the liquid interface can be seen in the air chamber, growing larger downstream. This behaviour is related to the increasing size of cells towards the outlet of the domain that leads to numerical deviation from a totally sharp interface between liquid and gas phases, hence it is not physical phase change. When creating the grid, great effort was put into enabling sufficient spatial and temporal resolutions that minimised this effect within the bounds of reasonable computing power requirements, especially inside the nozzle and in the vicinity of the orifice exit in the air chamber at high needle lift with the highest velocities. The outcome has been quite good on balance throughout the results of most test cases, particularly in areas of interest inside the nozzle, hence the spatial resolution was kept fixed for all test cases within the objectives of this paper.

\subsection{Test Case 2: 400 bar inlet at $300 \mathrm{~K}$ and 1 bar outlet at $300 \mathrm{~K}$}

By $0.18 \mathrm{~ms}$ ASOI with $25 \mu \mathrm{m}$ needle lift, cavitation has already formed as seen in Figure 4. The cavitation region appears attached to the orifice entrance and extends to about one third of the orifice length; some vapour reaches the nozzle outlet and cavitation patterns are found inside the body of the liquid jet. Sensitivity analysis showed that this effect was not predicted with incompressible simulations and constant fluid properties. At the beginning of injection the area downstream of the needle seat has pressure equal to the chamber pressure, while upstream of the needle seat the pressure is equal to the injection pressure. When the needle starts lifting, the total volume of the nozzle increases, thus the pressure drops, and in areas of low pressure even inside the chamber cavitation can be found. The in-nozzle circular cross-section planes reveal that the vapour phase exists near the nozzle inlet in two separate void regions, connected to respective vortical flow structures. At full needle lift, $0.88 \mathrm{~ms}$ ASOI, limited cavitation was seen initiating at the orifice inlet moving downstream despite the presence of a system of four vortices persisting along the orifice with a well-defined structure of helicity. The liquid jet's structure is not intact like in Test Case 1 but appears multiphase on this plane, linked to the highly swirling motion of the jet. At $25 \mu \mathrm{m}$ descending needle lift, $1.78 \mathrm{~ms}$ ASOI, phenomena similar to those at $0.18 \mathrm{~ms}$ ASOI are seen but with more intense cavitation inside the nozzle. With the needle about to close, the pressure decreases as the flow decelerates and drops locally to values below the vapour pressure, intensifying the formation of cavitation. Downstream, there is no cavitation present on this vertical plane; however, the cross-section plots indicate that there are again two separate cavitation regions that extend throughout half the orifice hole. Contrary to what was predicted at $25 \mu \mathrm{m}$ ascending needle lift, $0.18 \mathrm{~ms}$ ASOI, the cavitation regions at $25 \mu \mathrm{m}$ descending needle lift are related to a pair of counter rotating vortices on the lower side of the orifice that later grow and occupy the whole orifice cross-section, but with quite low levels of helicity overall. The experimental work of [10] has shown similar behaviour. Regarding temperature, there was a marginal increase to what predicted with 60 bar chamber pressure, indicating the balance of viscous diffusion and phase change effects.

The total volume of vapour inside the orifice is plotted in Figure 5 for both chamber pressures of 1 bar and 60 bar. The injection into 60 bar displays very little cavitation, only at $\sim 1.1 \mathrm{~ms}$ and at $2.3-2.5 \mathrm{~ms}$ of elapsed time. The injection into 1 bar cavitates heavily almost throughout the whole injection event, except for a period of time in the region of highest needle lift. During the needle closing stage the presence of cavitation is higher overall than that of 
the opening stage, reaching a maximum value 2.5 times higher. At the very end of injection, the total volume of vapour was $\sim 40 \%$ of the total orifice volume. The wavy nature of the traces in this figure is indicative of the unsteadiness of the flow and cavitation voids that grow and collapse continuously.

Figure 6 shows the presence of air in the orifice during injection. The points of interest are the beginning and the very end of injection. When the needle starts lifting, the pressure inside the sac drops as the overall volume of the nozzle increases. This pressure drop pulls the fluid inside the orifice backwards, and this in turn pulls air from the chamber inside the orifice. Immediately afterwards, as the fuel starts flowing towards the nozzle exit, air is pushed back and leaves the orifice completely. The injection into 1 bar chamber pressure pulls in 6 times more air, equivalent to $\sim 10 \%$ of the orifice volume. A very small quantity of air is also present in the orifice during the last $80 \mu$ s before needle closure. This is air that remained very close to the nozzle exit and, as instabilities grew on the surface of the jet, entered the orifice when the interface of liquid and gases separated from the nozzle wall.

\subsection{Test Case 3: 900 bar inlet at $300 \mathrm{~K}$ and 35 bar outlet at $300 \mathrm{~K}$}

The maximum flow rate at full needle lift was calculated to be $\sim 60 \%$ higher than in the case of 400 bar injection into 60 bar back pressure. Figure 7 shows that the cavitation regions on the central vertical symmetry plane are generally small. The most significant change in the flow, in comparison to the 400 bar injections, is the cavitation pocket that is noticed on the lower side of the orifice at $0.18 \mathrm{~ms}$ ASOI. In general, due to high momentum, a part of the flow passes through the sac area and then enters the orifice; this results in flow separation on the lower side of the nozzle entry and consequently cavitation pockets. As can be seen on the circular cross-section planes, there is an amount of cavitation out of the central vertical plane. A form of primary breakup is observed and a quantity of gas is engulfed within the liquid core of the jet. At full needle lift, $0.88 \mathrm{~ms}$ ASOI, no cavitation is present inside the orifice, similarly to the findings of [97]. At $1.78 \mathrm{~ms}$ ASOI, a ligament that has detached from the liquid core can be seen just next to the orifice exit. The different cavitation patterns between the $25 \mu \mathrm{m}$ descending needle lift at $1.78 \mathrm{~ms}$ ASOI and the $25 \mu \mathrm{m}$ ascending needle lift at $0.18 \mathrm{~ms}$ ASOI suggest again strong hysteresis effects. The velocity inside the orifice exceeded values of $450 \mathrm{~m} / \mathrm{s}$ at full needle lift, with strong helicity. Analysis of the fuel temperature field showed higher values than at 400 bar injection, reaching $50 \mathrm{~K}$ higher than the nominal injection temperature, particularly at the early and late injection phases.

\subsection{Test Case 4: 900 bar inlet at $353 \mathrm{~K}$ and 35 bar outlet at $353 \mathrm{~K}$}

The higher fuel and air temperature enhanced most of the effects noticed in Test Case 3. The lower fuel viscosity and decreased air density led to an increased flow rate of the order $2 \%$. The higher vapour pressure led to more cavitation overall in Figure 8 than the injection of $300 \mathrm{~K}$. The increased injection temperature caused a more intense secondary flow, especially in the early and late timings of $25 \mu \mathrm{m}$ ascending and descending needle lift. Specifically, at low needle lift, a pair of vortices was seen on the lower side of the orifice, close to the orifice inlet, which moved upwards in the downstream direction and approached the top side. At $25 \mu \mathrm{m}$ needle lift before closure there was one large vortex throughout the orifice and a large volume of cavitation in the core of the nozzle, extending to the outlet. The flow throughout injection carried greater helicity than at $300 \mathrm{~K}$. The surface of the jet presented more intense instabilities that led to breakup close to the domain outlet.

\subsection{Test Case 5: 900 bar inlet at $333 \mathrm{~K}, 35$ bar outlet at $550 \mathrm{~K}$}

The increased temperature in the chamber results in reduced density of air, by almost half; this implied reduced drag on the surface of the jet. Therefore, a small increase in the flow rate compared to Test Case 3 was found. In Figure 9, at $0.18 \mathrm{~ms}$ ASOI a small cavitation region at the entrance of the nozzle is seen. This was related to the fact that the recirculation zone in that region had reduced in size and was observed in general for runs with fuel temperature set to $333 \mathrm{~K}$, highlighting that the vapour pressure increase was not sufficient to promote cavitation within the smaller recirculating field. At maximum needle lift, weak but symmetric cavitation patterns are seen along the length of the nozzle and the liquid jet has heavily ruptured. The last timing of Figure 9 presents significant cavitation that reaches the outlet of the nozzle and large voids are formed inside the core of the liquid jet. The fuel temperature increased to 
levels of $380 \mathrm{~K}$ inside the nozzle at the beginning of injection, cooling down by about $30 \mathrm{~K}$ during the main injection event and increasing again to levels of 360-370 K towards the end of injection.

\subsection{Test Case 6: 900 bar inlet at $333 \mathrm{~K}, 35$ bar outlet at $333 \mathrm{~K}$ and injector walls at $473 \mathrm{~K}$}

The injection with the nozzle wall temperature set to $473 \mathrm{~K}$ showed a slightly increased flow rate in comparison to adiabatic walls. In Figure 10, at maximum needle lift, there is almost no cavitation because the high flow velocities don't allow the fluid to heat up locally to much greater temperature than the nominal. However, at the late timing of $25 \mu \mathrm{m}$ descending needle lift $1.78 \mathrm{~ms}$ ASO, the reduced flow velocity resulted in increased temperature and increased levels of cavitation both at the top and on the lower side of the orifice. The liquid jet is completely fragmented and very clear hysteresis effects can be seen between the first and last time instances. One main vortex was seen at the early part of injection, similar to Test Case 3 , and by the timing of maximum needle lift two pairs of counter rotating had formed stabilising the flow. At the late timing of $1.78 \mathrm{~ms}$ ASOI though there was again one main vortex but with the opposite rotation direction to that of the early injection phase. It is also noted that at the early phases of injection the fuel temperature inside the nozzle reached levels of $400 \mathrm{~K}$ due to heat soak. Later, at full needle lift the temperature dropped to levels of $350-380 \mathrm{~K}$. This case exhibited slightly higher flow rate $(1-2 \%)$ throughout the injection, particularly close to the end. To put things into perspective, a change in temperature from $350 \mathrm{~K}$ to $470 \mathrm{~K}$ would cause the fuel viscosity to drop by $\sim 75 \%$ and the density to drop by $\sim 15 \%$.

\subsection{Comparing vapour/air volumes during injection for all cases}

The volume of vapour inside the orifice for all 900 bar injections is plotted in Figure 11. The case of 900 bar, $300 \mathrm{~K}$ lies between the volume traces calculated for the two injections of 400 bar (consult Figure $\mathbf{5}$ as well and note the different vertical scale). There is a lot of cavitation early in the injection, with a peak at $\sim 250 \mu$ ASOI. This peak is $20 \%$ higher than the corresponding one of the 400 bar injection into 1 bar but it is present for half the time period. At the needle closing stage, cavitation is present for the same time period as for the 400 bar injection into 1 bar air, but it is significantly lower, at a level of $\sim 10 \%$. At 900 bar, the highest temperature of $353 \mathrm{~K}$ shows more intense cavitation than at $300 \mathrm{~K}$, especially at the late stages, reaching levels similar to those of the 400 bar injection into 1 bar chamber pressure. At the early stages of injection, the case with $333 \mathrm{~K}$ fuel and $550 \mathrm{~K}$ air temperature presents vapour volume in the order of $50-60 \%$ of the case with $300 \mathrm{~K}$ and the injection with $333 \mathrm{~K}$ fuel/air and $473 \mathrm{~K}$ wall temperature even smaller. As mentioned earlier, at $333 \mathrm{~K}$ flow separation and recirculation zone at the entrance of the orifice had reduced in size and the parallel increase in vapour pressure was not sufficient to promote cavitation in that field. Later through the injection, and while the needle is close to its highest lift, it is the injection into $550 \mathrm{~K}$ air that produced the highest level of cavitation, but in low volume equivalent to $\sim 1.5 \%$ of the total orifice volume. Close to the end of injection, the case with $473 \mathrm{~K}$ walls produced the highest volume of vapour, followed closely by the case of $353 \mathrm{~K}$ and then by the case with $550 \mathrm{~K}$ air.

The volume of air inside the orifice is plotted in Figure 12. It is shown that the case with $333 \mathrm{~K}$ fuel/air and $473 \mathrm{~K}$ walls had the highest volume of air in the orifice at needle closure and beyond, reaching levels of up to $75 \%$ of the total volume of the orifice. This followed the increased vapour volume and indicated condensation of the latter. The $473 \mathrm{~K}$ walls case was followed closely by the case of $353 \mathrm{~K}$ fuel-air with adiabatic walls, showing vapour volume about $55 \%$ of the total orifice volume. The injection into $550 \mathrm{~K}$ air showed no really different amount of air in the orifice in comparison to $300 \mathrm{~K}$. The initial volume of air that entered the orifice for 900 bar injection was between the two 400 bar injections shown earlier in Figure 6 (note the different abscissa scale), being $\sim 65 \%$ higher than that of the 400 bar injection into 60 bar air.

\section{RESULTS - PART II: Flow Behaviour Immediately after the End of Injection}

The following sections present results from about $50 \mu$ s before EOI (i.e. before the needle touches the needle seat) to about $200 \mu$ s after EOI. As shown in all previous sections, the in-nozzle flow decelerated during the descending phase of the needle. When the needle finally closed, the in-nozzle flow was gradually brought to a halt. The final timing of $200 \mu \mathrm{s}$ AEOI was chosen as the time when the velocity magnitude inside the orifice had dropped below $4-5 \mathrm{~m} / \mathrm{s}$. 
This may be an arbitrary threshold value but it was considered a good indication that the flow had practically 'stopped'. To put this into context, the time needed to travel the distance of one nozzle diameter with such low velocity is $\sim 25 \mu$ s, which is quite large, specifically $\sim 10 \%$ of the total duration of injection. Contours of volume fraction of liquid, vapour and air are presented at various instances to demonstrate the evolution of the in-nozzle status. It is also noted that $200 \mu$ s correspond to about 2 crank angle degrees for an engine running close to 1650 RPM. For completeness, it is also noted that the simulations after EOI presented here were performed with the turbulence model always enabled. It can be quite challenging to isolate a single value of Reynolds number that one could consider as critical for full laminarisation under such transient conditions, particularly in the presence of complex multiphase phenomena and flow hysteresis effects. However, it is noted that the Reynolds number did not drop to values below 1000-2000 as despite the fact that the flow velocity gradually reduced inside the nozzle in the predominant direction of injection after needle closure, when the air back-filling process started, the velocity increased again in the opposite direction. The eddy viscosity in the nozzle did not fall to levels lower than $\sim 5$ times the fluid's viscosity, even at the slowest bulk flow stages.

\subsection{Test Case 1: 400 bar inlet and 60 bar outlet at $300 \mathrm{~K}$}

In Figure 13, at $50 \mu$ s before EOI, there is no cavitation and the surface of the liquid jet in the chamber area is quite smooth macroscopically with no apparent instabilities within the resolution of the numerical domain. The liquid jet broke up in the middle of the chamber domain just $10 \mu$ s before the EOI. The mass of liquid that remained attached to the nozzle formed a thin ligament and part of this started moving backwards towards the nozzle exit, a combination of shearing effects and the liquid's deceleration gradually 'propagating' from the needle seat area. The flow inside the orifice comes gradually to a halt, while the liquid that is in the chamber area is still in motion, resulting in a contraction of the jet's diameter at the nozzle exit. A throat is created that forces the interface between the liquid and the gas to separate from the orifice wall, giving space to the surrounding air to enter the orifice. By $30 \mu$ AEOI the body of liquid that is located inside the nozzle had detached from that in the chamber area. The latter had the form of a long ligament that grew thinner with time and moved slowly further away from the nozzle, leaving the domain outlet located $\sim 10$ diameters downstream the nozzle exit by $1 \mathrm{~ms}$ AEOI. As the long ligament detached from the main body of liquid, the interface inside the nozzle formed a strongly concave shape. At $10 \mu \mathrm{s}$ AEOI, air has already started entering the nozzle around the liquid core. The last subfigure of Figure 13 shows by a set of circular cross sections of the orifice that there is no liquid on the walls of the orifice for approximately half diameter close to the nozzle outlet. Upstream of that point there is liquid fuel film present whose thickness increases towards the orifice entrance. Air enters the orifice in Figure 14 with higher speed on the top side, causing asymmetric flow that leads to a small pocket of air engulfed by liquid. Later this pocket resurfaces and connects with the main volume of air.

The ligament that appeared very soon after the end of injection was the type of dribble that was described by [100] as immediate dribble. The flow behaviour outside the nozzle also bears some resemblance to the experimental results of [23] for 1000 bar injection into 10 bar chamber pressure. In general though it does not fully resemble the dribble captured by the LES studies of [101] for 500 bar injection into 10 bar chamber pressure via an axial single-hole Diesel injector nozzle. The multi-hone injector dribble captured by the experiments of [102] for 200 bar injection into 1 bar was qualitatively similar to that in Figure 13; however, the experiment exhibited dribbling for longer time at such low injection and chamber pressure. The last ligament detached from the injector $0.8 \mathrm{~ms}$ AEOI in the experimental study, whilst in the current simulation the ligament had already detached by $0.03 \mathrm{~ms}$. At the 1000 bar injection of [102] detachment of thin ligaments was observed between 0.03-0.25 ms AEOI.

\subsection{Test Case 2: 400 bar inlet and 1 bar outlet at $300 \mathrm{~K}$}

The lower air chamber pressure led to higher fuel velocity which took longer time to decelerate. The respective higher momentum required higher pressure drop after needle closure in order to be brought to a halt. However, with the ambient pressure being significantly lower than in Test Case 1, even a small in-nozzle pressure drop would lead to local pressure values lower than the vapour pressure and lead to cavitation. The presence of vapour inhibited further 
local pressure drop but the momentum of the liquid fuel was not reduced as quickly as in the case of the higher chamber pressure, causing the creation of further vapour. Figure 15 presents the evolution of the flow from $20 \mu \mathrm{s}$ before EOI. The bulk of the flow inside the nozzle is cavitating before the end of injection and the jet shape in the chamber is highly unstable. At $10 \mu$ s before EOI the jet is already fragmented into long ligaments that gradually thin out and get detached from the body of liquid that is located inside the nozzle. A cavitation region is also formed in the area downstream of the needle seat and upstream of the sac. The interface of liquid and gas separates from the nozzle wall initially at the top and air starts entering the orifice from that point at about $10 \mu \mathrm{s}$ AEOI, pushing the moving liquid towards the lower side of the orifice. The cavitation region upstream of the sac has reached its maximum size. As air moves further inside the orifice $20 \mu$ AEOI, the pressure rises and the vapour starts condensing back to liquid, pulling more air inside the orifice. The work of [101] predicted similar results with their LES work at 500 bar injection pressure into 10 bar chamber pressure. At $30 \mu$ s AEOI there is a large pocket of vapour inside the nozzle and an equally large volume of air, separated by a thin volume of liquid. This indicates that the pressure level in there is still equal to the vapour pressure, despite the fact that air has entered the nozzle. As the main liquid volume moves towards the sac, a thin film of liquid remains on the orifice walls. The air that enters the orifice creates a shear layer that pushes the thin film towards the sac and also creates instabilities on the film's surface. $20 \mu \mathrm{s}$ later, at $50 \mu \mathrm{s}$ AEOI, the two gases have mixed already and the vapour has condensed. The small ligament of liquid that exists outside the nozzle exit at this timing, gets totally detached from the nozzle later at $100 \mu$ s AEOI. Moreover, for about one nozzle diameter upstream of the nozzle exit on the top side of the orifice, there is no liquid present. The body of liquid fuel inside the nozzle comes to a halt and the last detached ligament moves further away from the nozzle exit. Eventually, the nozzle volume is occupied only by liquid fuel and air. The pressure everywhere equalizes to the ambient pressure. The fluid motion comes to a halt forming a thin liquid film on the orifice walls with the rest of the orifice being almost full of entrained air. The fluid domain at the end of this simulation, $190 \mu$ s AEOI, is also shown in the last subfigure of Figure 15 where it can be seen that the liquid film exists circumferentially along the full length of the orifice. This state resembles the initial conditions that were reported by the 300 bar into 1 bar optical nozzle experiments of [10], where large air pockets occupied the orifice at the start of injection in a series of consecutive injections as a result of prior-injection effects. All in all, the major part of the process presented here appears similar to what described by [100] as immediate dribble, and belongs to the first mode of dribbling process of [102] with some air ingestion. Practically it resembles well both the experiments of [102] for 200-1000 bar injection into 1 bar pressure and the experiments of [23] for 1000 bar injection in 10 bar pressure. Moreover, there is a good agreement with the findings of [103] for injection with 400 bar pressure, who reported that at the end of injection the spray width had increased and the liquid jet was converted to a liquid sheet structure that broke into ligaments. The predicted dribble resembles the one captured by the experiments in [45] for a single-hole injector with 1500 bar injection pressure into 1 bar ambient.

Figure 16 shows the vapour and air volume fractions at $30 \mu$ s AEOI. The total volume of vapour inside the orifice from $\sim 80 \mu$ s before EOI and for a short period after EOI is shown in Figure 17 for both 400 bar injections. The injection into 60 bar chamber pressure has no vapour present in the orifice throughout this period, as seen previously in Figure 5. The injection into 1 bar has a different behaviour. There is an increasing volume of vapour present in the orifice until the needle closes. After needle closure the volume of vapour decreases. At $30 \mu$ AEOI the amount of vapour diminishes in an abrupt way; this coincides with the entrainment of air in the orifice, as can be seen in Figure 16 and Figure 17, and the rise of pressure in the orifice that condenses the vapour into liquid creating space for air. These results are qualitatively close to the results of [101] and follow the same trend for overall ingested air as a function of chamber pressure. However, the values are about one order of magnitude lower; this quantitative difference is expected as the orifice used here has approximately 5 times smaller volume than that used by [101]. At $100 \mu \mathrm{s}$ AEOI all motion has settled, resulting into $40 \%$ of the orifice filled with air for the case of injection into 60 bar chamber pressure and $63 \%$ for the case of injection into 1 bar chamber pressure. 


\subsection{Test Case 3: 900 bar inlet and 35 bar outlet at $300 \mathrm{~K}$}

Figure 18 shows that the jet is fragmented into ligaments even before the EOI. As the needle closes, there is cavitation downstream of the needle seat and as the liquid decelerates the diameter of the jet is reduced at the nozzle exit. The part of the jet that had not exited the domain forms thin long ligaments. This is similar to what was seen in previous sections for 400 bar injection pressure and described as immediate dribble according to [100]. Specifically, [100] reported that higher injection pressure resulted in more droplets in the immediate dribble, something that is also true here, especially in comparison to the 400 bar injection into 60 bar chamber pressure. At $10 \mu$ s AEOI air enters the orifice domain from both the top and bottom in the shown 2D vertical section of the nozzle exit; this is all around the tip of the liquid core in 3D. The liquid retreats, pulling more air inside the nozzle. At the end of this process the computational domain looks similar to the one produced by Test Case 1. The presence of vapour is minimal as it has condensed due to high pressure. The experiments of [23] showed similar in-nozzle flow field with 1000 bar fuel injection into 1 bar chamber pressure. The shape of the fuel film in Figure 18 is different to the one shown earlier in

Figure 13 for Test Case 1 of 400 bar injection into 60 bar chamber pressure. Specifically, in Figure 13, there was a very thin film close to the nozzle exit whilst upstream at about half-length of the orifice the film thickness increased sharply. In the present case, there is a shorter wall surface area close to the nozzle exit with no liquid present whilst upstream of that there is a thicker film, quite uniformly distributed along approximately half the length of the orifice.

\subsection{Test Case 4: 900 bar inlet and 35 bar outlet at $353 \mathrm{~K}$}

The higher fuel temperature increased the vapour pressure and produced increased levels of in-nozzle cavitation.

Figure 19 shows that at $20 \mu$ s before EOI a cavitation area occupies about half of the nozzle orifice. The continuous liquid core of the jet ends about one diameter downstream the nozzle exit; two long thin ligaments are present, extending towards the outlet of the air domain. The dribble at this point resembles the experiments of [104] with 1500 bar injection. At $10 \mu$ s before EOI the size of the cavitation zone has decreased and the liquid fuel inside the orifice is already moving backwards. Air starts entering the orifice from the lower side of the nozzle exit, backfilling gradually the nozzle, whilst some liquid fuel is being expelled at the same time from the top side of the orifice. At EOI air has reached the orifice inlet, see also Figure 20 for the air fraction, and by $270 \mu$ s AEOI air has already made it upstream the orifice inside the nozzle sac. By about 10-30 $\mu$ s AEOI the predicted flow appeared quite similar to the results of [101] at $60 \mu \mathrm{s}$ AEOI for 500 injection pressure. The interface between liquid and gases was diffused and vapour was present at $\sim 10$ times lower volume fraction than the liquid. Once more, the form of the immediate dribble of this injection, when compared to the lower pressure injections, matches the findings of [100] and compares well with the results of [23, 102], but does not fully agree with the findings of [45, 101]. The last subfigure of Figure 19 shows a non-axisymmetric behaviour; some 'lumps' of fuel appear at various points on the orifice wall in quite pronounced manner.

\subsection{Test Case 5: 900 bar inlet at $333 \mathrm{~K}$ and 35 bar outlet at $550 \mathrm{~K}$}

The resulting flow in Figure 21 resembles in general the injection of Test Case 3 with $300 \mathrm{~K}$. Immediate dribble is again present. At $20 \mu$ s before EOI there is wide-spread cavitation in the vicinity of the orifice's entrance including the sac. The liquid core has decelerated and a large ligament is moving away from the core, albeit still thinly attached. 10-20 $\mu$ s later, more ligaments of liquid have detached from the liquid core. The latter has started moving back towards the nozzle, and its cross-section area has reduced at EOI, forming a throat similar to the one seen in previous injections into high pressure. The state of the nozzle orifice is similar to the images acquired by [104] for 1500 bar injection. Air has started entering the orifice at $\sim 10 \mu$ sEOI, from the top side of the nozzle exit. $20 \mu$ s after that, air pushes further inside the orifice, reaching gradually the orifice entrance by about $100 \mu$ s AEOI. The liquid that moves back towards the sac leaves a relatively smooth thin liquid film on the wall with the air's shearing actions inducing wavy patterns on the film. In the last two subfigures of Figure 21 at $220 \mu$ s AEOI, the vertical and circular cross sections of the orifice reveal a film of quite uniform thickness reaching the orifice entrance and sac. The vapour in the domain remained at levels lower than $2 \%$ and mostly confined to the vicinity of the liquid-gas interface. At the 
end, the predicted flow field resembled the one predicted by the LES work of [101] for 1500 bar injection, and the experiments of [23]. However, the field is different to the results of [45] obtained by RANS.

\subsection{Test Case 6: 900 bar inlet and 35 bar outlet at $333 \mathrm{~K}$, walls at $473 \mathrm{~K}$}

The effect of heated nozzle walls is quite pronounced and changes the dynamics of the in-nozzle flow at EOI. In Figure 22, at $20 \mu \mathrm{s}$ before EOI there is already a very small amount of liquid inside the orifice. There is also a large volume of vapour and an equivalent one of air that have not yet mixed, see also Figure 23. The experimental work of [102] did not capture similar behaviour as it mentioned that air never entered the orifice before EOI; however, their injections were performed at $298 \mathrm{~K}$. Here, by about $10 \mu \mathrm{s}$ AEOI, all vapour has condensed into liquid, leaving an area that is occupied by air and liquid, each with volume fraction of order 0.5 . The mixture of liquid and air moves deeper inside the nozzle and mixes further with the liquid in the area of the sac. The pressure in the sac area rises locally and pushes the multiphase flow back towards the nozzle's outlet. This way a small quantity of this mixture is expelled from the orifice at about $90 \mu \mathrm{s}$ AEOI, which is again in the category termed immediate dribble, despite the fact that it has been created by a mechanism that appears different to all the ones noted before. At the same time, the instabilities that grew on the surface of the wall fuel film, gradually developed into a form that has engulfed a pocket of air at $370 \mu$ s AEOI. Similar instabilities grow at various places along the orifice but not as pronounced to further block the whole of the cross-sectional orifice area closer to the nozzle exit. The last two subfigures of Figure 22 resemble the distribution of liquid volume fraction of the injections at higher fuel temperature and the one shown in [101] for higher injection pressure.

\subsection{Comparing vapour/air volumes and liquid fuel discharge after needle closure for all cases}

Figure 24 shows the volume of vapour inside the orifice before and after needle closure for the 900 bar injections. For 900 bar $300 \mathrm{~K}$ injection the vapour volume lies between the two 400 bar $300 \mathrm{~K}$ injections shown earlier in Figure 17. The behaviour is quite different to the 400 bar injection into 1 bar chamber pressure though in the sense that the amount of vapour for 900 bar has diminished before needle closure. This happens $20 \mu$ s before the EOI and coincides with the time that the average pressure inside the sac reaches the chamber pressure. As seen earlier in Figure 11, the volume of vapour inside the nozzle orifice in the final stages of injection increases with temperature. In Figure 24, at $5 \mu$ s before EOI, the case of $353 \mathrm{~K}$ exhibits still presence of vapour with decreasing level, while the case of $300 \mathrm{~K}$ does not exhibit vapour at all. Then, at $2 \mu$ s before EOI, there is no vapour in both cases. The $333 \mathrm{~K}$ fuel injection into $550 \mathrm{~K}$ air resulted in higher values of vapour volume than the $300 \mathrm{~K}$ case, but broadly lower values of vapour volume than the $353 \mathrm{~K}$ case. In contrast, the injection of $333 \mathrm{~K}$ fuel-air temperature with $473 \mathrm{~K}$ wall temperature shows similar levels of vapour volume in the last stages of needle closure to the injection with $353 \mathrm{~K}$ fuel-air temperature and adiabatic walls. However, it then exhibits the highest peak of vapour volume amongst all case just before vapour condenses at about $20 \mu$ s before EOI, broadly at the same timing that air fills approximately $73 \%$ of the orifice volume in Figure 25. It is also noted that in the case of $333 \mathrm{~K}$ with $473 \mathrm{~K}$ walls, air not only reached the highest level amongst all cases but started appearing in the orifice the earliest before EOI too. The case of $333 \mathrm{~K}$ injection into $550 \mathrm{~K}$ air chamber shows air starting to enter the orifice after needle closure; up to $20 \mu$ s after EOI the curve of $550 \mathrm{~K}$ is identical to the $300 \mathrm{~K}$ one. Later, however, air continues to enter the orifice in the former case, filling about $62 \%$ of the orifice volume by $\sim 200 \mu$ s after EOI. For the case of $353 \mathrm{~K}$, air started entering the orifice about $50 \mu$ s later and in the end it reached the second highest total volume. The volume of air that entered the orifice with 900 bar injection at $300 \mathrm{~K}$ is about $34 \%$ of the orifice volume, $\sim 6$ percentile units lower than the 400 bar injection into 60 bar chamber pressure at $300 \mathrm{~K}$ shown earlier in Figure 17. The higher temperature injections have a clearly different shape to those of $300 \mathrm{~K}$, and to the one reported by [101] at $300 \mathrm{~K}$ with a single-hole injector where air started entering the orifice after EOI. The levels of air volume in Figure 25 appear in reasonable agreement with the volume of void in the orifice of Spray A and in each one of the 3 nozzle holes of Spray B presented recently by [48] for 1500 bar injection into 20 bar back pressure with $343 \mathrm{~K}$ fuel temperature and $303 \mathrm{~K}$ air. However, the results of [48] did not exhibit void volume before EOI either. 
The average pressure in the sac during the processes of vapour volume decay and air backfilling is shown in Figure 26 for the 400 bar and 900 bar injections at $300 \mathrm{~K}$. The pressure is decreasing, reaching a level before EOI that is slightly lower than that of the chamber pressure. The pressure for both 400 bar injections drops roughly with the same rate. Their difference is approximately 30-40 bar, smaller than the absolute difference between the two air chamber pressures. Thus, while the first injection reaches 60 bar pressure $\sim 40 \mu$ s before EOI, the pressure in the sac of the injection into 1 bar keeps on dropping until about $4 \mu$ s before EOI. Furthermore, when the needle closes, the pressure in the sac of the 60 bar chamber case drops instantly to 20 bar, a 66\% drop. $4 \mu$ s later the pressure level has recovered but for an extra $4 \mu$ s there is an oscillation of decreasing amplitude, not higher than 10 bar around the nominal level of the chamber pressure. These results are close to the findings of $[45,101]$, albeit with a smaller pressure drop at the time that the needle closes and a smaller volume of ingested air. The modelling work of [101] predicted pressures about one order of magnitude lower than the chamber pressure at needle closure but, like here, pressure values recovered very quickly. The case of 900 bar exhibited qualitatively the same trend to the 400 bar injections but with much steeper rate. In addition, at $\sim 20 \mu$ sefore needle closure, the pressure in the sac is lower than the chamber pressure. At the closing of the needle, there is a drop in pressure similar to the one that was seen for the 400 bar injection into 60 bar. This is a drop of $67 \%$ compared to the pressure in the sac at that time.

Figure 27 shows the liquid volume in the air chamber just before needle closure and immediately after, over a time domain of $300 \mu \mathrm{s}$. This, when studied in conjunction with the air volume inside the nozzle (Figure 17 and Figure 25) can provide an understanding of the measure of immediate fuel dribble. EOI is at $2.58 \mathrm{~ms}$ in Figure 27 and it is reminded that the air chamber is only about $1.2 \mathrm{~mm}$ long, hence the amount of liquid fuel in the chamber diminishes quickly over the time domain of $300 \mu \mathrm{s}$ as fuel leaves the chamber. The smallest liquid volume is shown for the case of 900 bar with $473 \mathrm{~K}$ walls because the nozzle has already almost emptied and backfilled by air at the timing of needle closure in Figures 22-23. The test case of $550 \mathrm{~K}$ air chamber shows that the dribble volume continues stronger than the other cases after EOI as the amount of cavitation in the nozzle is fairly small at EOI and the orifice is full of liquid fuel in Figure 21. The case of $353 \mathrm{~K}$ shows the second lowest fuel dribble because it is associated with the nozzle emptying quickly in the last stages of needle closure in Figure 19. The 900 bar case at $300 \mathrm{~K}$ shows the largest initial amount of dribble as the nozzle is full of liquid just before needle closure and the liquid jet carries a strong core in Figure 18, leading to the slowest rate of air backfilling thereafter in Figure 25. The two 400 bar cases show consistent behaviour. The interested reader may compare Figure 27 qualitatively with recently measured fuel dribble quantities in [24]. Quantitative comparison is not directly possible because the length downstream the nozzle exit over which the dribble was measured in [24] was about 1.7-5 mm long and the dribble was recorded over $1.4 \mathrm{~ms}$ AEOI. It is also noted that [24] used a 3-hole injector nozzle of 91-93 $\mu \mathrm{m}$ hole diameter with $\sim 500 \mu \mathrm{m}$ maximum needle lift and $n$-dodecane injection at 500-1500 bar with 308-363 K, and gas pressures broadly in the range 7-60 bar with temperatures $300-900 \mathrm{~K}$, in comparison to the 7-hole injector nozzle of $120 \mu \mathrm{m}$ hole diameter, $\sim 250 \mu \mathrm{m}$ maximum needle lift and $n$-tridecane injection at 400-900 bar with 1-35 bar gas and 300-550 K used here. Despite these differences, the scale of dribble volume shown in [24] is of the same order to that in Figure $27\left(10^{-3}-10^{-2} \mathrm{~mm}^{3}\right)$ as the injection and back pressure conditions were broadly within the same range to those studied here. Moreover, the dribble volume in [24] was measured to be larger for a gas temperature of $473 \mathrm{~K}$ than at $293 \mathrm{~K}$, which is a qualitatively consistent trend with that of the current study.

\section{RESULTS - PART III: Flow Behaviour Longer after the End of Injection}

The following sections present the evolution of the liquid and gaseous phases inside the nozzle orifice over a significant amount of time after the end of injection. The effect of evaporation and cavitation models on the predicted multiphase phenomena after needle closure was studied in some detail. Phase change due to evaporation is a process that is slow compared to phase change from cavitation. The phase change from liquid to gas is quite small overall as the driving force is the partial pressure of vapour, but mostly because it takes place just on the liquid-gas interface. Due to the small transfer rate compared to cavitation, and the larger timescales involved, it was considered reasonable 
not to have both evaporation and cavitation models active at the same time. All runs were conducted primarily with the evaporation model enabled only. In some test cases the cavitation model was enabled instead for comparison. The simulations started at the last time instance AEOI of the results shown in Part II. The length of these simulations was set to $8 \mathrm{~ms}$, i.e. about 4 times the injection duration.

\subsection{Test Case 1: 400 bar inlet and 60 bar outlet at $300 \mathrm{~K}$}

In Figure 28, at the beginning of the simulation, half the volume of the nozzle orifice is already full of air and there is a thin liquid film on the walls in the region where air has backfilled the orifice. This film provides a large surface area available to evaporation. As time passes though, under the effect of surface tension, this film forms small lumps of liquid in a wavy pattern and eventually develops into separate droplets. This is displayed in Figure $\mathbf{2 8}$ by the circular cross-sections at $0.93 \mathrm{~ms}$ AEOI. Specifically it can be seen that the droplet that has been formed on the lower wall of the nozzle does not obstruct a wide section of the circumference of orifice. Instead, two additional droplets of similar size can be seen on the orifice wall, which are located off the symmetry plane. A similar behaviour was also reported by [102]. In addition, the surface of the main body of liquid becomes gradually normal to the axis of the orifice and parallel to the outlet. The interface between liquid and gases gets diffused by evaporation over time; vapour volume fraction data, indicated that there was vapour present, primarily in the vicinity of the main liquid-gas interface but its fraction was typically lower than $1 \%$. In areas where the film had formed localised small droplets on the surface of the orifice, concentration of vapour was also evident. At the end of simulation this high concentration has diffused over a larger area towards the nozzle orifice exit. The surface of the liquid is reduced and is about equal to the orifice cross section. The overall mass of vapour has reached a constant amount. In order for more liquid to evaporate, the existing vapour must leave the orifice. Since the flow is stagnant, the only way for this to happen is through diffusion. This procedure is very slow and resolving it with further physical running time within the limitations of available computational resources was not considered of further practical significance, particularly when considering that under real engine running conditions another injection could follow within that physical time.

\subsection{Test Case 2: 400 bar inlet and 1 bar outlet at $300 \mathrm{~K}$}

An interesting observation in Figure 29 is that the liquid film under the force of surface tension is developing locally into liquid lump formations which are larger than the ones predicted under the conditions of Test Case 1. At the beginning of the simulation, the liquid film is already thicker close to the nozzle exit. By $1 \mathrm{~ms}$ AEOI, a volume of liquid has been formed that occupies the whole cross section of the orifice acting as a plug, trapping a pocket of air and vapour behind it, similarly to what has been reported by the experiments of [102]. This quantity of liquid is gradually moving towards the nozzle exit. In addition, evaporation produces extra vapour inside the trapped region of gases, increasing the local pressure and inducing further force to the volume of liquid ahead.

To study the prediction of the formation and motion of this liquid plug further, the simulation was repeated with the cavitation model enabled and the evaporation model disabled. Figure 30 shows that the same type of multiphase dynamics was initially predicted and a large droplet in plug form was found inside the orifice close to the nozzle outlet at a timing of about $0.9 \mathrm{~ms}$ AEOI in this simulation as well. However, while the evaporation simulation predicted droplet motion towards the nozzle outlet in subsequent time steps, the cavitation model predicted the droplet starting to move slowly backwards towards the nozzle interior. The explanation for this difference in behaviour is that when the liquid plug was formed, a quantity of gas containing both vapour and air was trapped behind the droplet. The evaporation model was producing vapour, thereby increasing the pressure inside the void behind the droplet, pushing the droplet outwards. In contrast, the cavitation model condensed the existing vapour. This way the overall volume of gas decreased and the pressure dropped in turn, thus pulling the droplet further inside the nozzle orifice. These results are proof that the models work as they should and that the actual physics should be considered in the mechanisms and submodels involved with the simulations, as the predicted outcome can be quite different. Moreover, the results reveal that small variations in the predicted pressure field locally may end up having considerable impact on the overall filling or emptying mechanism of the nozzle orifice, even well after needle closure. 
Figure 31 shows the transient evolution of the total volume of vapour inside the nozzle orifice with evaporation modelling enabled for both cases of 400 bar injection. At the end of injection, Test Case 2 with 1 bar chamber pressure exhibits already a large amount of vapour. The rate at which vapour increased AEOI is higher than Test Case 1 due to the surface area available for evaporation being higher. Moreover, the volume of gases inside the orifice is also larger, so there is more space available for the vapour to diffuse. Figure 32 shows the liquid volume fraction of Test Cases 1-2 at $0.42 \mathrm{~ms}$ AEOI as some evaporation still takes place, along with the area density and mass transfer rate. The two driving forces of evaporation are also illustrated separately for better clarity: the interfacial area (in the form of area density $\mathrm{mm}^{2} / \mathrm{mm}^{3}$ ) and the mass transfer rate (dependent on the partial pressure of vapour). The overall area of the wall boundaries in the orifice and sac regions was $4.61 \times 10^{-1} \mathrm{~mm}^{2}$ and the predicted interface area for Test Case 1 and Test Case 2 was $9.18 \times 10^{-2} \mathrm{~mm}^{2}$ and $1.98 \times 10^{-1} \mathrm{~mm}^{2}$, respectively, i.e. of the same order. The rate is quite low, except in some small areas, implying that saturation of the gaseous phase is impeding further evaporation.

The effect of the liquid plug motion inside the nozzle orifice with evaporation modelling enabled was studied further by running the simulation for longer time AEOI. Figure 33 shows the evolution of the in-nozzle plug past $19 \mathrm{~ms}$ AEOI. The droplet eventually makes it to the nozzle outlet with its main body remaining inside the orifice but also wetting a region of the external nozzle wall as well. A view of the external nozzle wall has been included in Figure 33 to illustrate clearer this behaviour. At the same time, at the top of the nozzle exit, a small gap between nozzle wall and droplet enables gases inside the orifice behind the droplet to leak outside. Detailed study of these data showed that there was clear evaporation of the droplet and local diffusion. A word of caution applies here: the coarser grid in the chamber area, together with the large time-step that was used to predict the transport of this droplet, have probably affected the prediction of the detailed droplet interface, but the key physical behaviour is still clear. In fact, this behaviour appears very close to the one captured by the experiments of [105] with the same injection and back pressures. It is noted though that the nozzle orifice diameter used by [105] was approximately $20 \%$ larger than the one used here and the circular area of the external wall that was covered by fuel was about $470 \mu \mathrm{m}$ in diameter, whilst in the present simulations a circular area that was about $45 \%$ smaller in diameter (about $250 \mu \mathrm{m}$ ) was measured. Similar behaviour was observed by [66], where a vaporising droplet in quiescent environment was captured moving due to its location with respect to the wall boundaries; in case of transient temperature fields the mechanism of plug motion may also be coupled to thermocapillary effects [106]. Such a form of late fuel discharge can be described as 'late cycle' dribble according to [100] who reported late cycle dribble with 5-20 bar back pressure.

\subsection{Test Case 3: 900 bar inlet and 35 bar outlet at $300 \mathrm{~K}$}

The distribution of liquid volume fraction inside the nozzle from EOI to $7.5 \mathrm{~ms}$ AEOI, as well as the state of the vapour volume fraction at $7.5 \mathrm{~ms}$ AEOI, are shown in Figures 34-35. The overall fluid behaviour is similar to that shown earlier, with the liquid fuel retracting into the nozzle. There is a large droplet on the upper side of the nozzle orifice that is left behind as the main liquid film retreats. This was not found to move towards the nozzle exit by running the simulation further. The simulation was also run by enabling the cavitation model and the result was the same to that with the evaporation model enabled. This behaviour is different to what was observed by the simulations of Test Case 2 where the liquid droplet moved towards the nozzle orifice exit when the evaporation model was applied and backwards towards the inlet when the cavitation model was applied. In the current case the stagnant droplet can be explained by the fact that the droplet does not fully block the whole orifice cross-section and the increased (or decreased) pressure of gas behind the inside can be balanced.

\subsection{Test Case 4: 900 bar inlet 35 bar outlet at $353 \mathrm{~K}$}

The use of higher fuel and air temperature resulted in a quite different status of the nozzle at the beginning of this simulation. Specifically, the liquid interface appeared diffused without clear film on the orifice walls soon after needle closure, as shown earlier in Figure 19 by 0.27 ms ASOI. Liquid occupied a large part of the orifice volume, but this was distributed over the first half of the orifice, starting from the orifice inlet. Over time this diffused further, as shown in Figure 36 at $7.5 \mathrm{~ms}$ AEOI, with vapour produced not only in the orifice region but also in the area just 
downstream of the needle seat and upstream the sac. It is noted that with the cavitation model enabled instead of evaporation the diffused vapour region inside the orifice was much shorter and confined closer to the orifice inlet.

\subsection{Test Case 5: 900 bar inlet at $333 \mathrm{~K}$ and 35 bar outlet at $550 \mathrm{~K}$}

The higher chamber temperature resulted in a higher volume of air entering the nozzle. At the beginning of the simulation there is a large area of liquid film present on the walls of the orifice, see Figure 37. On the basis of the dynamics discussed in previous simulations, two droplets are created. One of these gets connected to the main liquid body, while the second stays detached having formed a plug already by $4.5 \mathrm{~ms}$ AEOI, separated from the liquid in the sac by a gas region, similarly to what [102] reported. Analysis of vapour fraction contours showed that this gas region consisted of air and vapour. Downstream the plug there was much lower concentration of vapour as air dominated gas presence.

\subsection{Test Case 6: 900 bar inlet and 35 bar outlet at $333 \mathrm{~K}$, walls at $473 \mathrm{~K}$}

Increasing the wall temperature had a strong effect on the dynamics of the flow and amount of vapour produced towards the end of injection. Soon after EOI there is a gas pocket already trapped inside the liquid body in the sac region, as shown earlier Figures 22-23. Figure 38 shows that the liquid plug and film on the walls gradually evaporate and as fluids expand, a quantity of liquid reaches the nozzle outlet and extends outside the nozzle orifice. This behaviour resembles the one noticed for Test Case 2 in Figure 33, albeit with weaker late liquid expulsion, and the experimental results of [23].

\subsection{Comparing vapour/air volumes long after needle closure for all cases}

The transient evolution of the total volume of vapour inside the nozzle orifice is shown in Figure 39. The curve of the $300 \mathrm{~K}$ case lies between the 400-60 bar and 400-1 bar curves presented earlier in Figure 31, with less than 1\% of the total orifice volume being filled with vapour at the end. The volume of vapour increases rapidly in the first $200 \mu$ s but from then onward it increases only slightly. This is because the presence of liquid at the nozzle exit separates the orifice from the rest of the environment and saturation conditions are reached. Injection at $353 \mathrm{~K}$ does not show the same behaviour as the $300 \mathrm{~K}$ case, i.e. a high evaporation rate in the first $200 \mu \mathrm{s}$ and a lower one later, but a vapour volume that is steadily increasing. This is mostly related to the behaviour of the diffused interface in the orifice region at $353 \mathrm{~K}$. Moreover, the presence of liquid and gases in the same region leads to vapour saturated conditions faster. Indicatively, at $\sim 110 \mu$ AEOI, the overall evaporation rate for $300 \mathrm{~K}$ was $4.9 \mathrm{~mm}^{3} / \mathrm{s}$, while for 353 $\mathrm{K}$ this was $2.1 \mathrm{~mm}^{3} / \mathrm{s}$. About $300 \mu$ s later, the respective values were $1.98 \mathrm{~mm}^{3} / \mathrm{s}$ and $0.4 \mathrm{~mm}^{3} / \mathrm{s}$, showing that despite the higher temperature the evaporation rate had dropped quickly. For cases with $550 \mathrm{~K}$ air chamber and $473 \mathrm{~K}$ walls the evaporation simulations started at a later time AEOI. Therefore, in the first part of the simulations the volume of vapour drops as the cavitation model forces it to condense. For the $550 \mathrm{~K}$ air temperature, soon after the initial dip, evaporation leads to a two-stage increase in vapour volume. The $300 \mathrm{~K}$ case showed similar behaviour, i.e. a twostage increase in vapour volume, one of large rate over the first $200 \mu$ s and a second of lower rate thereafter. The case of $474 \mathrm{~K}$ walls displays a flat curve past the short initial dip due to diffused interface and saturation effects.

\section{RESULTS - PART IV: Flow after the End of Injection with Chamber Pressure Decrease}

In a running engine the fuel injection is followed by the expansion stroke, during which the pressure inside the cylinder decreases. The effect of such pressure decrease was investigated by applying a transient pressure boundary condition at the chamber outlet. The transient pressure boundary was imposed by means of an in-cylinder pressure trace that was measured in a single-cylinder Diesel research engine at motoring conditions [75], as shown in Figure 40. Test Cases 7 and 8 were simulated with this dynamic boundary condition to study the effect of realistic transient in-cylinder air pressure conditions in comparison to constant air back pressure studied earlier. The timescales present in a fuel injection are vastly different from the timescales involved with the piston motion of a typical engine. The pressure decrease occurs over a much longer period of time compared to the duration of injection. Therefore, the following simulations started at 35 bar and were run up to the point that the pressure in the chamber had decreased to 10 bar. Still, this is a period of time equal to about four full injection events. In real life the air temperature would 
decrease simultaneously with the pressure during expansion. However, it was decided to run two cases with this pressure boundary, one at $300 \mathrm{~K}$ and a second at $550 \mathrm{~K}$, to decouple pressure-temperature effects.

\subsection{Test Case 7: 35 bar initial chamber pressure at $300 \mathrm{~K}$}

Figure 41 shows the evolution of the multiphase flow inside the injector and chamber for the case of $900 \mathrm{bar}, 300 \mathrm{~K}$ injection with the air chamber pressure decreasing from 35 bar. This can be compared with the predicted nozzle status at constant air pressure of 35 bar shown earlier in Figure 34. The results of the first four timings look very similar to the simulations with constant pressure as the decrease in pressure is not significant over this period. From then on, the air pressure decreases steadily and this has a significant impact on the droplet that is close to the nozzle exit as it starts moving towards the air chamber. This is affected also by the presence of a quantity of gas upstream of this droplet which starts to expand due to pressure drop and starts pushing the droplet outwards. The fact that the droplet only partially blocks the orifice, allows for trapped gas to also escape towards the chamber. Eventually a quantity of liquid makes it out of nozzle. This behaviour can be termed 'blow down' dribble according to [100]. Such effect was not seen in Figures 34-35 with constant air pressure of 35 bar as even at $7.5 \mathrm{~ms}$ AEOI the liquid fuel resides well within the orifice.

\subsection{Test Case 8: 35 bar initial chamber pressure at $550 \mathrm{~K}$}

Figure 42 shows the evolution of the multiphase flow inside the injector and chamber for the case of 900 bar, $333 \mathrm{~K}$ injection with the air pressure decreasing from 35 bar. This can be compared with the predicted nozzle status at constant air pressure of 35 bar shown earlier in Figure 37. After the end of injection, the liquid films on the nozzle walls develop into two main formations, one being a droplet on the lower surface of the nozzle closer to the nozzle exit and a pair of drops closer to the nozzle inlet. In the constant 35 bar chamber pressure simulation of Figure 37 the liquid drop formations at $0.92 \mathrm{~ms}$ AEOI are not too dissimilar to those at $1.1 \mathrm{~ms}$ AEOI in Figure 42. However, the decreasing pressure in Figure 42 leads gradually to a nozzle state where the single droplet on the lower surface closer to the orifice exit persists in size, whilst the pair of drops closer to the orifice inlet evolve into a single drop attached to the upper surface of the orifice, providing no obstruction to the gases inside the nozzle. Hence, trapped air sees a passage to move towards the chamber, transporting away part of the diffused droplet interface. A direct comparison of the liquid fraction at $2.5 \mathrm{~ms}$ AEOI in Figure $\mathbf{4 2}$ with Figure 37 shows that the fuel has moved close to the orifice exit for the case with decreasing pressure whilst for constant pressure the fuel is mostly in the form of a plug located in the first half of the orifice.

\section{RESULTS - PART V: Relifting the Injector Needle}

\section{Test Case 9: 400 bar inlet and 1 bar outlet at $300 \mathrm{~K}$}

The state of the flow field inside the injector at the end of a pilot injection is very important as this sets the initial condition for the next injection. The simulations of the injections that were studied earlier used as initial condition a nozzle full of liquid and a chamber area full of air, both at rest. This might be a good idealised approximation but not as realistic representation of the in-nozzle conditions at the start of the injection over a series of consecutive injection events. Therefore, it was considered useful to simulate a second injection starting from the predicted state of the nozzle AEOI. The evolution of the second injection event can be seen in Figure 43, together with the original injection at the same timings ASOI for direct comparison. One of the differences between the two cases is that in the original injection event cavitation appeared in the needle seat area, while in the second injection no such prediction occurred. The hypothesis for such cavitation occurrence is that when the needle was lifted the internal nozzle volume increased and the pressure dropped in turn. The low pressure also forced the liquid to move towards the interior of the nozzle. The high density of the liquid however, implies that a lot of energy is needed for such motion and, in combination with the high liquid viscosity, the fluid doesn't accelerate fast enough to compensate for the needle's motion. In the test case of the second injection, such behaviour is clearly not present anymore as the orifice is full of gas. At $90 \mu \mathrm{s}$ ASOI and $7 \mu \mathrm{m}$ needle lift, the tip of the jet in the original condition has advanced more in space than the one in the second injection. In addition, the shape of the jet's tip is not the same for both injections. The original 
one displays a sharp interface and rounded mushroom shape, whilst the second one exhibits an abstract pointy shape and a more diffused interface at $110 \mu$ S ASOI, despite showing generally marginal difference in penetration length. However, by $130 \mu \mathrm{s}$ ASOI the second injection exhibits the formation of a wide dilute mushroom structure. Cavitation appears mainly at $150 \mu$ s ASOI for both injections, but it is more developed in the second injection. At $260 \mu \mathrm{s}$ ASOI the cavitation pattern appears to have started from both the top and bottom sides of the orifice inlet for the original injection but for the second injection there is a single larger stronger cavitating region in the vicinity of the top side only of the orifice inlet. The liquid jet inside the chamber appears equally fragmented for both injection events. The early spray formation of the second injection appears to resemble the multi-hole injector experiments of $[94,95]$ for injections before the beginning of which the nozzle was full of a mixture of liquid and gas. Moreover, recent single-hole Spray D experimental data with an optical nozzle [50] showed a qualitatively similarly disturbed spray tip pattern to the one shown here after relifting the needle.

\section{SUMMARY AND CONCLUSIONS}

The present work focused on numerical modelling of the flow inside an injector nozzle with a moving needle, coupled to an air chamber. Transient RANS simulations were performed with compressibility of all phases accounted for and with submodels for cavitation and evaporation. Fluid properties were functions of pressure and temperature based on Tridecane. The validated computational methodology was used over a range of injection and back pressures, namely 400 bar into 1 and 60 bar, and 900 bar into 35 bar. All cases were run initially with initial temperature field at $300 \mathrm{~K}$ for both fuel and air. The injection case of 900 bar into 35 bar was also run at $353 \mathrm{~K}$ fuel and air, $333 \mathrm{~K}$ fuel and 550 $\mathrm{K}$ air, as well as $333 \mathrm{~K}$ fuel and air with injector walls at $473 \mathrm{~K}$. The results were studied initially during injection to understand the state of the nozzle orifice at needle closure and then monitored after the end of injection to identify the mechanism of immediate and late fuel discharge. The main conclusions of this study can be summarised as follows:

- The 400-1 bar chamber pressure resulted in greatly increased presence of cavitation compared to the 400-60 bar case. Cavitation initiated at the orifice inlet and was more pronounced at lower needle lifts. This also resulted in higher instabilities on the surface of the liquid jet.

- At 900-35 bar the volume of vapour from cavitation was generally lower than the 400-1 bar case for most of injection, with only exception being at early needle lift.

- At 900 bar, $353 \mathrm{~K}$, the volume of vapour was higher than at $300 \mathrm{~K}$, particularly at the latest stages of injection. The highest amount of vapour inside the nozzle at the end of injection was noticed at the $473 \mathrm{~K}$ wall temperature case, followed by the injection case of $353 \mathrm{~K}$ and then the one of $333 \mathrm{~K}$ fuel into $550 \mathrm{~K}$ air chamber.

- The $473 \mathrm{~K}$ wall temperature did not result in increased vapour volume from cavitation throughout the injection event, but only at the last stages of injection. Cavitation originated at both the top and bottom sides of the orifice inlet. It also resulted in air from the chamber entering the orifice before the end of injection.

- At the early stages of needle lift, air entered the nozzle. The quantity of air reduced at higher temperature. The lower chamber pressure resulted in higher quantity of air entering the nozzle.

- All injections resulted in some form of immediate fuel dribble after needle closure and air backfilling the orifice. After an amount of liquid fuel had left the orifice, a film formed on the walls. A higher chamber pressure resulted in thinner film close to the orifice exit but a larger part of the orifice was occupied by liquid fuel with thicker film upstream. Higher temperatures led to a thinner liquid film.

- The quantity of air that entered the nozzle orifice after needle closure was linked to the amount of vapour from cavitation during injection, particularly when the nozzle orifice emptied at the most intense cavitating conditions. The quantity of air was also linked to the type of liquid film that formed on the orifice walls, as thicker films halfway inside the orifice were associated with less air backfilling.

- The liquid volume leaving the nozzle after needle closure was larger at $550 \mathrm{~K}$ air chamber than at lower temperatures because the orifice was almost full of liquid fuel at needle closure and air backfilling was slower. 
The smallest volume of liquid discharge was observed with heated walls because the nozzle orifice had almost emptied and partially backfilled by air by needle closure. The case of $353 \mathrm{~K}$ showed the second lowest volume of liquid fuel discharge because it was associated with the nozzle emptying quickly and back filling already with air in the last stages of needle closure. The $300 \mathrm{~K}$ case showed the largest volume of liquid fuel discharge just before needle closure as the orifice was full of liquid and the liquid jet carried a strong core, leading to the slowest rate of air backfilling thereafter.

- The liquid film formed soon after the end of injection tended to develop into large droplet formations on the wall, particularly in the case of 400-1 bar and 900-35 bar injections at $300 \mathrm{~K}$. Such droplets merged and formed a liquid plug a couple of orifice diameters upstream the nozzle exit, trapping air inside the orifice. The plug gradually moved toward the nozzle outlet, manifesting itself as late dribble and wetting the outer surface of the nozzle. Evaporation modelling accelerated this process while cavitation modelling led to the plug moving backwards into the nozzle. This was linked to the gas pressure increasing by evaporation or decreasing by vapour condensation behind the plug, highlighting the necessity for enabling appropriate models during different phases of in-nozzle simulation.

- The use of a transient pressure outlet based on an engine's expansion stroke pressure trace affected the process of late fuel expulsion by accelerating phase change and pulling fuel out of the nozzle in multiphase form faster.

- Starting a second injection from the resulting state of the nozzle at the end of the original injection resulted initially in a deformed liquid jet tip without the classic mushroom shape and a temporarily lower liquid jet penetration, with greater cavitation.

Some preliminary LES simulations were also conducted during the work of the current paper where it was noticed that enhanced cavitation phenomena were predicted, particularly in cases of incipient cavitation, and associated effects on the status of the nozzle after the end of injection. Recent work by [19] with an injector of similar geometry to the one discussed here demonstrates some of these effects by experiments at $300 \mathrm{~K}$ and LES simulations.

\section{ACKNOWLEDGEMENTS}

Financial support by the Engineering and Physical Science Research Council (EPSRC) via an iCASE award with Delphi Diesel Systems is gratefully acknowledged. Delphi are also gratefully acknowledged for financial and technical support. The authors also acknowledge the use of High Performance Computing Facilities at University College London and Imperial College London, and associated support services, in the completion of this work.

\section{REFERENCES}

1. Greeves, G., Khan, I.M., Wang, C.H.T and Fenne, I., 1978. Origins of Hydrocarbon emissions from Diesel engines. SAE Paper 770259.

2. Pos, R., Avulapati, M., Wardle, R., Cracknell, R.F., Megaritis, T. and Ganippa, L., 2017. Combustion of ligaments and droplets expelled after the end of injection in a multi-hole diesel injector. Fuel, Volume 197, pp. 459-466.

3. Birgel, A., Ladommatos, N., Aleiferis, P., Zülch, S., Milovanovic, N., Lafon, V., Orlovic, A., Lacey, P. and Richards, P., 2008. Deposit Formation in the Holes of Diesel Injector Nozzles: A Critical Review. SAE Paper 2008-01-2383.

4. Andoh, H. and Shiraishi, K., 1986. Influence in injection and combustion phenomena by elimination of hole nozzle sac volume. SAE Paper 860416.

5. Soteriou, C., Andrews, R. and Smith, M., 1995. Direct injection Diesel sprays and the effect of cavitation and hydraulic flip on atomization. SAE Paper 950080.

6. Bergwerk, W., 1959. Flow Pattern in Diesel Nozzle Spray Holes. Proceedings of the Institution of Mechanical Engineers, Vol. 173, pp. 655-660.

7. Chaves, H., Knapp, M., Kubitzek, A., Obermeier, F. and Schneider, T. 1995. Experimental Study of Cavitation in the Nozzle Hole of Diesel Injectors Using Transparent Nozzles. SAE Paper 950290. International congress and exposition, Detroit, Michigan, February 27-March 2, 1995. 
8. Chaves, H. and Obermeier, F., 1998.Correlation between light absorption signals of cavitating nozzle flow within and outside of the hole of a transparent Diesel injection nozzle. ILASS-Europe $14^{\text {th }}$ European Conference on Liquid Atomization and Spray Systems, July 6-8, 1998, Manchester, UK.

9. Badock, C., Wirth, R., Fath A., and Leipertz, A., 1999. Investigation of cavitation in real size Diesel injection nozzles. International Journal of Heat Fluid Flow, Vol. 20, pp. 538-544.

10. Mitroglou, N., McLorn, M., Gavaises, M., Soteriou, C. and Winterbourne, M., 2014. Instantaneous and ensemble average cavitation structures in Diesel micro-channel flow orifices. Fuel, Vol. 116, pp. 736-742.

11. Aleiferis, P.G., Hardalupas, Y., Kolokotronis, D., Taylor, A.M.K.P., Arioka, A. and Saito, M., 2006. Experimental Investigation of the Internal Flow Field of a Model Gasoline Injector Using Micro-Particle Image Velocimetry, SAE Transactions, Journal of Fuels and Lubricants, Vol. 115, pp. 597-606, SAE Paper 2006-013374.

12. Aleiferis, P.G., Hardalupas, Y., Kolokotronis, D., Taylor, A.M.K.P and Kimura, T., 2007. Investigation of the Internal Flow Field of a Diesel Model Injector Using Particle Image Velocimetry and CFD, SAE Paper 200701-1897.

13. Arcoumanis, C., Flora, H., Gavaises, M. and Badami, M., 2000. Cavitation in Real-Size Multi-Hole Diesel Injector Nozzles, SAE Paper 2000-01-1249.

14. Serras-Pereira, J., van Romunde, Z.R., Aleiferis, P.G., Richardson, D., Wallace, S. and Cracknell, R.F., 2010. Cavitation, Primary Break-up and Flash Boiling of Gasoline, iso-Octane and $n$-Pentane with a Real-Size Optical Direct-Injection Nozzle. Fuel, Vol. 89, pp. 2592-2607.

15. Aleiferis, P.G., Serras-Pereira, J., Augoye, A., Davies, T.J., Cracknell, R.F. and Richardson, D., 2010. Effect of fuel temperature on in-nozzle cavitation and spray formation of liquid hydrocarbons and alcohols from a realsize optical injector for direct-injection spark-ignition engines. International Journal of Heat and Mass Transfer, Vol. 53, pp. 4588-4606.

16. Butcher A.J., Aleiferis, P.G. and Richardson, D., 2013. Development of a real-size optical injector nozzle for studies of cavitation, spray formation and flash-boiling at conditions relevant to direct-injection spark-ignition engines. International Journal of Engine Research, Vol. 14, pp. 557-577.

17. Hayashi, T., Suzuki, M. and Ikemoto, M., 2013. Effects of internal flow in a Diesel nozzle on spray combustion. International Journal of Engine Research, Vol. 14, pp. 646-654.

18. Makri, K., Lockett, R. and Jeshani, M., 2019. Dynamics of post-injection fuel flow in mini-sac diesel injectors Part 1: Admission of external gases and implications for deposit formation. International Journal of Engine Research, pp. 1-21.

19. Gomez-Santos, E., Shia, J., Gavaises, M., Soteriou, C., Winterbourn, M. and Bauerd, W., 2020. Investigation of cavitation and air entrainment during pilot injection in real size multi-hole diesel nozzles, Fuel, Vol. 263, 116746.

20. Dai, X., Wang, Z., Liu, F., Lee, C.-F., Sun, Q. and Li, Y., 2020. The effect of bubbles on primary breakup of diesel spray. Fuel, Vol. 263, 116664.

21. Wu, Z., Zhao, W., Li, Z., Deng, J., Hu, Z. and Li, L., 2019. A review of engine fuel injection studies using synchrotron radiation X-ray imaging, Automotive Innovation, Vol. 2, pp. 79-92.

22. Huang, W., Moon, S., Wang, J. Murayama, K., Arima, T., Sasaki, Y., Arioka, A. Nozzle tip wetting in gasoline direct injection injector and its link with nozzle internal flow, International Journal of Engine Research, Vol. 21, pp. 340-351.

23. Swantek, A.B., Duke, D.J., Tilocco, F.Z., Sovis, N. and Powell, C.F., 2014. End of injection, mass expulsion behaviors in single hole Diesel fuel injectors. ILASS-Americas 26th Annual Conference on Liquid Atomization and Spray Systems, May 2014, Portland USA.

24. Sechenyh, V., Duke, D.J., Swantek, A.B., Matusik, K.E., Kastengren, A.L., Powell, C.F., Viera, A., Payri, R. and Crua, C., 2020. Quantitative analysis of dribble volumes and rates using three-dimensional reconstruction of X-ray and diffused back illumination images of diesel sprays. International Journal of Engine Research, Vol. 21, pp. 43-54. 
25. Arcoumanis, C., Gavaises, M., Nouri, J. M., Abdul-Wahab, E. and Horrocks, R. W., 1998. Analysis of the flow in the nozzle of a vertical multi-hole Diesel engine injector. SAE Paper 980811.

26. Som, S., Aggarwal, S.K., El-Hannouny, E.M. and Longman, D.E., 2010. Investigation of Nozzle Flow and Cavitation Characteristics in a Diesel Injector. Journal of Engineering for Gas Turbines and Power, Vol. 132, 042802.

27. Mitroglou, N. and Gavaises, M., 2013. Mapping of cavitating flow regimes in injectors for medium-/heavy-duty Diesel engines. International Journal of Engine Research, Vol. 14, pp. 590-605.

28. Salvador, F.J., Martinez-Lopez, J., Caballer, M. and De Alfonso, C., 2013. Study of the influence of the needle lift on the internal flow and cavitation phenomenon in Diesel injector nozzles by CFD using RANS methods. Energy Conversion and Management, Vol. 66, pp. 246-256.

29. Salvador, F.J., Martinez-Lopez, J., Romero, J.V. and Rosello, M.D., 2013. Computational study of the cavitation phenomenon and its interaction with the turbulence developed in Diesel injector nozzles by Large Eddy Simulation (LES). Mathematical and Computer Modelling, Vol. 57, pp. 1656-1662.

30. Marcer, R., Le Cottier, P., Chaves, H., Argueyrolles, B., Habchi, C. and Barbeau, B., 2000. A validated numerical simulation of Diesel injector flow using a VOF method. SAE Paper 2000-01-2932.

31. Jia, M., Xie, M., Liu, H., Lam, W.H. and Wang, T., 2011. Numerical simulation of cavitation in the conicalspray nozzle for Diesel premixed charge compression ignition engines. Fuel, Vol. 90, pp. 2652-2661.

32. Befrui, B., Spiekermann, P., Shost, M.A. and Lai, M.C., 2013. VOF-LES studies of GDi multi-hole nozzle plume primary breakup and comparison with imaging data. ILASS Europe $25^{\text {th }}$ European Conference on Liquid Atomization and Spray Systems, September 1-4, 2013, Chania, Greece.

33. Greif, D. and Strucl, J., 2013. Numerical study of transient multi component fuel injection. SAE Paper 2013-012550.

34. Befrui, B., Corbinelli, G., Hoffmann, G., Andrews, R.J. and Sankhalpara, S.R., 2009. Cavitation and hydraulic flip in the outward-opening GDi injector valve-group. SAE Paper 2009-01-1483.

35. Bilicki, Z., Kestin, J. and Pratt, M.M., 1990. A Reinterpretation of the Results of the Moby Dick Experiments in Terms of the Nonequilibrium Model. ASME Journal of Fluids Engineering, Vol. 112, pp. 212-217.

36. Downar-Zapolski, P., Bilick, Z., Bolle, L. Franco, J., 1996. The non-equilibrium relaxation model for onedimensional flashing liquid flow. International Journal of Multiphase Flow, Vol. 22, pp. 473-483

37. Ming, P.J. and Zhang, X.Y., 2014. Numerical simulation of primary atomization with large eddy simulation method. $10^{\text {th }}$ International Conference on Heat Transfer, Fluid Mechanics and Thermodynamics, 14-16 July 2014, Orlando, USA.

38. Margot, X., Hoyas, S., Fajardo, P. and Patouna, S., 2011. CFD study of needle motion influence on the exit flow conditions of single-hole injectors. Atomization and Sprays, Vol. 21, pp. 31-40.

39. Gavaises, M., Papoulias, D., Giannadakis, E., Andriotis, A., Mitroglou, N. and Theodorakakos, A., 2008. Comparison of cavitation formation and development in Diesel VCO nozzles with cylindrical and converging tapered holes. THIESEL Conference on thermo- and fluid dynamic processes in Diesel engines, September 9 12, 2008, Valencia, Spain.

40. Margot, X., Garcia, A., Fajardo, P. and Patouna, S., 2010. Analysis of the cavitating flow in real size Diesel injectors with fixed and moving needle lift simulations. $5^{\text {th }}$ European Conference on Computational Fluid Dynamics, June 14-17, 2010, Lisbon, Portugal.

41. He, Z., Zhong, W., Wang, Q., Jiang, Z. and Fu, Y., 2013. An investigation of transient nature of the cavitating flow in injector nozzles. Applied Thermal Engineering, Vol. 54, pp. 56-64.

42. Meister, G.F., Alajbegovic, A., Ming-Chia, L. and Joon-Ho, Y., 2002. Transient simulation of DGI engine injector with needle movement. SAE Paper 2002-01-2663.

43. Xue, Q., Battistoni, M., Quan, S.P., Senecal, P.K., Pomraning, E., Schmidt, D.P. and Som, S., 2014. Eulerian modelling of fully-coupled Diesel injector flow and spray. ILASS-Americas $26^{\text {th }}$ Annual Conference on Liquid Atomization and Spray Systems, May 2014, Portland, USA. 
44. Xue, Q., Som, S., Battistoni, M., Longman, D.E., Zhao, H., Senecal, P.K. and Pomraning, E., 2013. Threedimensional simulations of the transient internal flow in a Diesel injector: Effects of needle movement. ILASSAmericas $25^{\text {th }}$ Annual Conference on Liquid Atomization and Spray Systems, May 2013, Pittsburgh, USA.

45. Battistoni, M., Kastengren, A.L., Powel, C.F. and Som, S., 2014. Fluid dynamics modelling of end-of-injection process. ILASS-Americas 26 th Annual Conference on Liquid Atomization and Spray Systems, May 2014, Portland, USA.

46. Battistoni, M., Xue, Q. and Som., S, 2016. Large-eddy simulation (LES) of spray transients: Start and end of injection phenomena. Oil and Gas Science and Technology, Vol. 71, Article No 4.

47. Zhang, W., Liu, H, Liu, C., Jia, M. and Xi, X., 2019. Numerical investigation into primary breakup of diesel spray with residual bubbles in the nozzle, Fuel, Vol. 250, pp. 265-276.

48. Battistoni M., Som S. and Powell, C.F., 2019. Highly resolved Eulerian simulations of fuel spray transients in single and multi-hole injectors: Nozzle flow and near-exit dynamics. Fuel, Vol. 251, pp. 709-729.

49. Yasutomi, K., Hwang, J., Pickett, L.M., Sforzo, B. et al., 2020. Transient internal nozzle flow in transparent multi-hole Diesel injector. SAE Paper 2020-01-0830.

50. Manin J., Pickett L.M. and Yasutomi K., 2018. Transient cavitation in transparent Diesel injectors. ICLASS $14^{\text {th }}$ Triennial International Conference on Liquid Atomization and Spray Systems, July 22-26, 2018, Chicago, USA.

51. Abers, P., Cenker, E., Yasutomi, K., Hwang, J. et al., 2019. Effect of pressure cycling on gas exchange in a transparent fuel injector, SAE Paper 2019-01-2280.

52. Yasutomi, K., Hwang, J., Manin, J. and Pickett, L.M., 2019. Diesel injector elasticity effects on internal nozzle flow. SAE Paper 2019-01-2279.

53. Jones, W.P. and Launder, B.E., 1972. The prediction of laminarization with a two-equation model of turbulence. International Journal of Heat and Mass Transfer, Vol. 15, pp. 301-314.

54. Launder, B.E. and Sharma, B.I., 1974. Application of the energy-dissipation model of turbulence to the calculation of flow near a spinning disc, Letters in Heat and Mass Transfer, Vol. 1, pp. 131-138.

55. Launder, B.E. and Spalding, D.B., 1974. The numerical computation of turbulent flows. Computer Methods in Applied Mechanics and Engineering, Vol. 3, pp. 269-289.

56. Wilcox, D.C., 1988. Re-assessment of the scale-determining equation for advanced turbulence models. AIAA Journal, Vol. 26, pp. 1299-1310.

57. Menter, F.R., 1993. Zonal two equation $k$ - $\omega$ turbulence models for aerodynamic flows. AIAA Paper 93-2906.

58. Noh, W.F. and Woodward, P., 1976. SLIC (Simple Line Interface Calculation). Proceedings of the $5^{\text {th }}$ International Conference on Numerical Methods in Fluid Dynamics, June 28-July 2, 1976, Twente, Netherlands. Lecture Notes in Physics, Vol. 59, pp. 330-340.

59. Hirt, C.W. and Nichols, B.D., 1981. Volume of fluid (VOF) method for the dynamics of free boundaries. Journal of Computational Physics, Vol. 39, pp. 201-225.

60. Muzaferija, S., Peric, M., Sames, P. and Schellin, T., 1998. A two-fluid Navier-Stokes solver to simulate water entry. Proceedings $22^{\text {nd }}$ Symposium on Naval Hydrodynamics, Washington, DC, pp. 277-289.

61. Park, I.R., Kim, K.S., Kim, J., and Van, S.H., 2009. A volume-of-fluid method for incompressible free surface flows, International Journal for Numerical Methods in Fluids, Vol. 61, pp. 1331-1362.

62. Schnerr, G.H. and Sauer, J., 2001. Physical and numerical modelling of unsteady cavitation dynamics. $4^{\text {th }}$ International Conference on Multiphase Flow, May 27 - June 1, 2001, New Orleans, USA.

63. Zwart, P.J., Gerber, A.G. and Belamri, T., 2004. A two-phase flow model for predicting cavitation dynamics. $5^{\text {th }}$ International Conference on Multiphase Flow, May 30 - June 4, 2004, Yokohama, Japan.

64. Rayleigh, L., 1917. On the pressure developed in a liquid during the collapse of a spherical cavity. Philosophical Magazine Series 6, Vol. 34, pp. 94-98.

65. Plesset, M.S., 1949. The dynamics of cavitation bubbles. Journal of Applied Mechanics, Vol. 16, pp. $228-231$.

66. Tanguy S., Menard, T. and Berlemont, A., 2007. A level set method for vaporizing two-phase flows. Journal of Computational Physics, Vol. 221, pp. 837-853. 
67. Brackbill, J.U., Kothe, D.B. and Zemach, C., 1992. A continuum method for modelling surface tension. Journal of Computational Physics, Vol. 100, pp. 335-354.

68. Hardt, S. and Wondra, F., 2008. Evaporation model for interfacial flows based on a continuum-field representation of the source terms. Journal of Computational Physics, Vol. 227, pp. 5871-5895.

69. ANSYS Fluent, v14.5 documentation.

70. Ndiaye, E.H.I., Bazile, J.P., Nasri, D., Boned, C. and Daridon, J.L., 2012. High pressure thermophysical characterization of fuel used for testing and calibrating Diesel injection systems. Fuel, Vol. 98, pp. 288-294.

71. Chorazewski, M., Dergal, F., Sawaya, T., Mokbel, I., Grolier, J.P.E. and Jose, J., 2013. Thermophysical properties of Normafluid (ISO 4113) over wide pressure and temperature ranges. Fuel, Vol. 105, pp. 440-450.

72. Kolev, N.I., 2007. Multiphase Flow Dynamics 3: Turbulence, Gas Absorption and Diesel Fuel Properties. Springer.

73. Yaws, C.L. and Gabbula, C., 2003. Yaws' handbook of thermodynamic and physical properties of chemical compounds. Knovel.

74. Papadopoulos, N. and Aleiferis, P.G., 2015. Numerical modelling of the in-nozzle flow of a Diesel injector with moving needle during and after the end of a full injection event. SAE International Journal of Engines, Vol. 8, pp. 228-2302, SAE Paper 2015-24-2472.

75. Talibi, M., 2015. Co-combustion of Diesel and gaseous fuels with exhaust emissions analysis and in-cylinder gas sampling. PhD Thesis, University College London, UK.

76. Birgel, A, 2011. Investigations on the formation of deposits in the holes of Diesel fuel injector nozzles. $P h D$ Thesis, University College London, UK.

77. Pickett, L.M., Genzale, C.L., Brunueaux, G., Malbec, L., Hermant, L., Christiansen, C. and Schramm, J., 2010. Comparison of Diesel spray combustion in different high-temperature, high-pressure facilities. SAE Paper 201001-2106.

78. Williams, R., Smith, A. and Buttery, I., 2013. Formation and removal of injector nozzle deposits in modern Diesel cars. SAE Paper 2013-01-1684.

79. Czarneski, F.E., Och, S.H. and Moura, L.M., 2015. Characterization of nozzle tip temperature of Diesel injector in a dual fuel engine. Proceedings of the European Combustion Meeting, Budapest, March 30-April 2, 2015.

80. Anantharaman, S. and Baskaran, M., 2015. A research on factors affecting nozzle tip temperature in Diesel engines. SAE Paper 2015-01-2791.

81. Schmidt, P.D. and Corradini, M.L., 2001. The Internal Flow of Diesel Fuel Injector Nozzles: A Review. International Journal of Engine Research, Vol. 2, pp. 1-22.

82. Jung, D.W., Jeong, J.H., Lim, O.T., Pyo, Y.D., Lee, J.Y. and Iida, N., 2011. Influence of pilot injection on combustion characteristics and emissions in a DI Diesel engine fuelled with Diesel and DME. SAE Paper 201101-1958.

83. La Rocca, A., MacMillan, D., Shayler, P., Murphy, M. and Pegg, I., 2014. CFD Investigation on the influence of in-cylinder mixture distribution from multiple pilot injections on cold idle behaviour of a light duty Diesel engine. SAE Paper 2014-01-2708.

84. Park, Y. and Bae, C., 20013. Effects of single and double post injections in Diesel PCCI combustion, SAE Paper 2013-01-0010.

85. Su, W., Lin, T. and Pei, Y., 2003. A compound technology for HCCi combustion in a DI Diesel engine based on the multi-pulse injection and the BUMP combustion chamber, SAE Paper 2003-01-0741.

86. Papadopoulos, N., 2017. Numerical study of transient in-nozzle fuel flow phenomena and near-nozzle effects during and after the end of injection for Diesel engines. PhD Thesis, University College London, UK.

87. Fimml, W., Chmela, F.G., Pirker, G. and Wimmer, A., 2010. Influence of cavitation in the injection nozzle on combustion in Diesel engines. International Journal of Engine Research, Vol. 11, pp.375-390.

88. Reid, B.A., Gavaises, M., Mitroglou, N., Hargrave, G.K., Garner, C.P., Long, E.J. and McDavid, R.M., 2014. On the formation of string cavitation inside fuel injectors. Experiments in Fluids, Vol. 55: 1662. 
89. Winklhofer, E., Kull, E., Kelz, E. and Morozov, A., 2001. Comprehensive hydraulic and flow field documentation in model throttle experiments under cavitation conditions. ILASS-Europe $17^{\text {th }}$ Annual Conference on Liquid Atomization and Spray Systems, September 2-6, 2001, Zurich, Switzerland.

90. Saha, K. and Li, X., 2013. Assessment of different cavitation models in mixture and Eulerian framework for two-phase flow in Diesel injectors. ASME Internal Combustion Engine Division Fall Technical Conference, October 13-16, 2013, Dearborn, USA.

91. Sou, A., Bicer, B. and Tomiyama, A., 2014. Numerical simulation of incipient cavitation flow in a nozzle of fuel injector. Computers and Fluids, Vol. 103, pp. 42-48.

92. Sou, A., Hosokawa, S. and Tomiyama, A., 2007.Effects of cavitation in a nozzle on liquid jet atomization. International Journal of Heat and Mass Transfer, Vol. 50, pp. 3575-3582.

93. Rybdylova, O., Al Qubeissi, M., Braun, M., Crua, C., Manin, J., Pickett, L.M., de Sercey, G., Sazhina, E.M., Sazhin, S.S. and Heikal, M., 2016. A model for droplet heating and its implementation into ANSYS Fluent. International Communication in Heat and Mass Transfer, Vol. 76, pp. 265-270.

94. Crua, C., Shoba, T., Heikal, M., Gold, M. and Higham, C., 2010. High-speed microscopic imaging of the initial stage of Diesel spray formation and primary breakup. SAE Paper 2010-01-2247.

95. Crua, C., Heikal, M.R. and Gold, M.R., 2015. Microscopic imaging of the initial stage of Diesel spray formation. Fuel, Vol. 157, pp. 140-150.

96. Ghiji, M., Goldsworthy, L., Brandner, P.A., Garaniya, V. and Hield, P., 2016. Numerical and experimental investigation of early stage Diesel sprays. Fuel, Vol. 175, pp. 274-286.

97. Payri, F., Margot, X., Patouna, S., Ravet, F. and Funk, M., 2009. A CFD study of the effect of the needle movement on the cavitation pattern of Diesel injectors. SAE Paper 2009-24-0025.

98. Masuda, R., Fuyuto, T., Nagaoka, M., von Berg, E. and Tatschl, R., 2005. Validation of Diesel fuel spray and mixture formation from nozzle internal flow calculation. SAE Paper 2005-01-2098.

99. Roth, H., Gavaises, M. and Arcoumanis, C., 2002. Cavitation initiation, its development and link with flow turbulence in Diesel injector nozzles. SAE Paper 2002-01-0214.

100.Eagle, W.E. and Musculus, M.P.B., 2014. Cinema-Stereo imaging of fuel dribble after the end of injection in an optical heavy-duty Diesel engine. THIESEL Conference on thermo- and fluid dynamic processes in Diesel engines, September 9-12, 2014, Valencia, Spain.

101.Battistoni, M., Poggiani, C. and Som, S., 2015. Prediction of the nozzle flow and jet characteristics at start and end of injection: transient behaviors. SAE International Journal of Engines, Vol. 9, pp. 84-97, SAE Paper 201501-1850.

102.Moon, S., Huang, W., Li, Z. and Wang, J., 2016. End-of-injection fuel dribble of multi-hole Diesel injector: Comprehensive investigation of phenomenon and discussion on control strategy. Applied Energy, Vol. 179, pp. 7-16.

103.Crua, C., de Sercey, G., Gold, M. and Heikal, M.R., 2013. Image-based analysis of evaporating Diesel sprays in the near-nozzle region. ILASS-Europe $25^{\text {th }}$ Annual Conference on Liquid Atomization and Spray Systems, September 1-4, 2013, Chania, Greece.

104.Stetsyuk, V., Crua, C., Pearson, R. and Gold, M., 2014. Direct imaging of primary atomisationin the near-nozzle region of Diesel sprays. ILASS-Europe $26^{\text {th }}$ Annual Conference on Liquid Atomization and Spray Systems, September 8-10, 2014, Bremen, Germany.

105.Turner, J.E., Stretsyuk, V., Crua, C., Gold, M.R. and Pearson, R.J., 2015. The effect of operating conditions on post-injection fuel discharge in an optical engine. ICLASS $13^{\text {th }}$ International Conference on Liquid Atomization and Spray Systems, August 23-27, 2015, Tainan, Taiwan.

106.Nguyen, N.-T. and Huang, X., 2005. Thermocapillary effect of a liquid plug in transient temperature fields. Japanese Journal of Applied Physics, Vol. 44, pp. 1139-1142. 


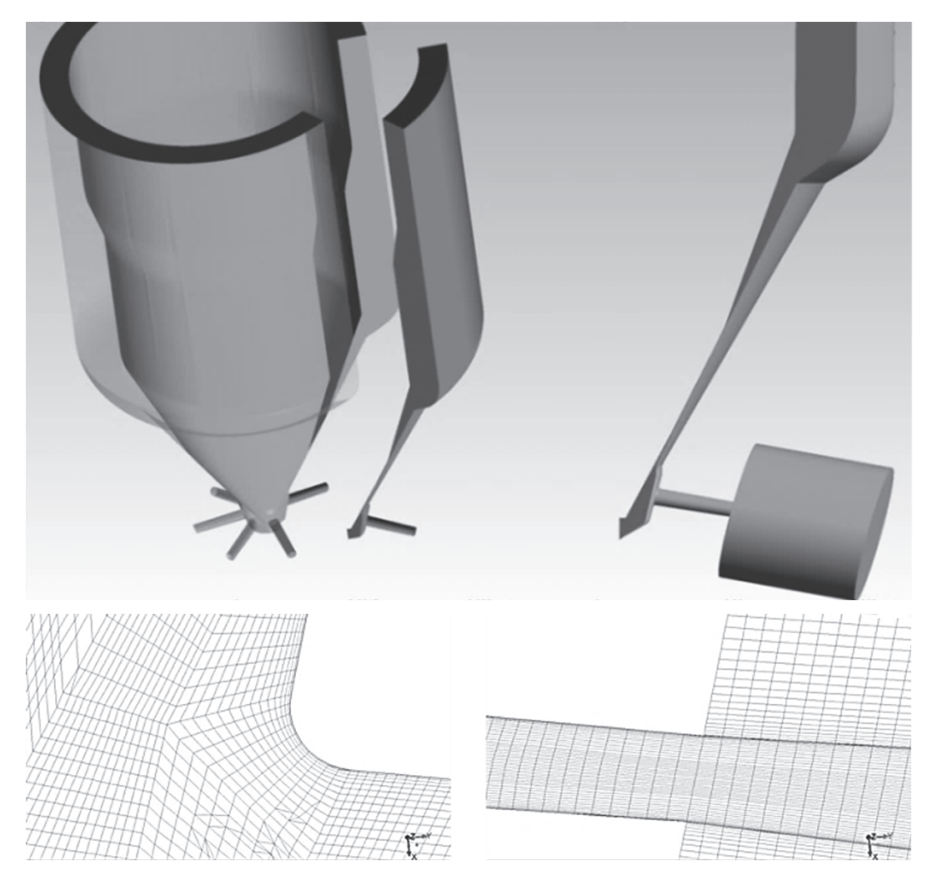

Figure 1. Geometry of the multi-hole injector, sector of a single hole with air chamber attached, details of the mesh at the orifice inlet and outlet areas.

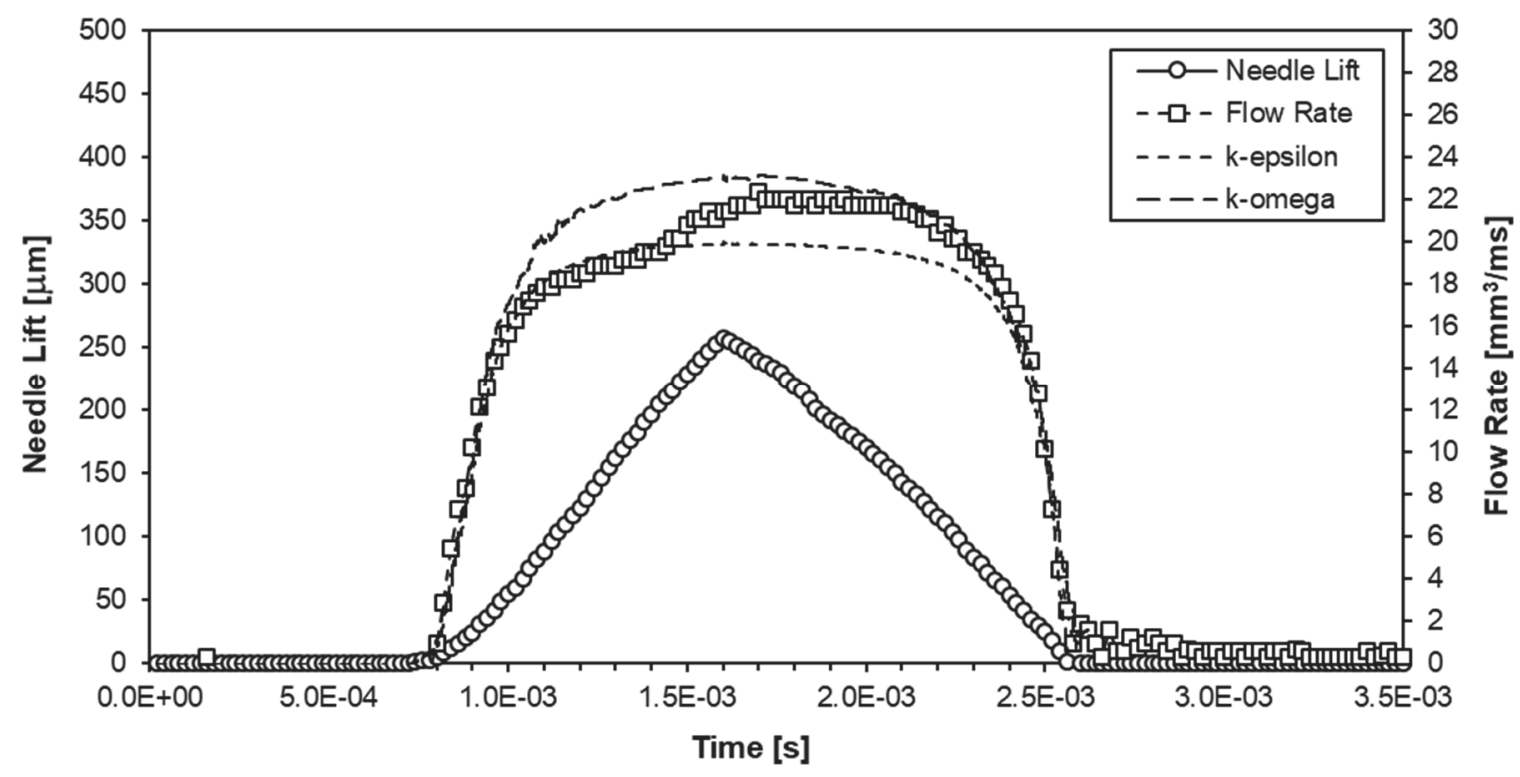

Figure 2. Needle lift and flow rate of injector, 400 bar inlet, 60 bar outlet. 

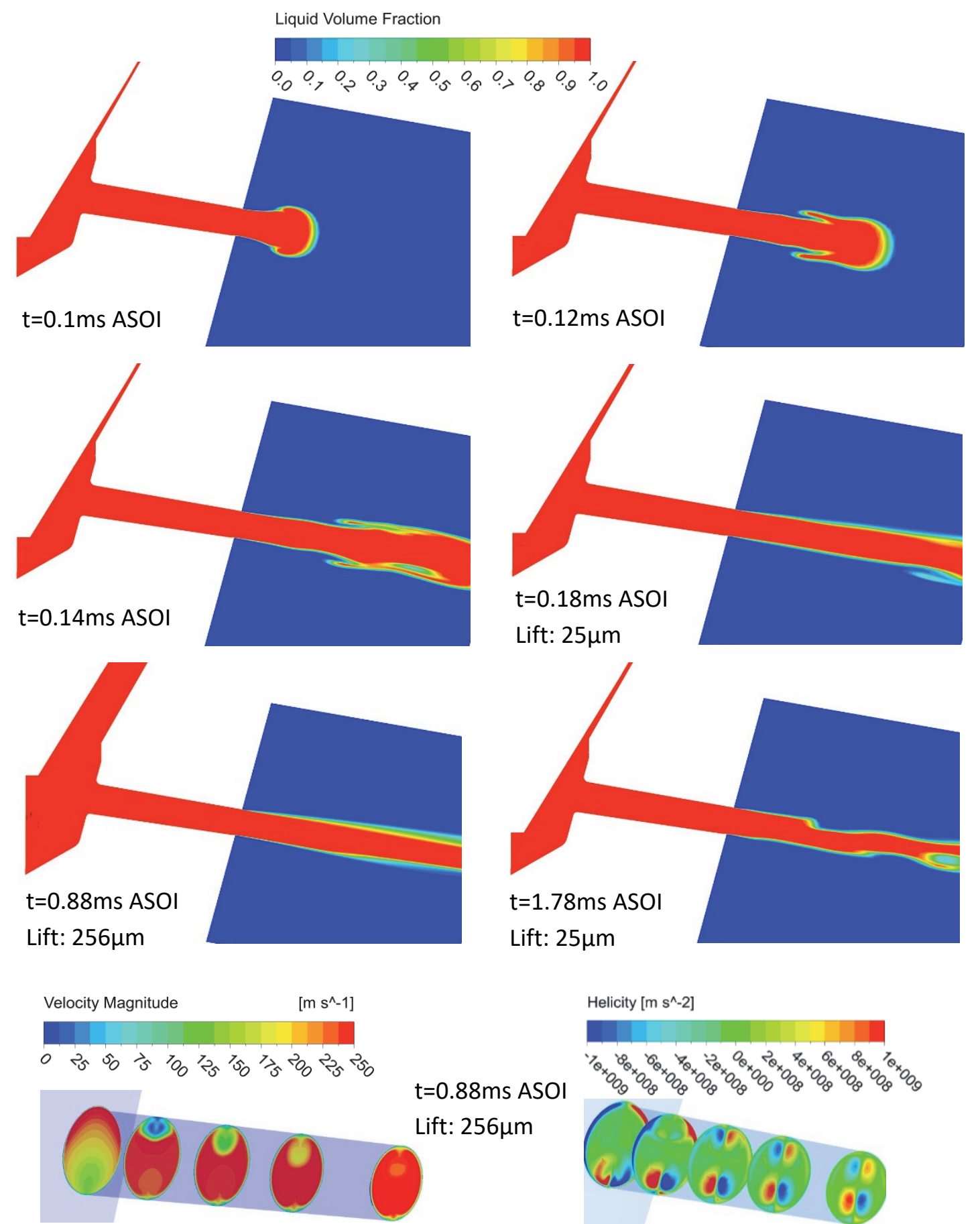

Helicity [ $\left.\mathrm{m} \mathrm{s}^{\wedge}-2\right]$
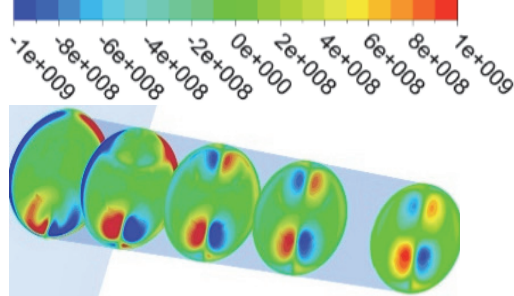

Figure 3. Liquid volume fraction and flow during injection, 400 bar inlet, 60 bar outlet, $300 \mathrm{~K}$ (Test Case 1). 

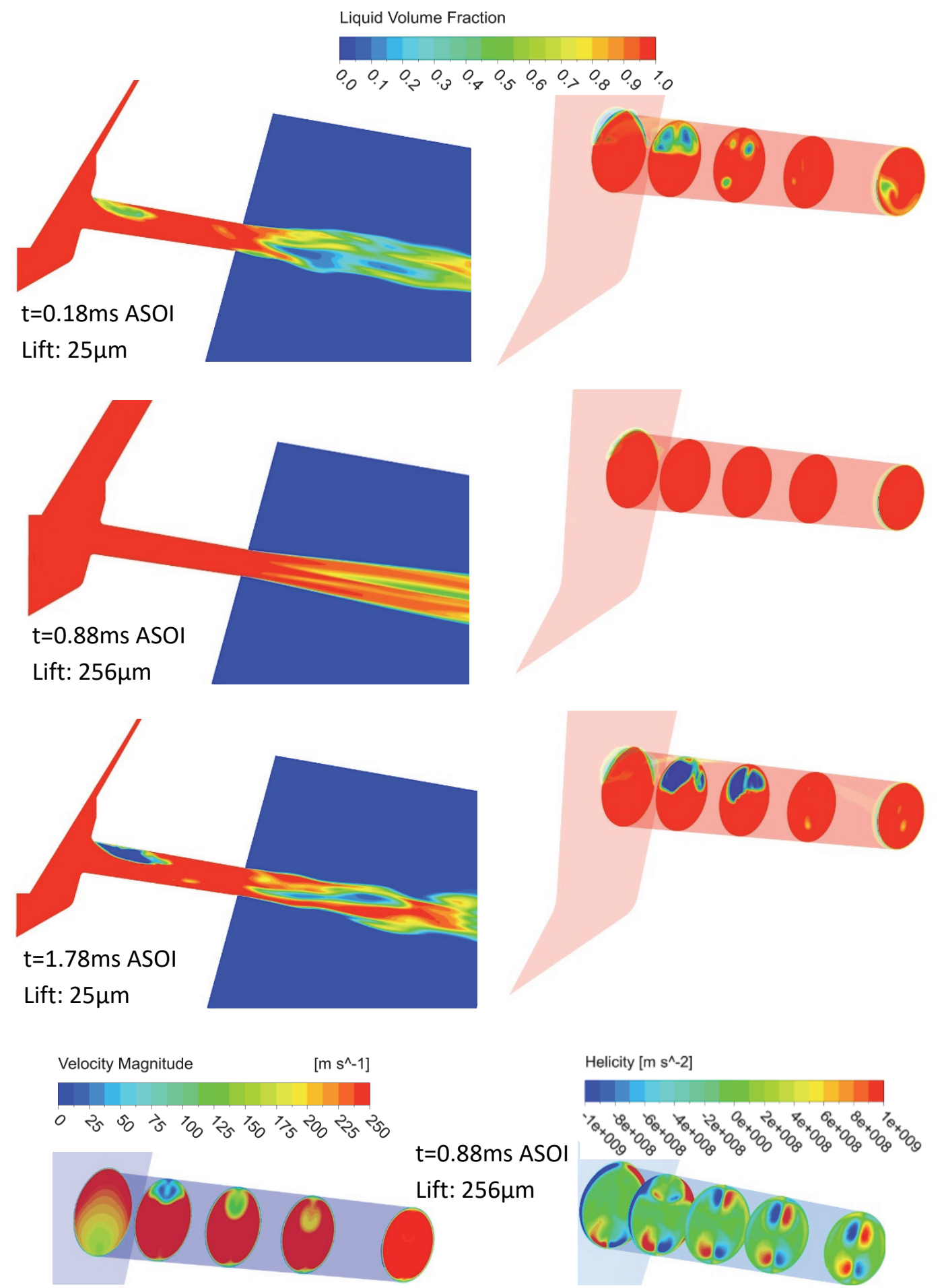

Figure 4. Liquid volume fraction and flow during injection, 400 bar inlet, 1 bar outlet, $300 \mathrm{~K}$ (Test Case 2). 


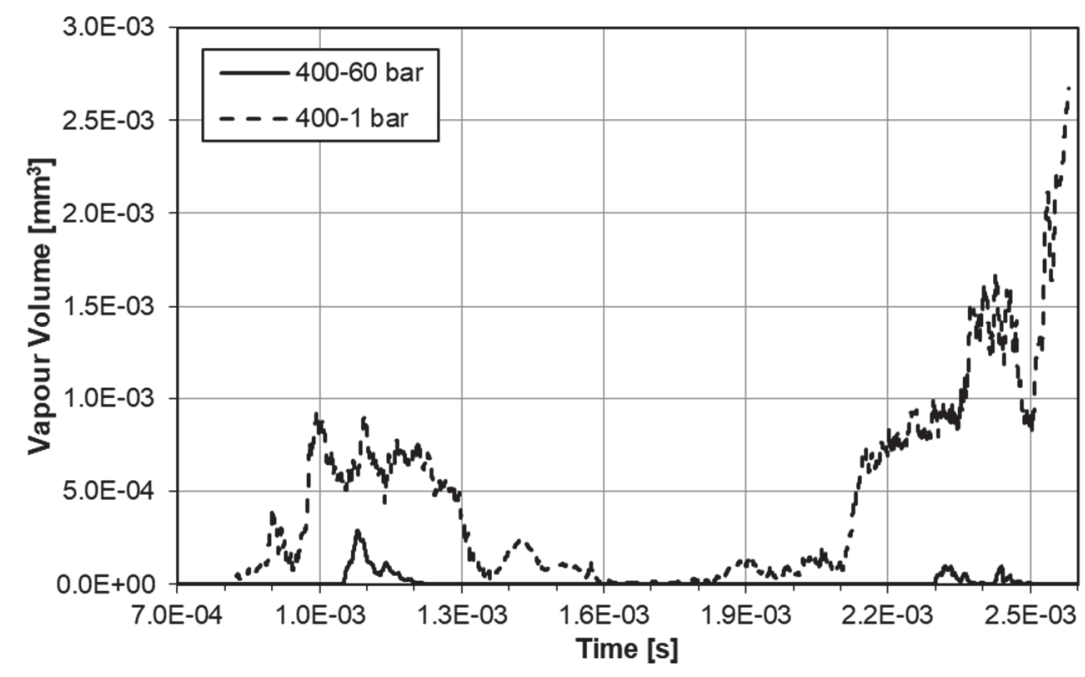

Figure 5. Total volume of vapour in the orifice during the 400 bar injections.

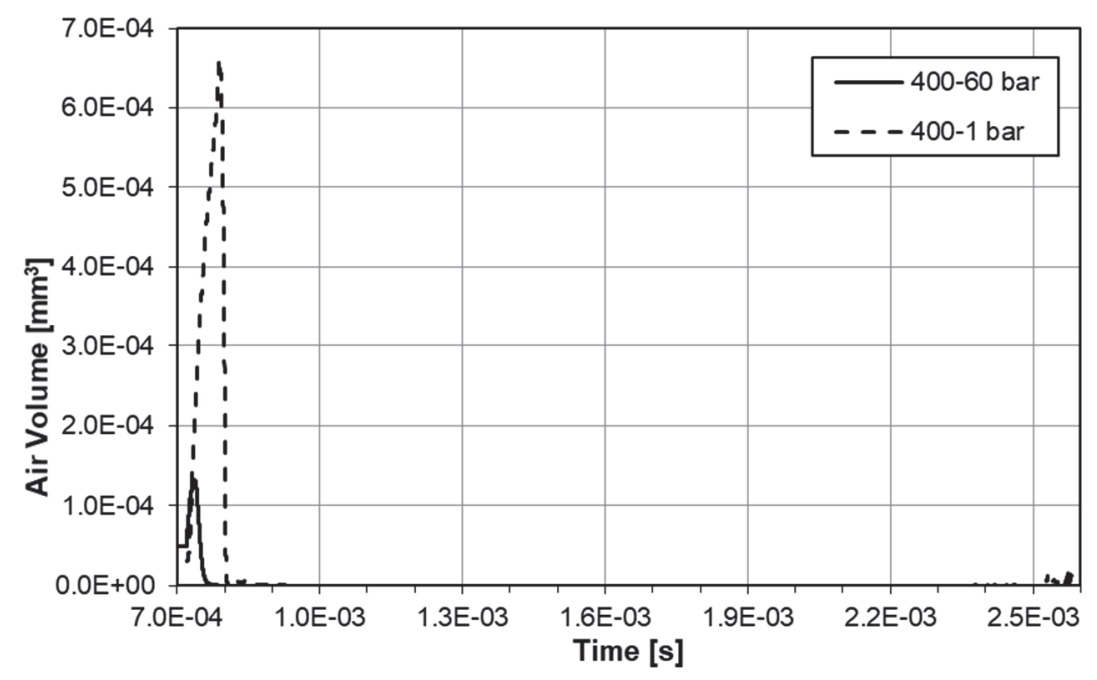

Figure 6. Total volume of air in the orifice during the 400 bar injections. 

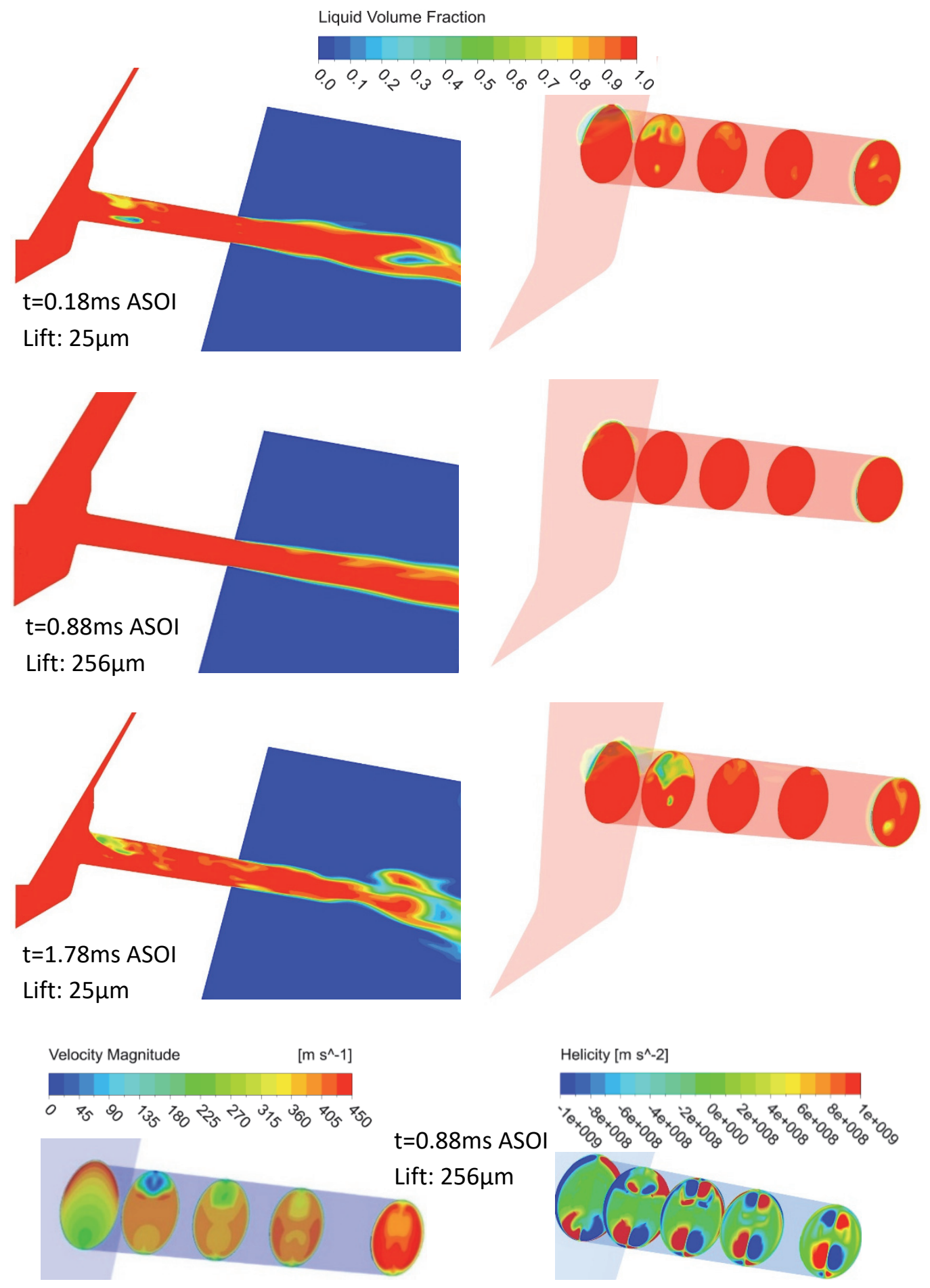

Figure 7. Liquid volume fraction and flow during injection, 900 bar inlet, 35 bar outlet, $300 \mathrm{~K}$ (Test Case 3). 

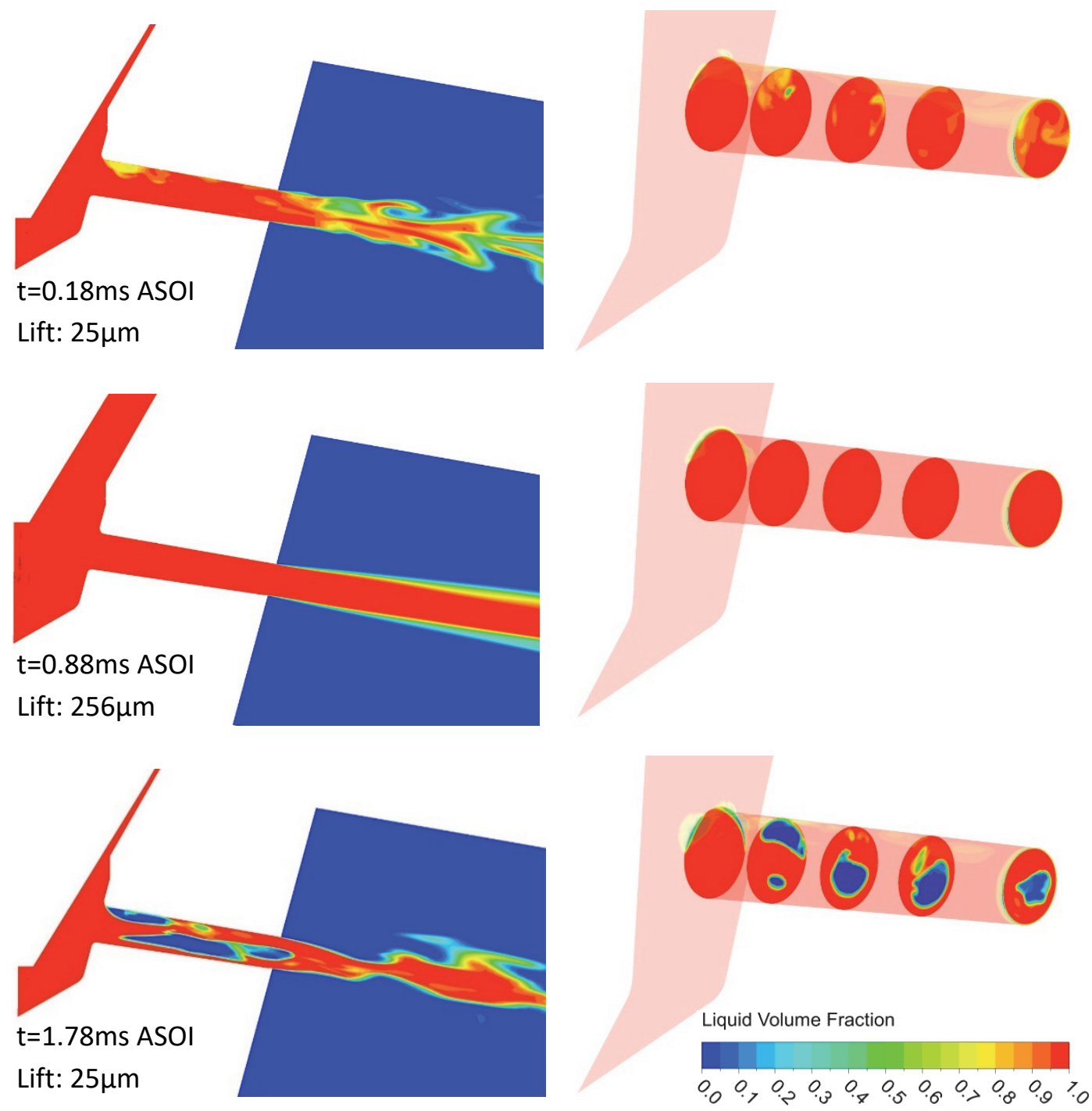

Figure 8. Liquid volume fraction during injection, 900 bar inlet, 35 bar outlet, $353 \mathrm{~K}$ (Test Case 4). 

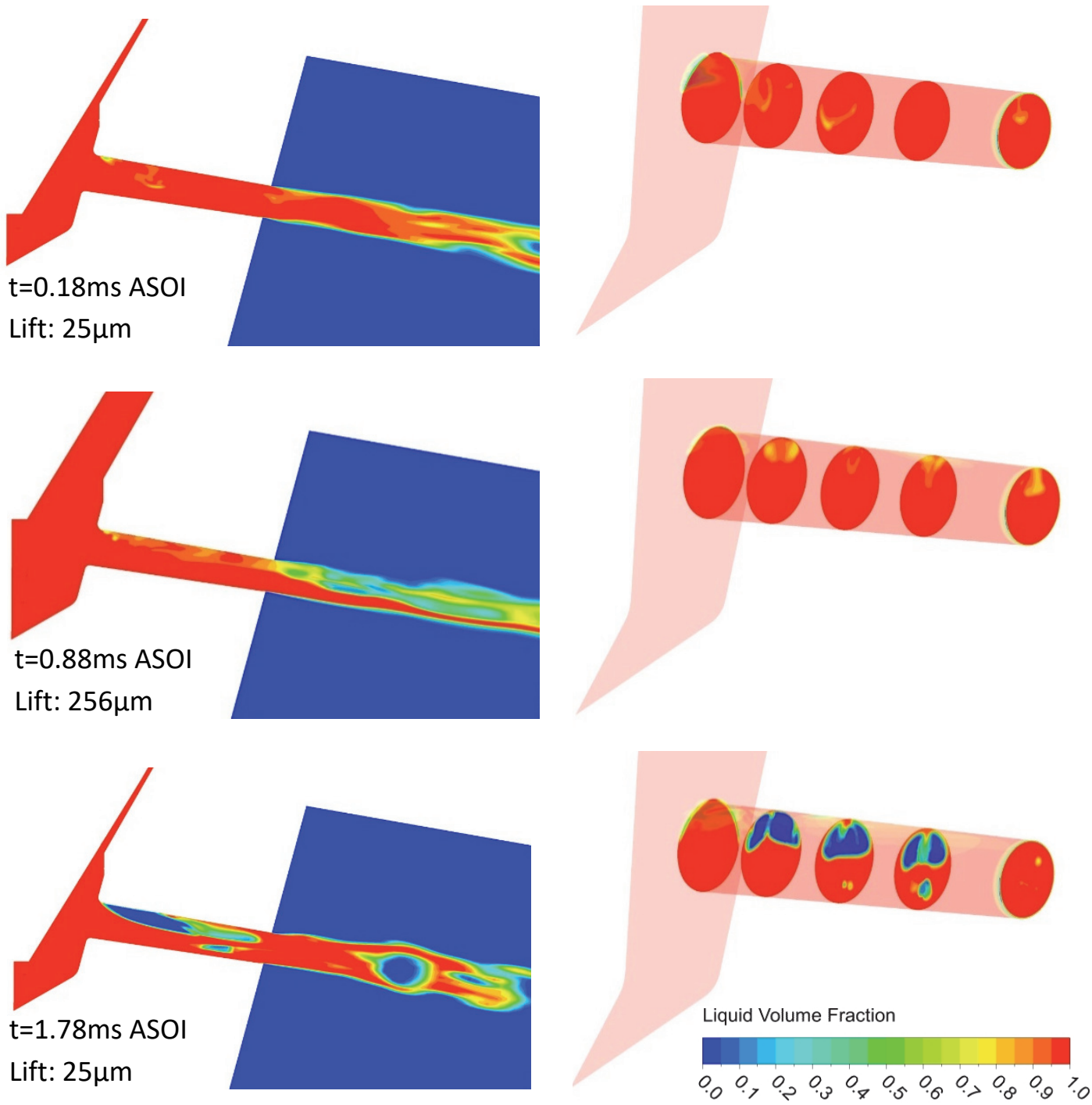

Figure 9. Liquid volume fraction during injection, 900 bar inlet at $333 \mathrm{~K}, 35$ bar outlet at $550 \mathrm{~K}$ (Test Case 5). 

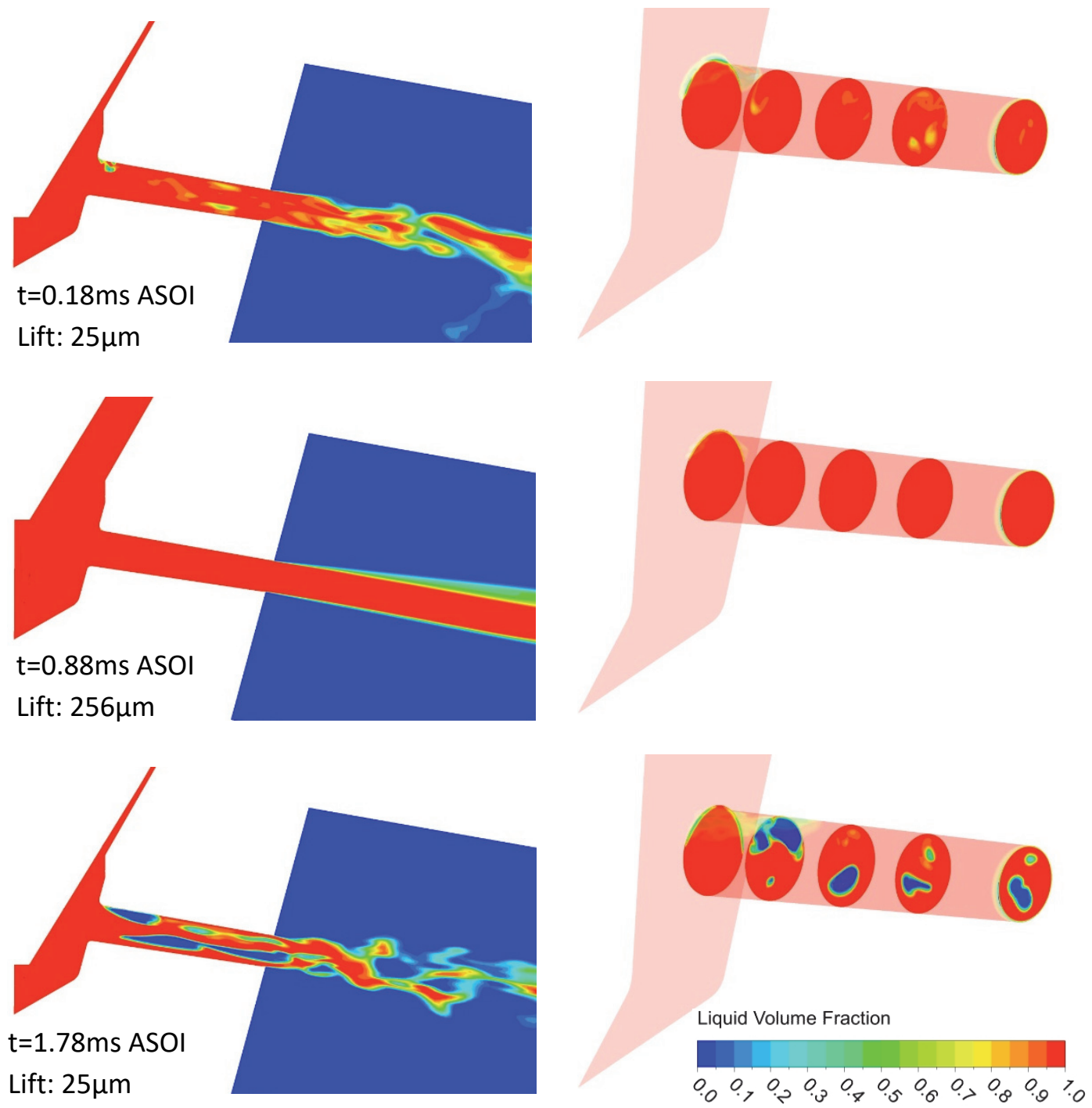

Figure 10. Liquid volume fraction during injection, 900 bar inlet, 35 bar outlet, $333 \mathrm{~K}$, injector walls at $473 \mathrm{~K}$ (Test Case 6). 


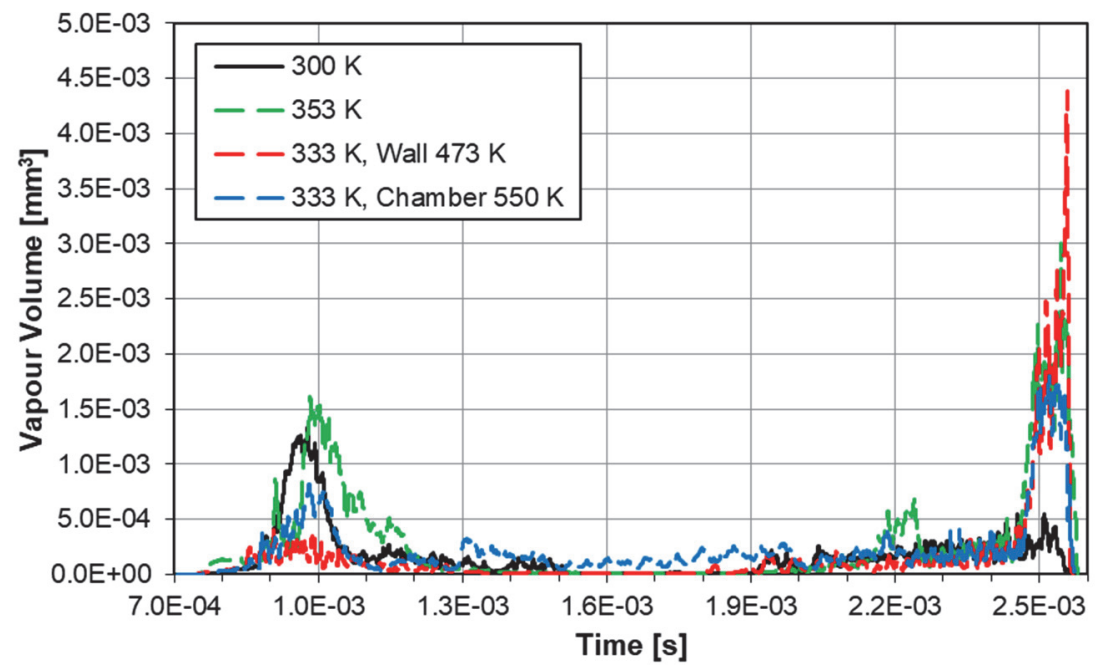

Figure 11. Total volume of vapour in the orifice during the 900 bar injections.

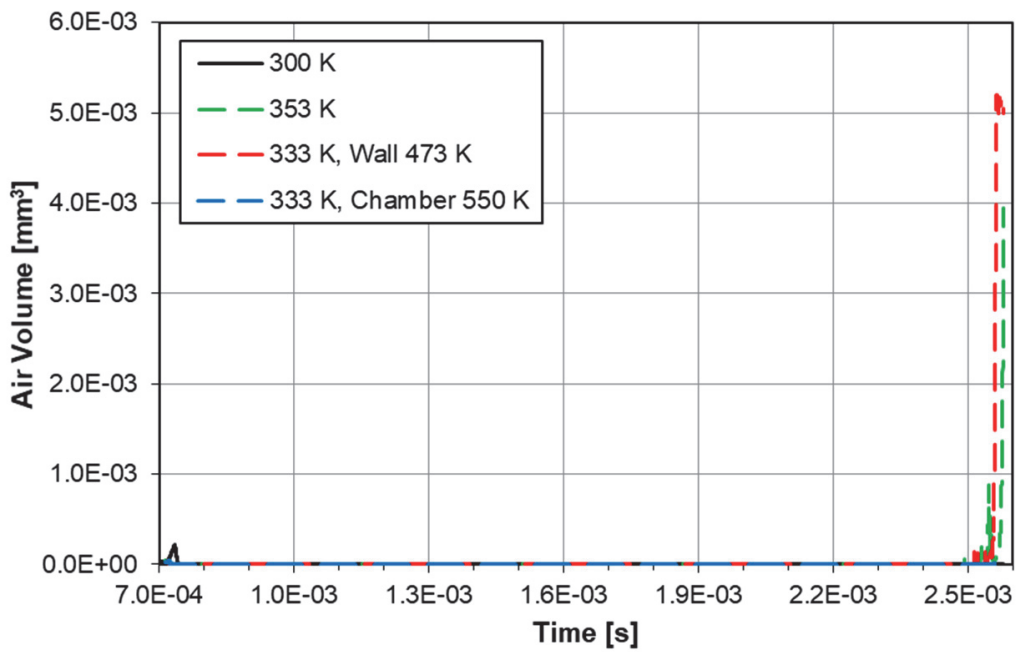

Figure 12. Total volume of air in the orifice during the 900 bar injections. 


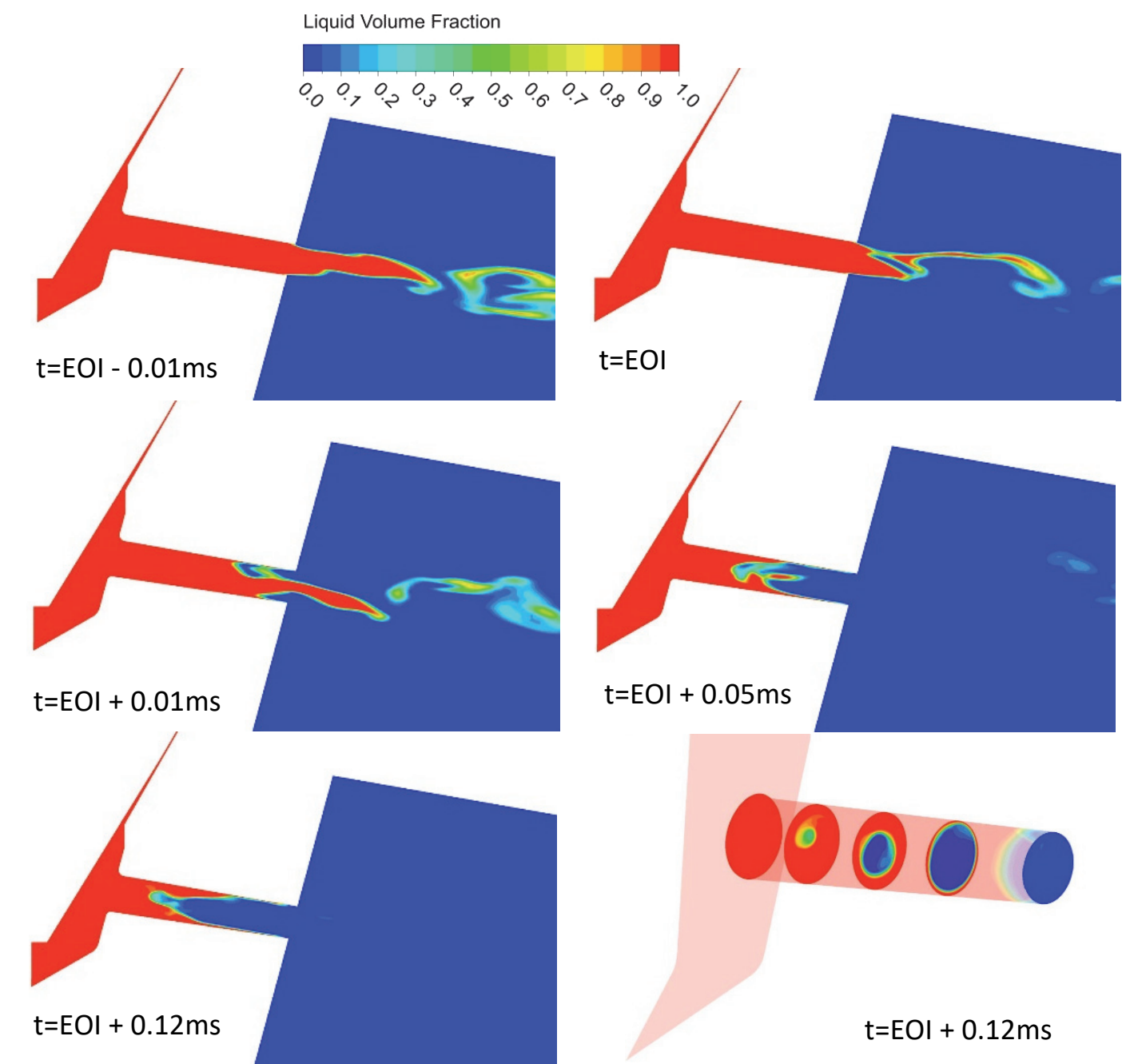

Figure 13. Liquid volume fraction AEOI, 400 bar inlet, 60 bar outlet, 300 K (Test Case 1).

Air Volume Fraction
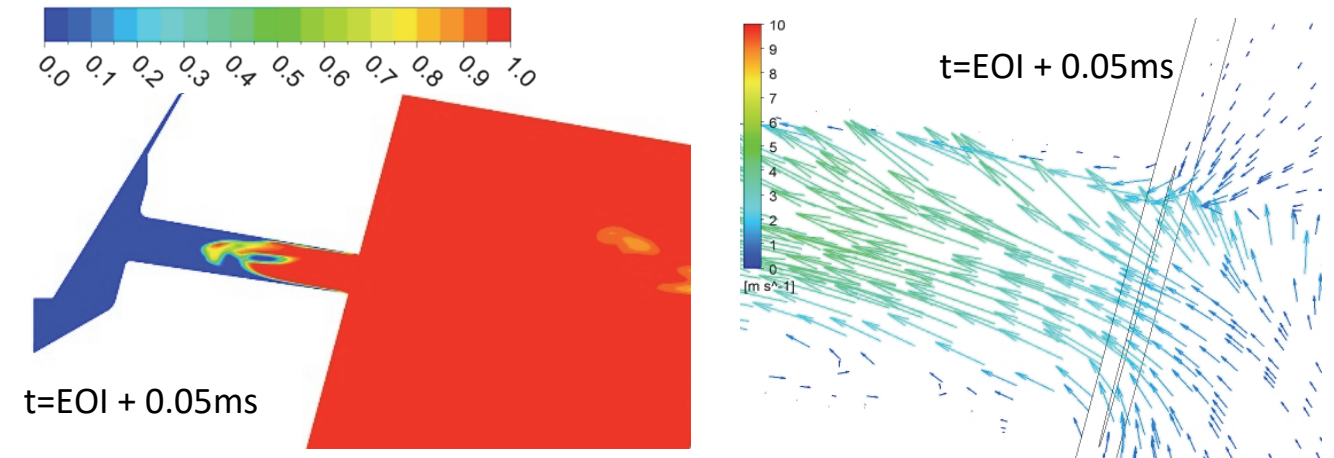

Figure 14. Air volume fraction and backflow velocity AEOI, 400 bar inlet, 60 bar outlet, 300 K (Test Case 1). 


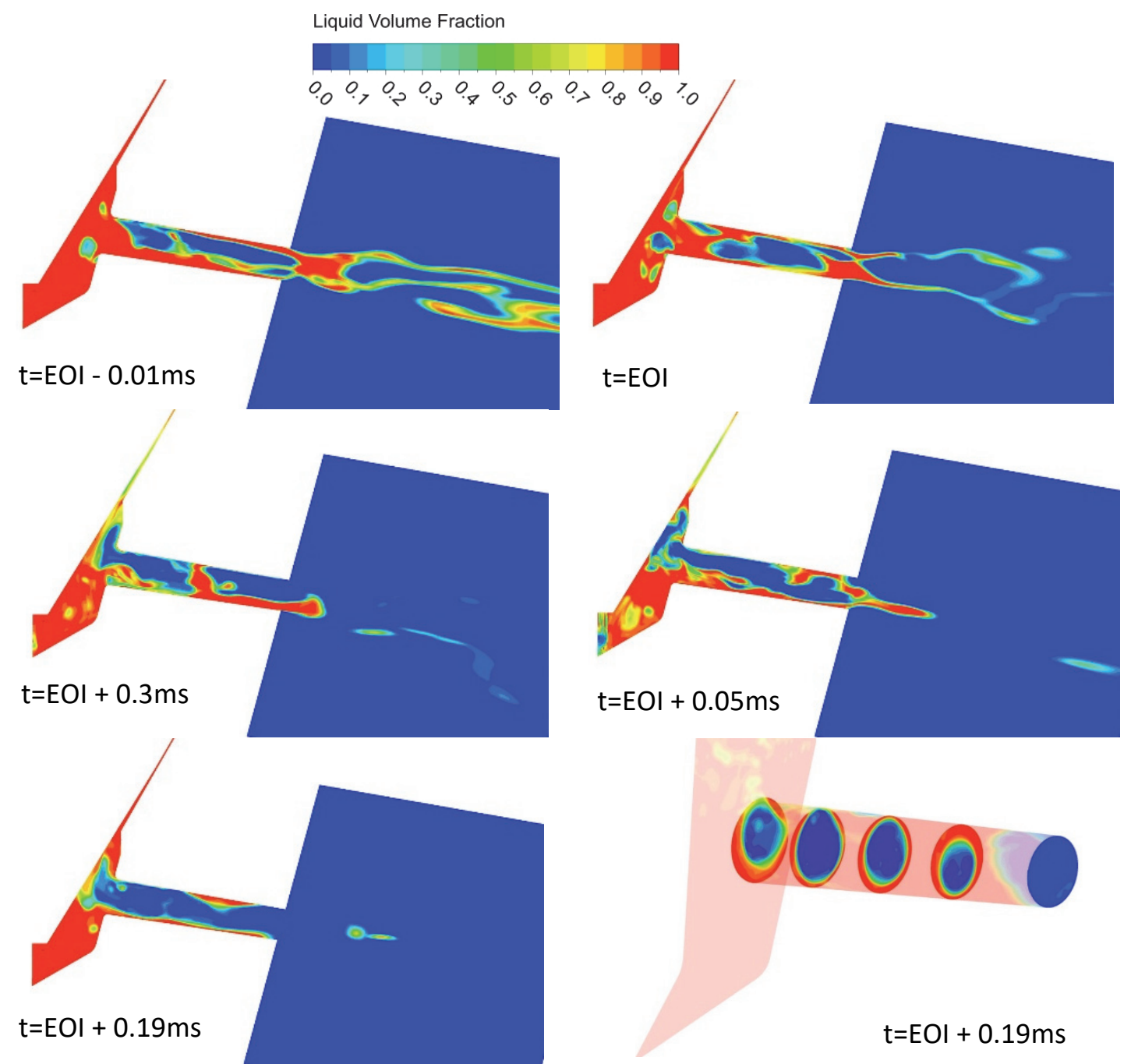

Figure 15. Liquid volume fraction AEOI, 400 bar inlet, 1 bar outlet, $300 \mathrm{~K}$ (Test Case 2).
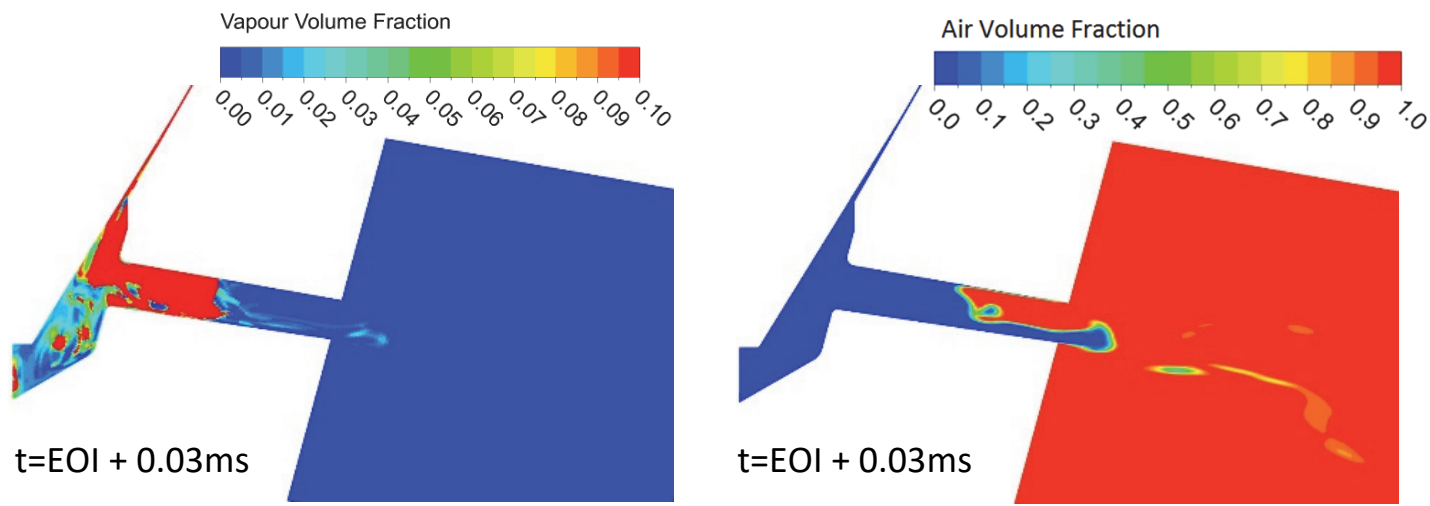

Figure 16. Vapour and air volume fraction AEOI, 400 bar inlet, 1 bar outlet, $300 \mathrm{~K}$ (Test Case 2). 


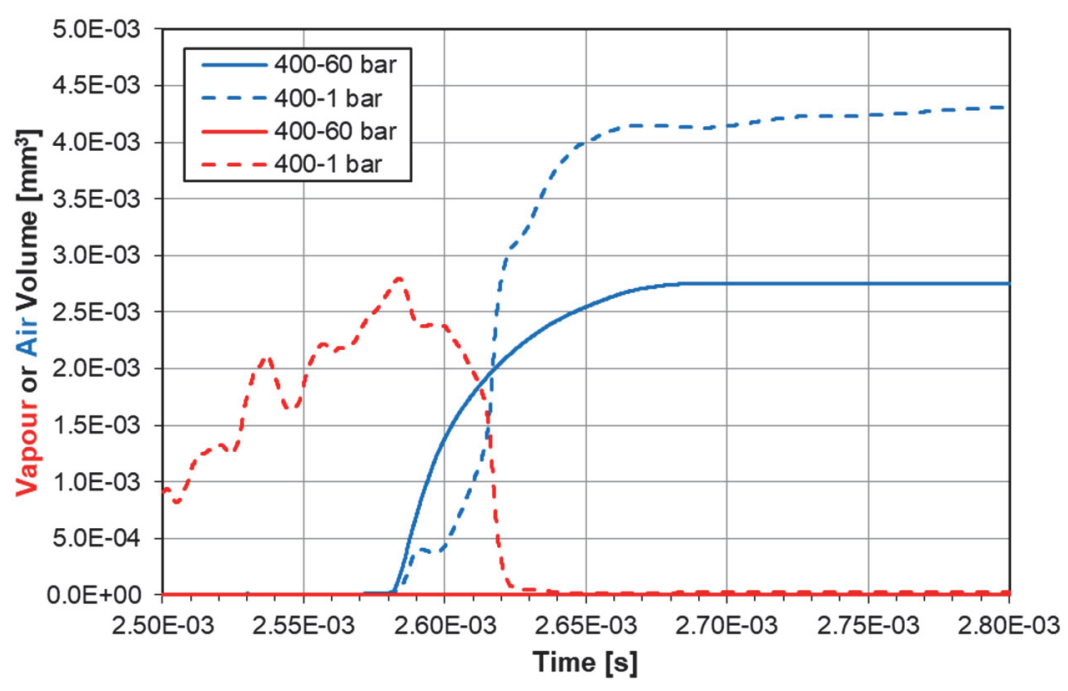

Figure 17. Total volume of vapour and air in the orifice before and after needle closure, $400 \mathrm{bar}, 300 \mathrm{~K}$.

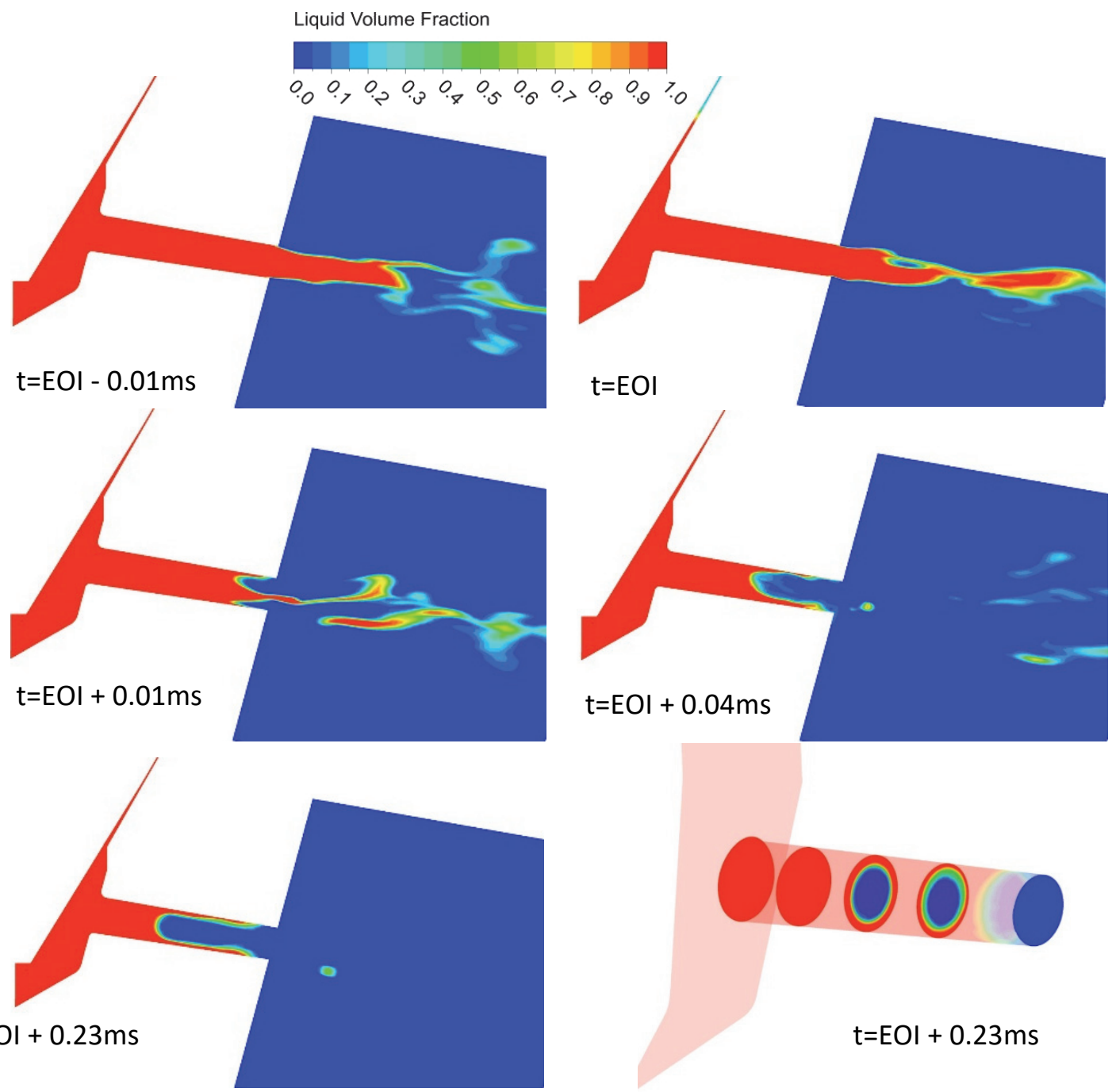

Figure 18. Liquid volume fraction AEOI, 900 bar inlet, 35 bar outlet, $300 \mathrm{~K}$ (Test Case 3). 


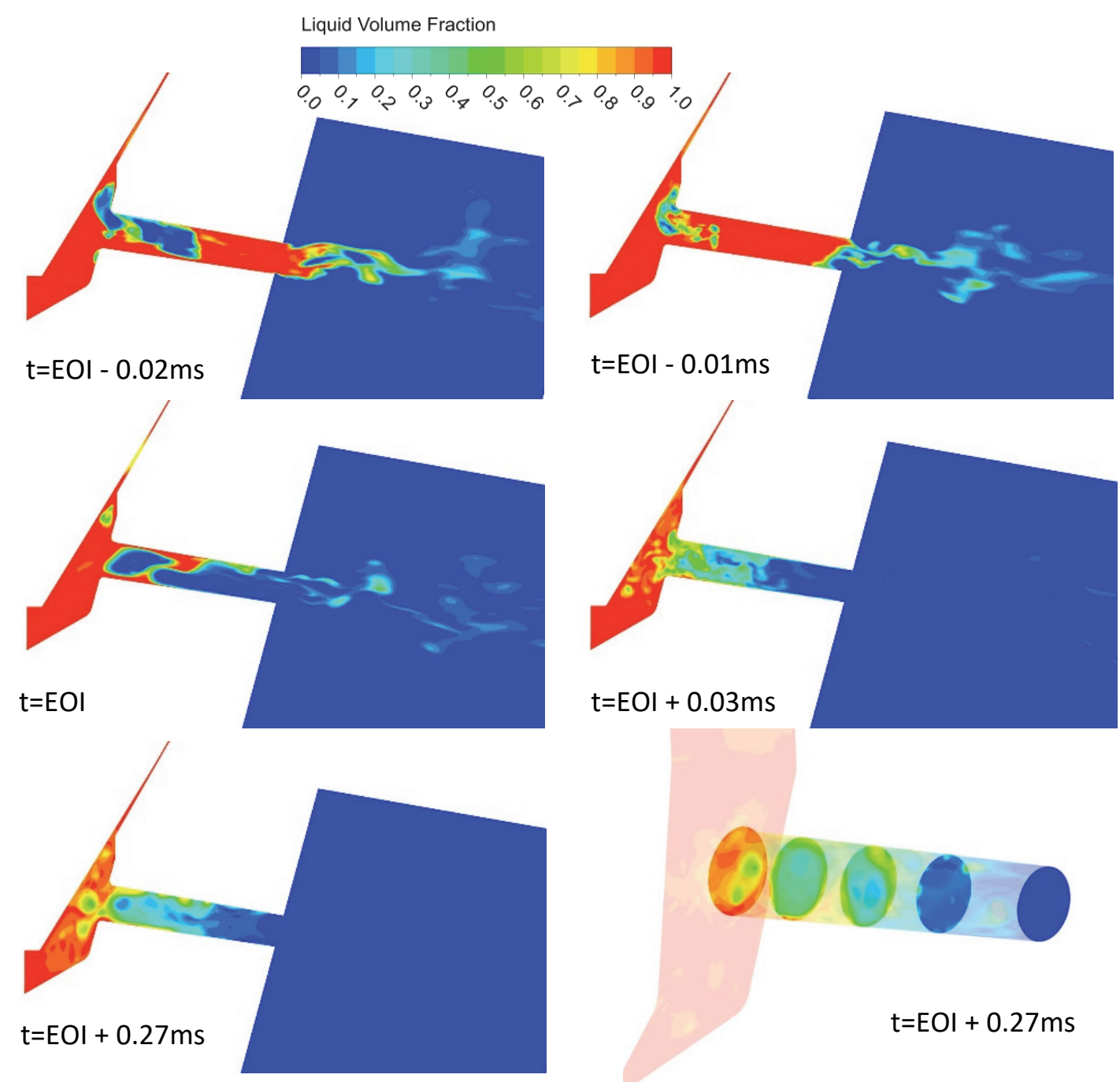

Figure 19. Liquid volume fraction AEOI, 900 bar inlet, 35 bar outlet, 353 K (Test Case 4).
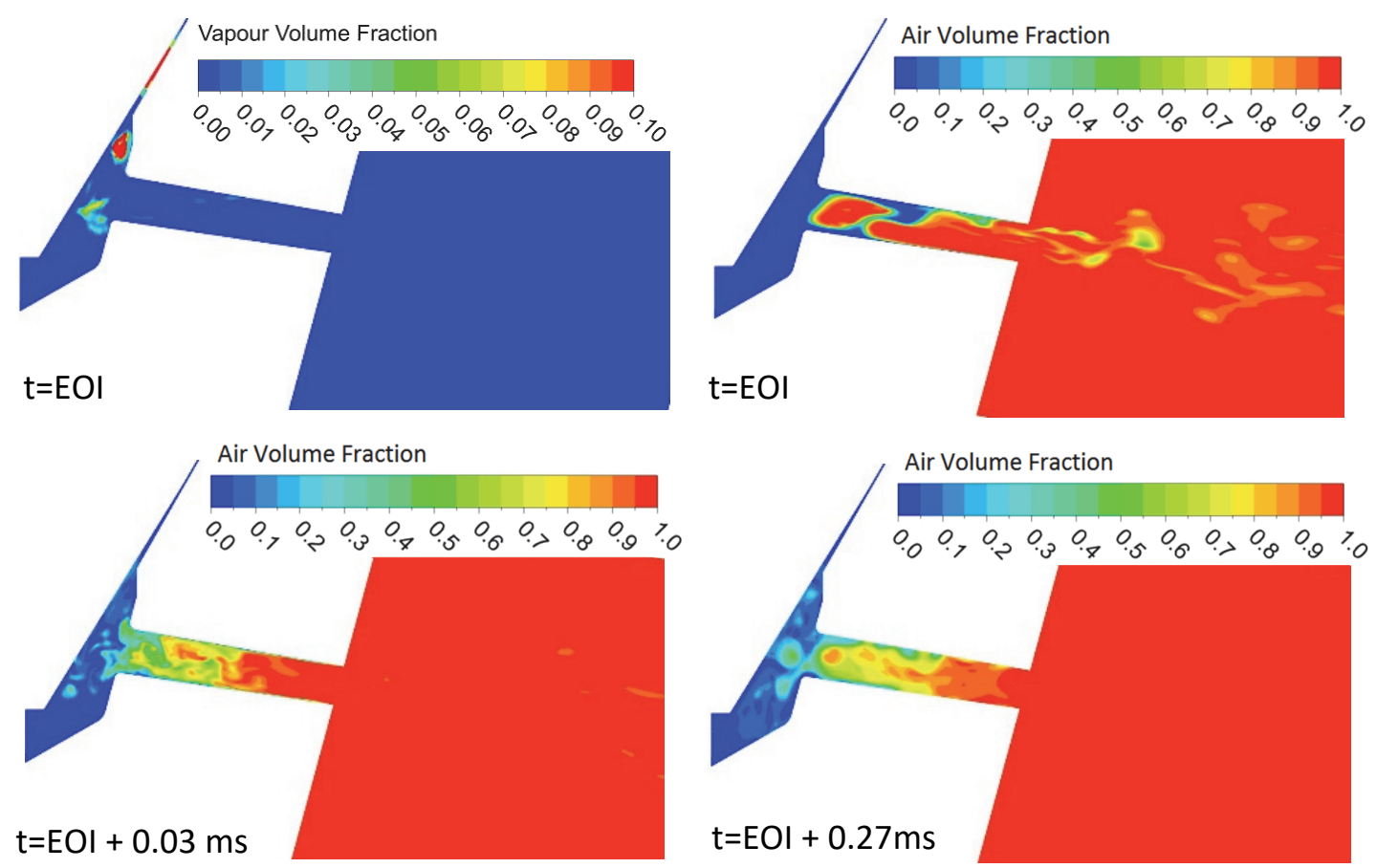

Figure 20. Vapour and air volume fraction AEOI, 900 bar inlet, 35 bar outlet, $353 \mathrm{~K}$ (Test Case 4). 


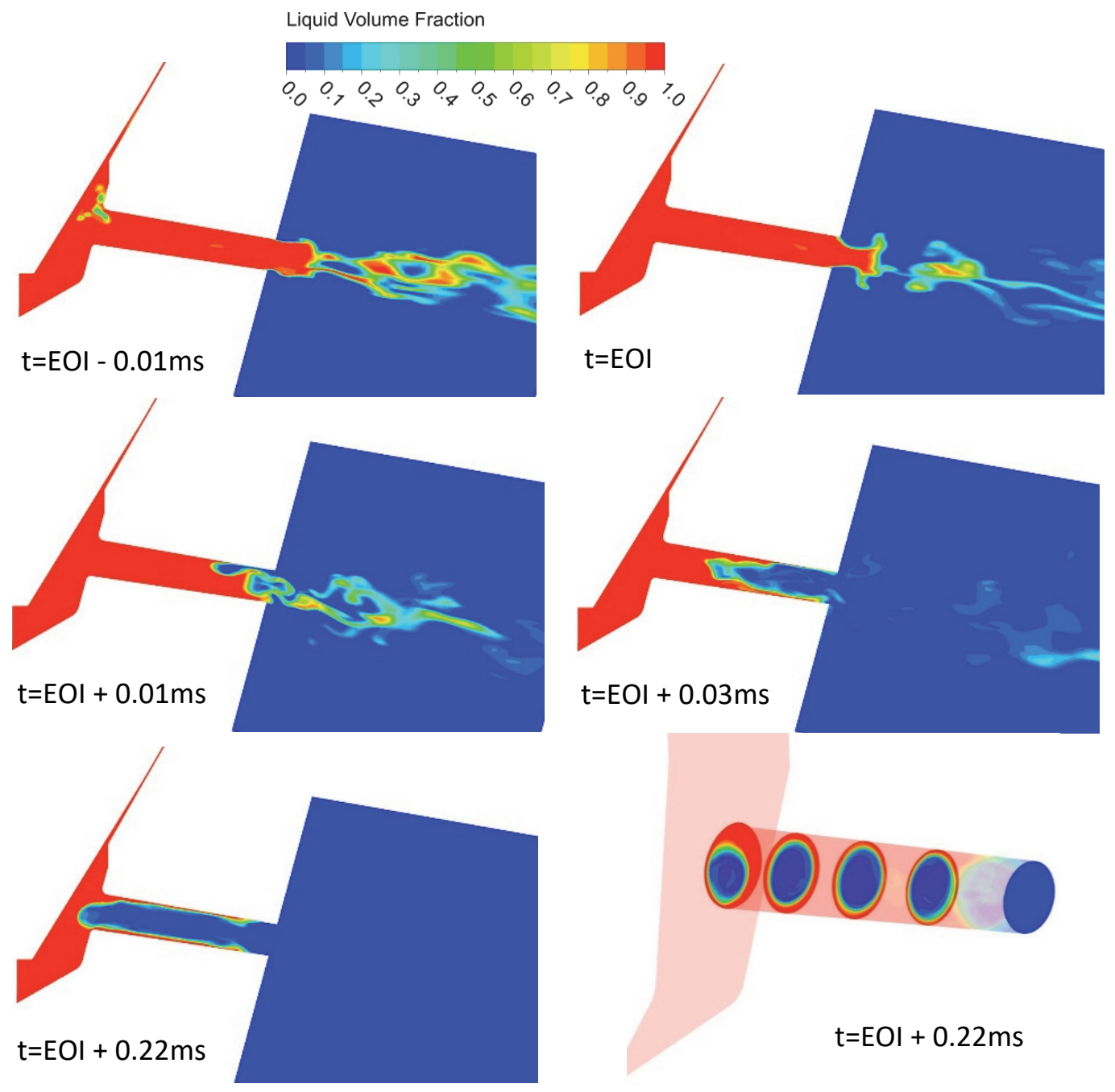

Figure 21. Liquid volume fraction AEOI, 900 bar inlet at 333 K, 35 bar outlet at $550 \mathrm{~K}$ (Test Case 5). 


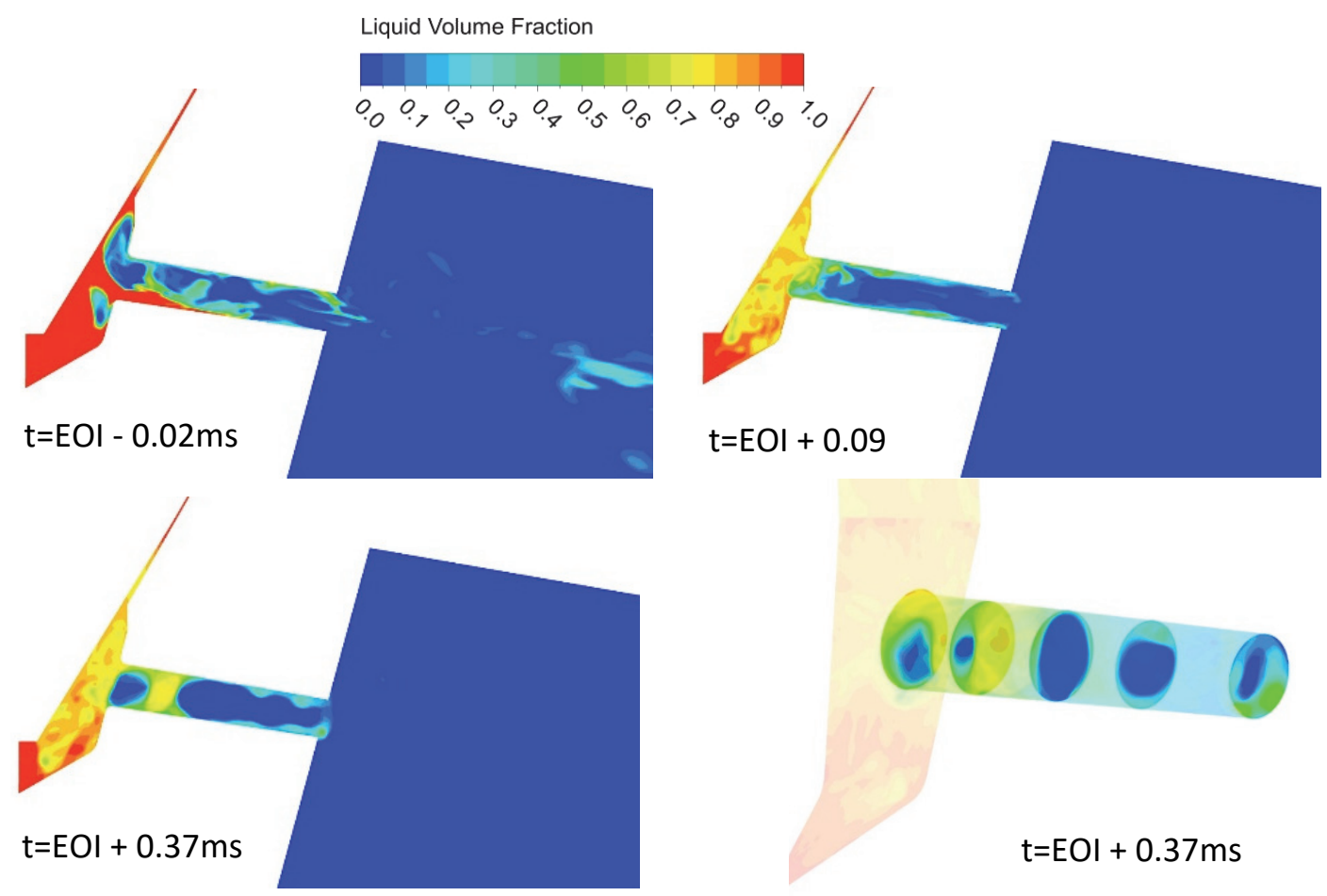

Figure 22. Liquid volume fraction AEOI, 900 bar inlet, 35 bar outlet, 333 K, walls 473 K (Test Case 6).
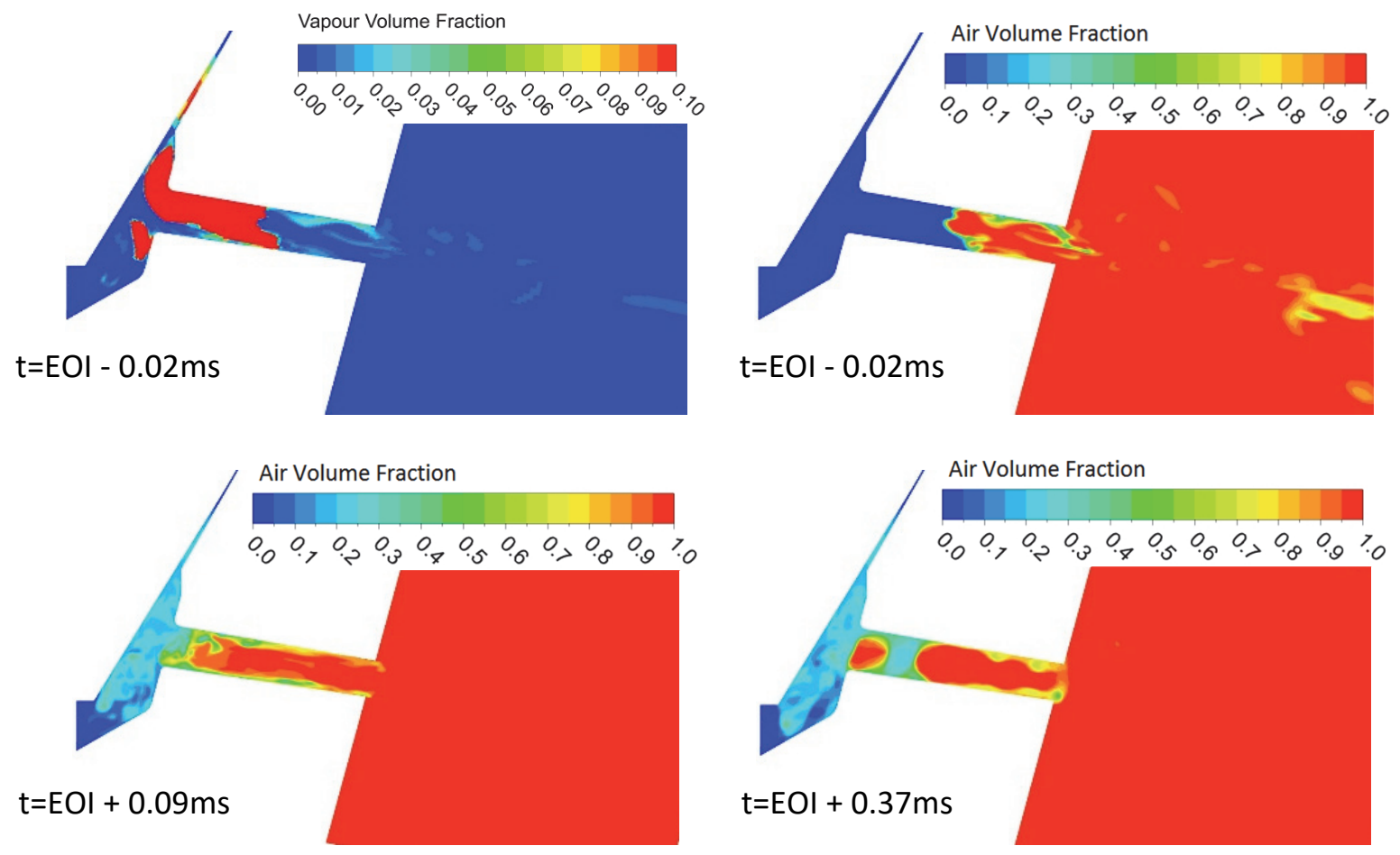

Figure 23. Vapour and air volume fraction AEOI, 900 bar, 35 bar outlet, 333 K, walls 473 K (Test Case 6). 


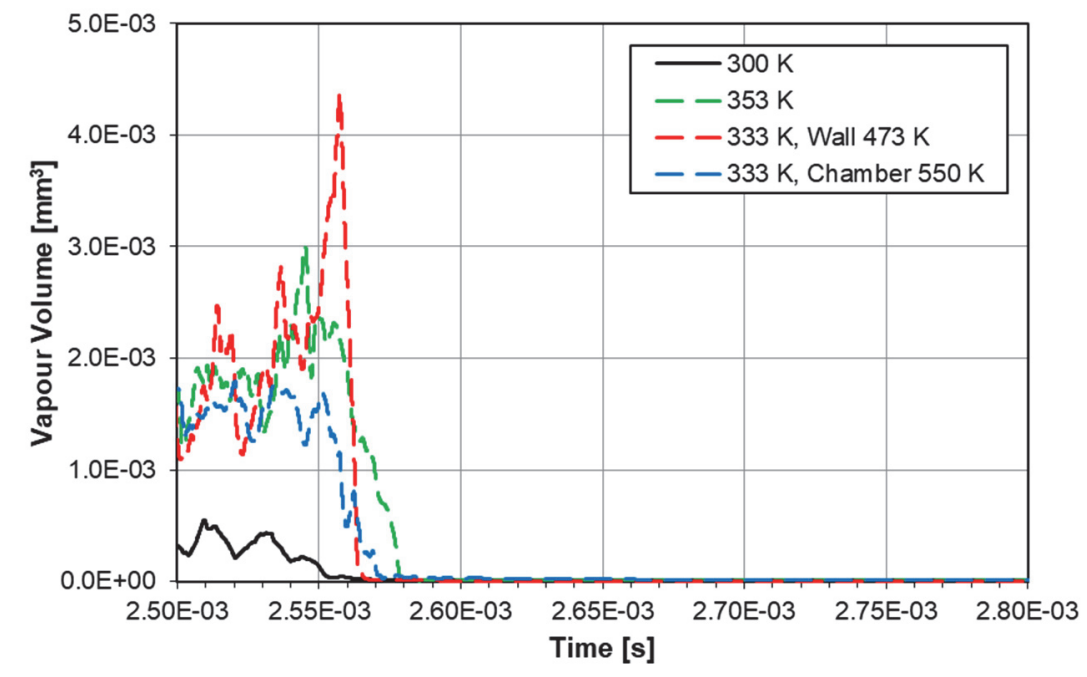

Figure 24. Total volume of vapour in the orifice before and after needle closure, 900 bar.

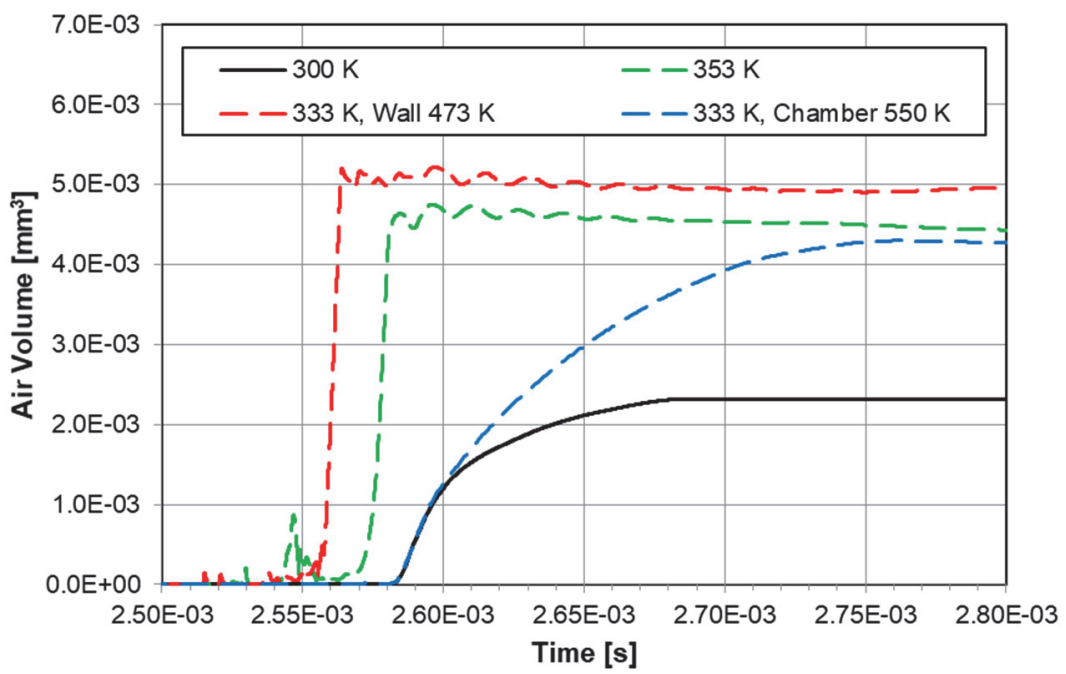

Figure 25. Total volume of air in the orifice before and after needle closure, 900 bar.

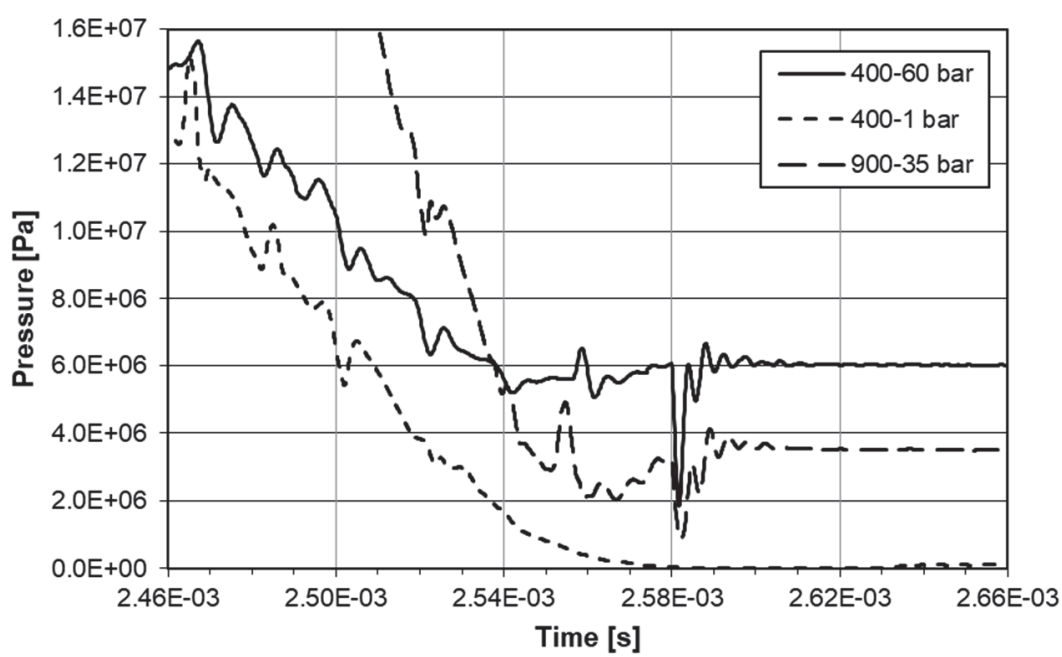

Figure 26. Average pressure in the sac before and after needle closure, $400 \mathrm{bar}, 900 \mathrm{bar}, 300 \mathrm{~K}$. 


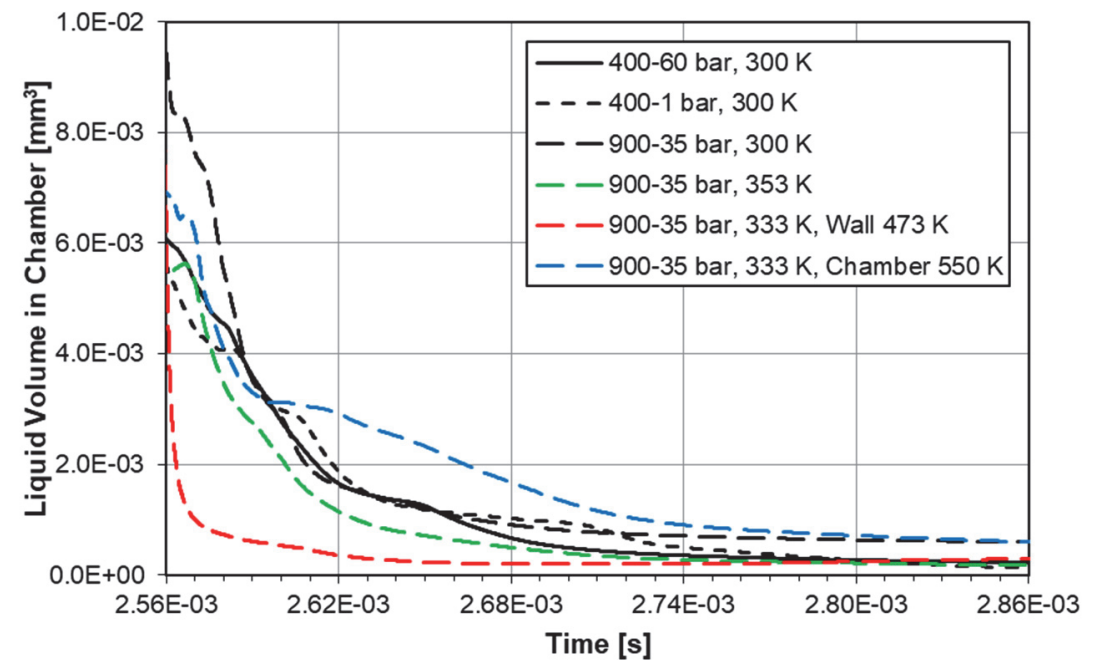

Figure 27. Total volume of liquid in the air chamber just before and after needle closure, 400 bar and 900 bar.

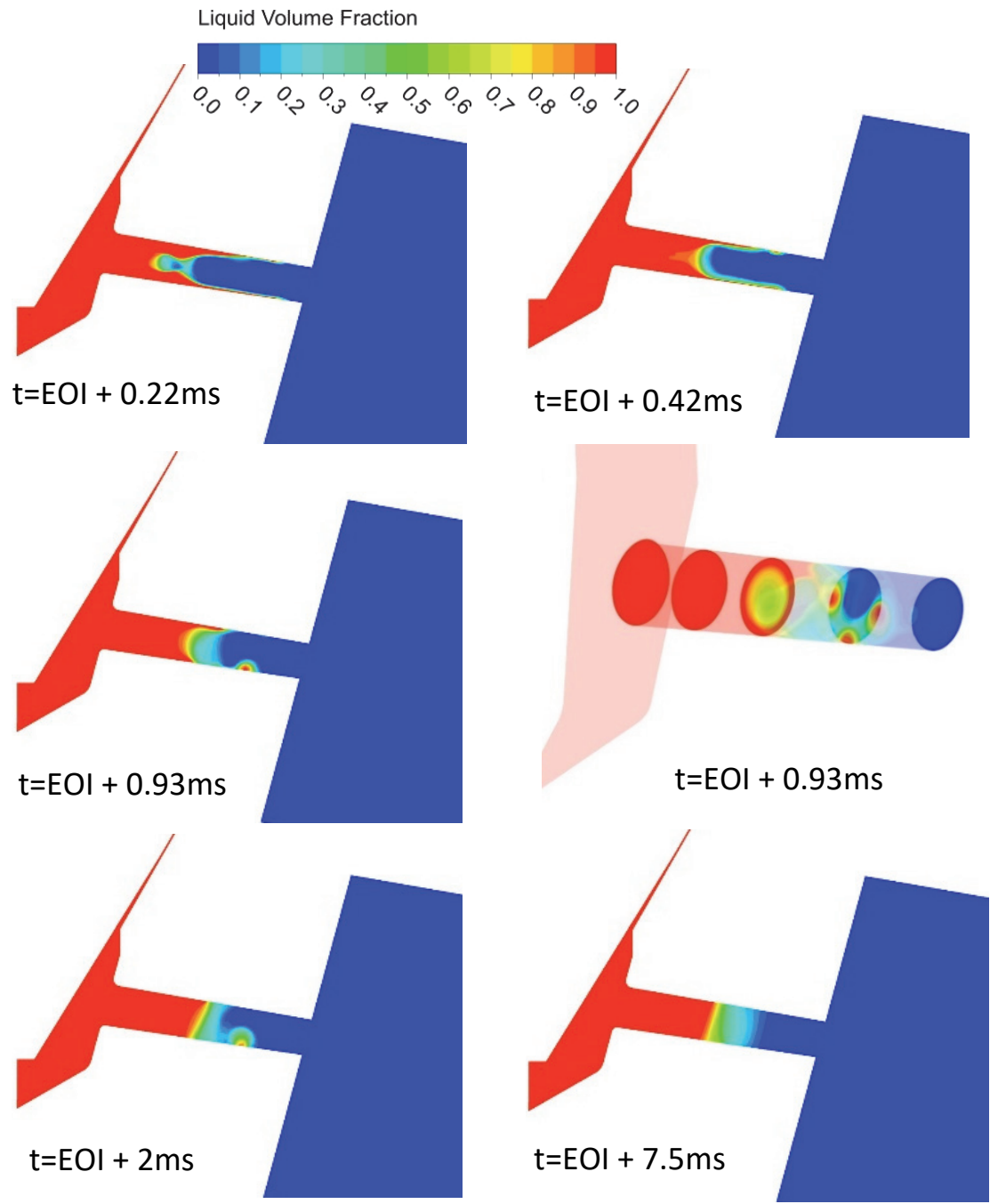

Figure 28. Liquid volume fraction at later timings AEOI, 400 bar inlet, 60 bar outlet, $300 \mathrm{~K}$ (Test Case 1). 


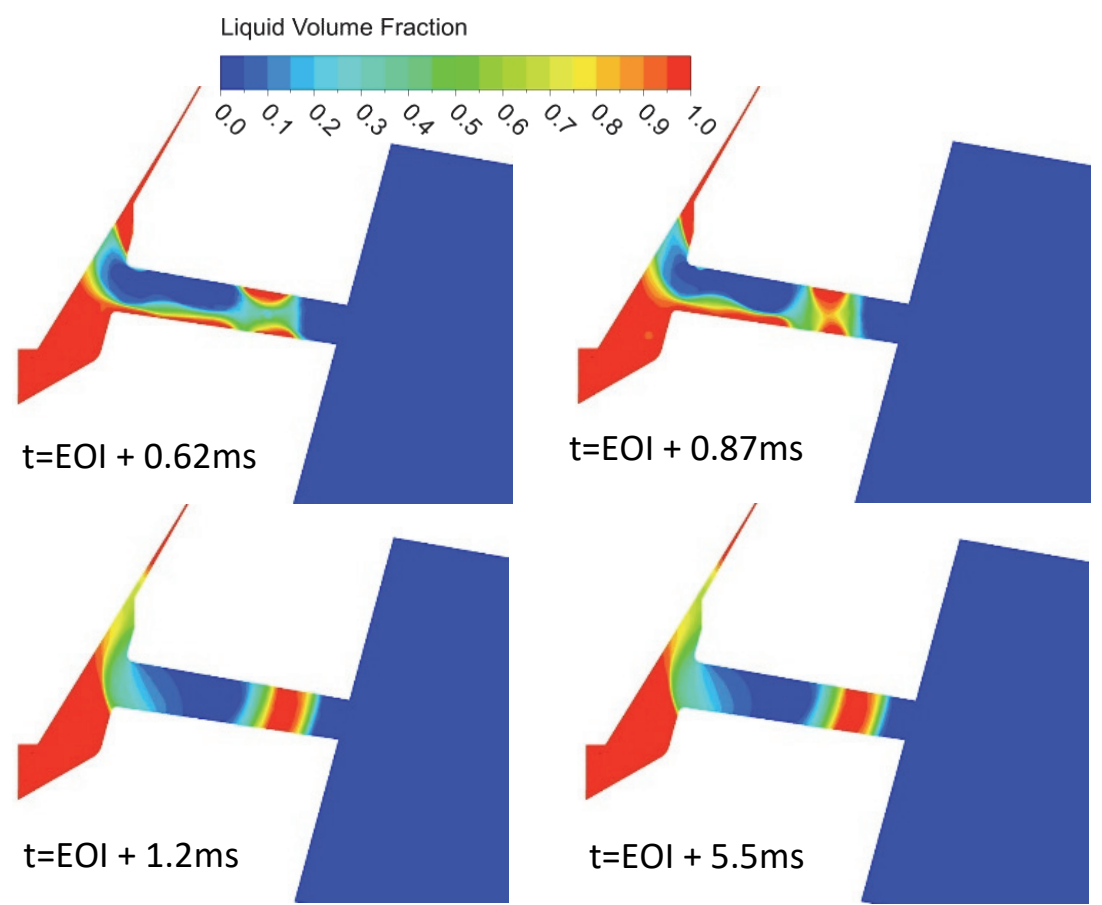

Figure 29. Liquid volume fraction at later timings AEOI, 400 bar inlet, 1 bar outlet, $300 \mathrm{~K}$ (Test Case 2).

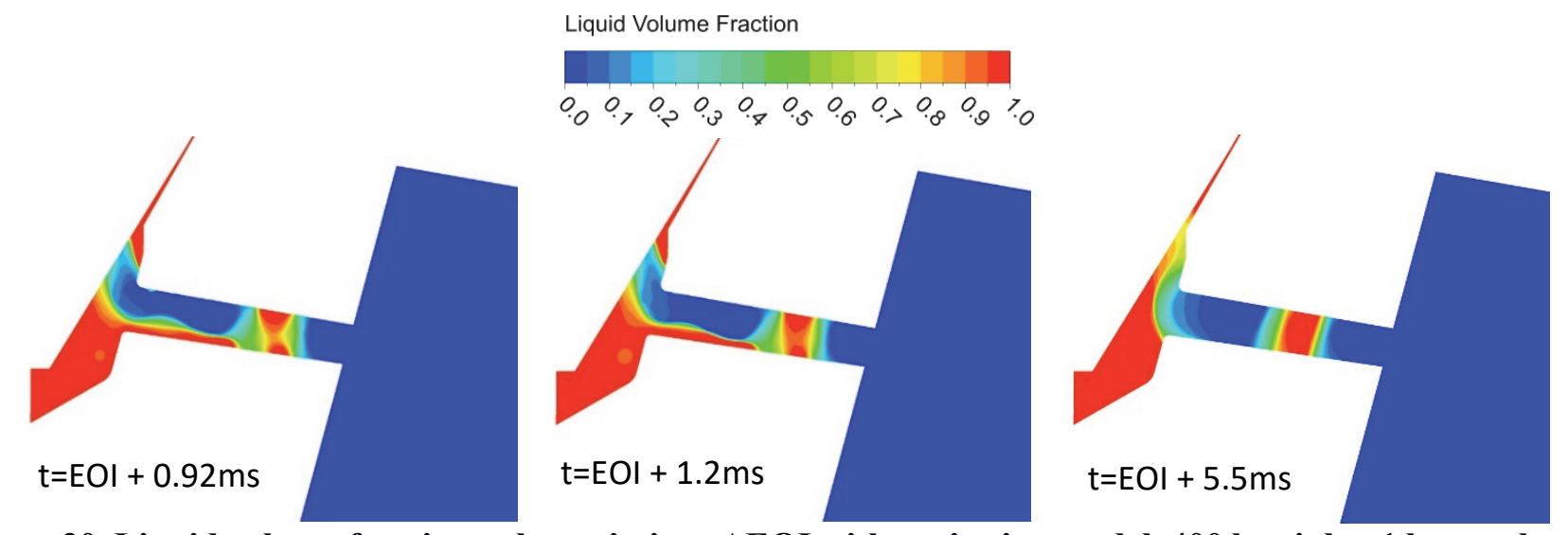

Figure 30. Liquid volume fraction at later timings AEOI with cavitation model, 400 bar inlet, 1 bar outlet, 300 K (Test Case 2). 


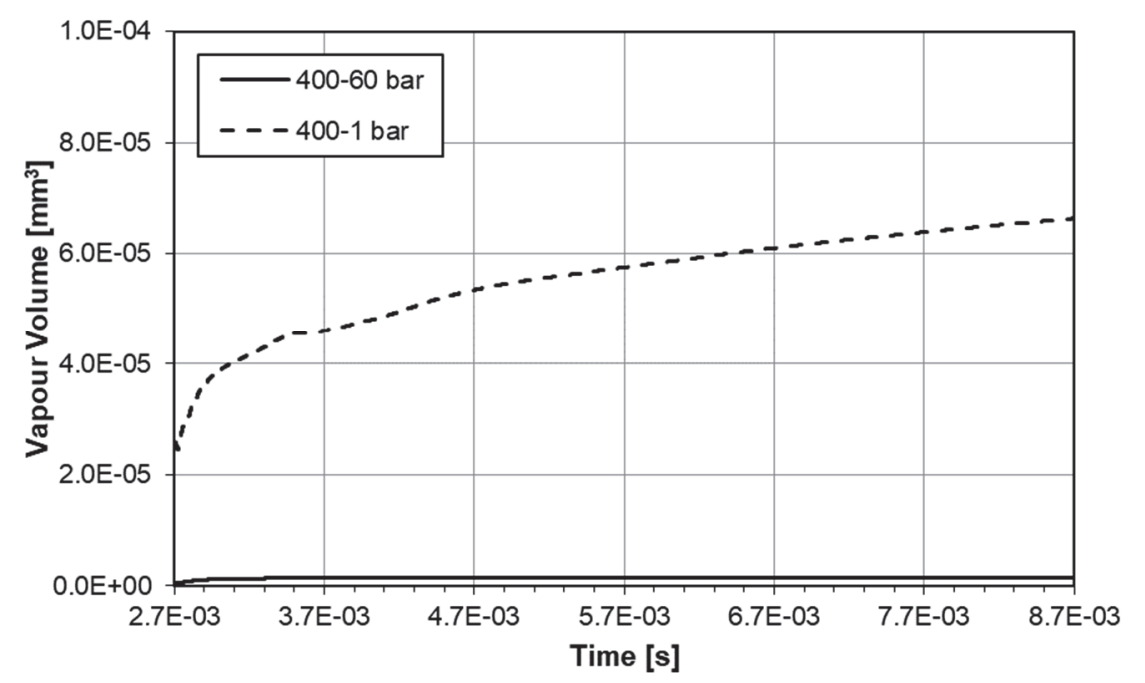

Figure 31. Total volume of vapour in the orifice AEOI, $400 \mathrm{bar}, 300 \mathrm{~K}$.
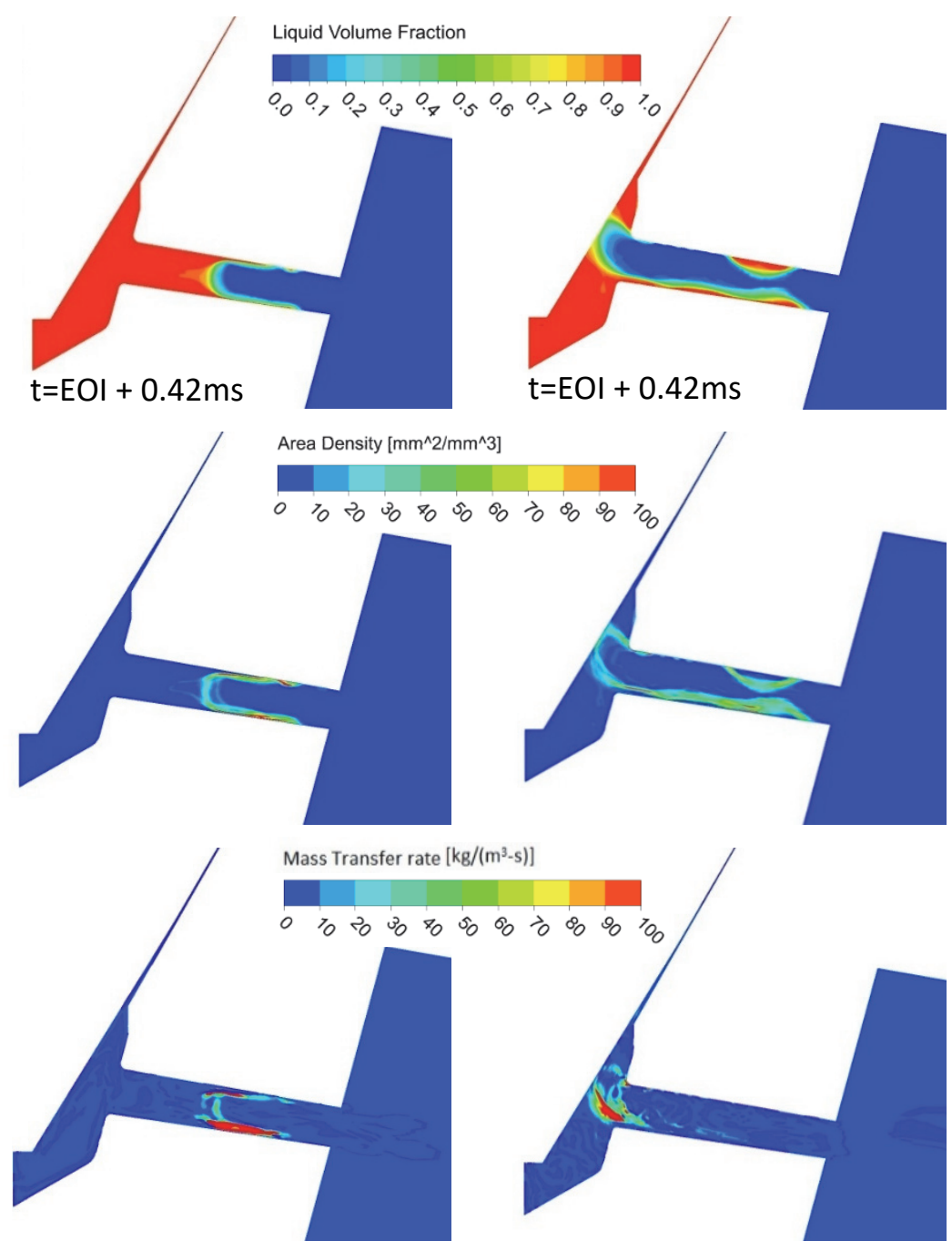

Figure 32. Liquid volume fraction, area density, mass transfer rate AEOI, 400 bar inlet, 60 bar outlet, $300 \mathrm{~K}$ (left, Test Case 1), 400 bar inlet, 1 bar outlet, $300 \mathrm{~K}$ (right, Test Case 2). 


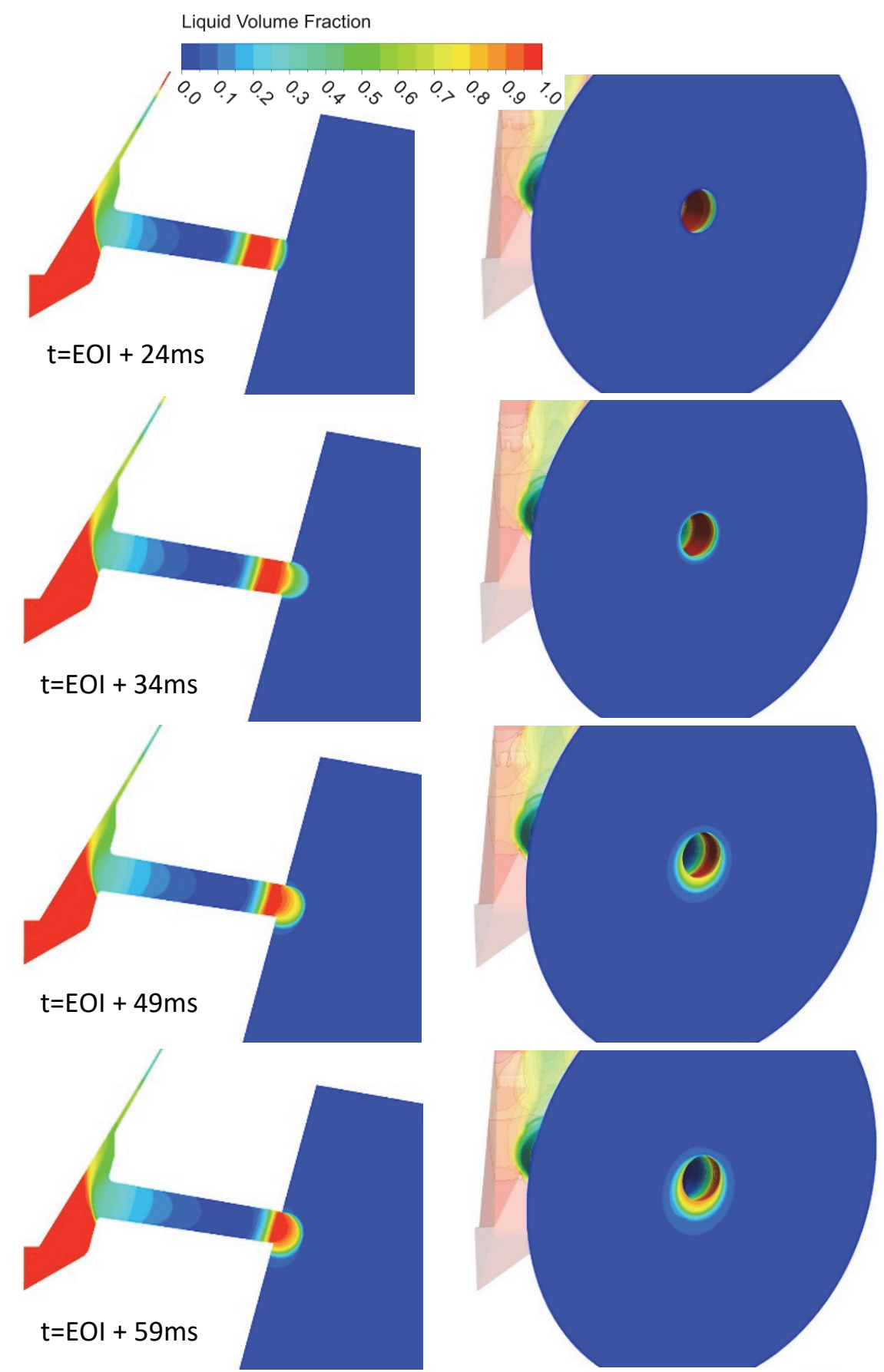

Figure 33. Liquid volume fraction at final stage AEOI with evaporation, 400 bar inlet, 1 bar outlet, $300 \mathrm{~K}$ (Test Case 2). 


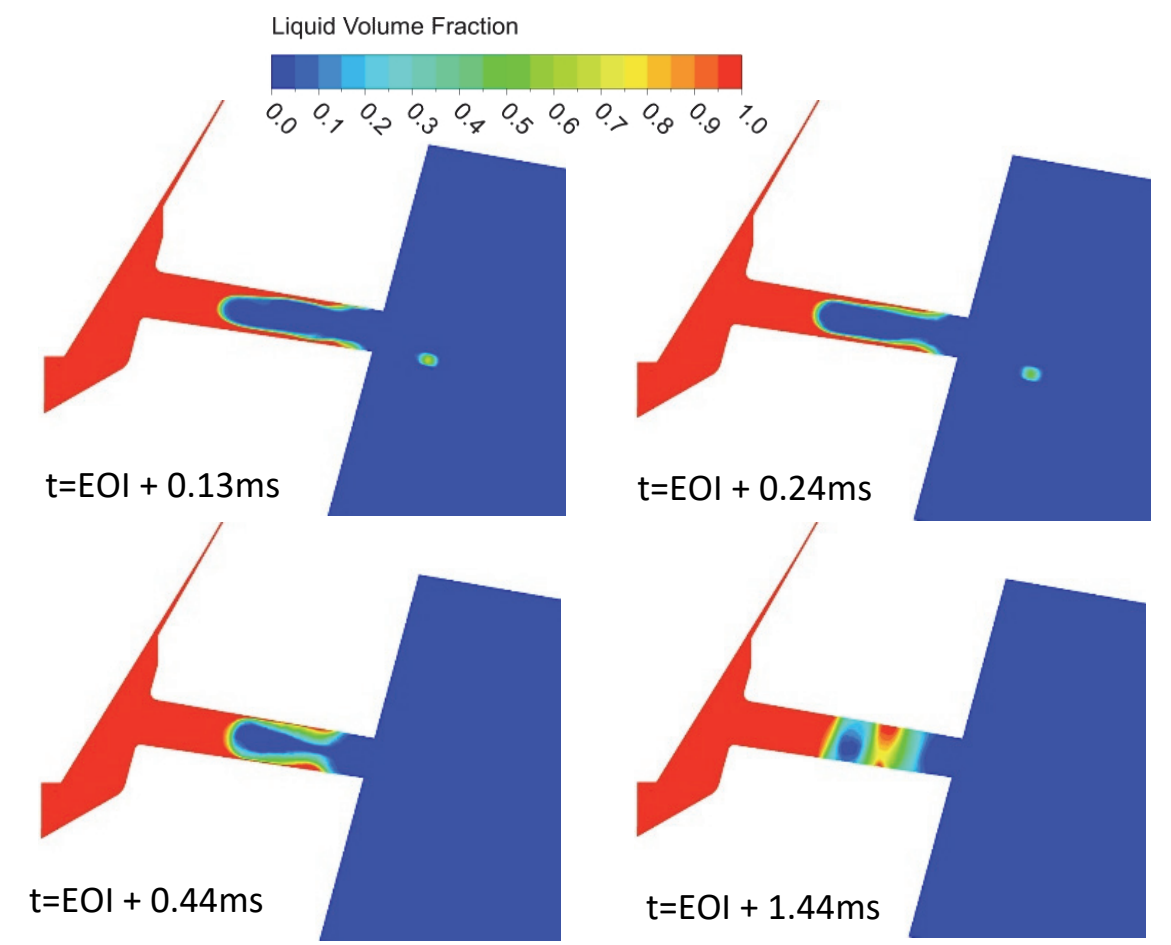

Figure 34. Liquid volume fraction at later timings AEOI, 900 bar inlet, 35 bar outlet, $300 \mathrm{~K}$ (Test Case 3).
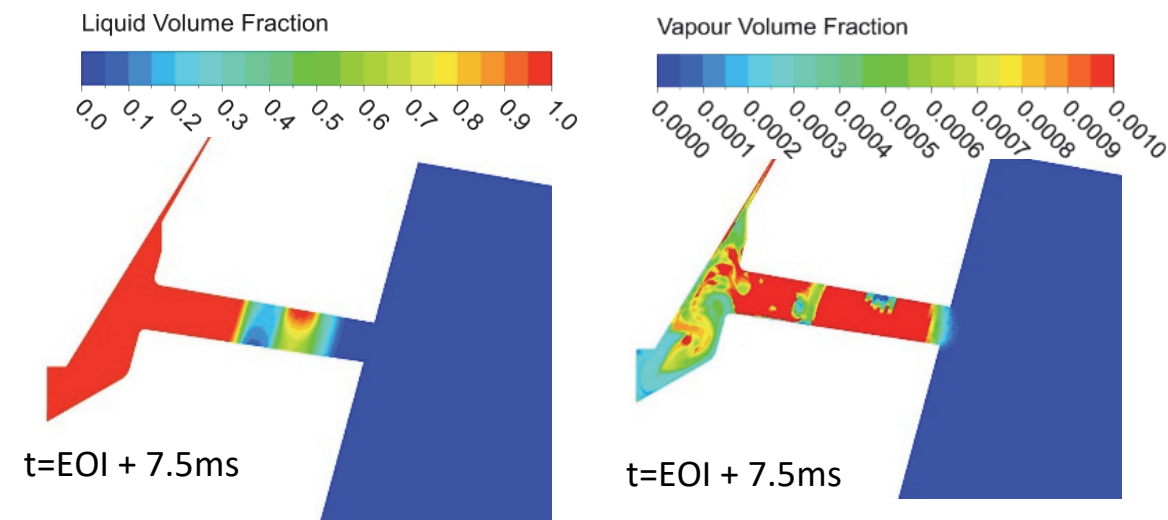

Figure 35. Liquid and vapour volume fraction at late timing AEOI, 900 bar inlet, 35 bar outlet, 300 K (Test Case 3). 

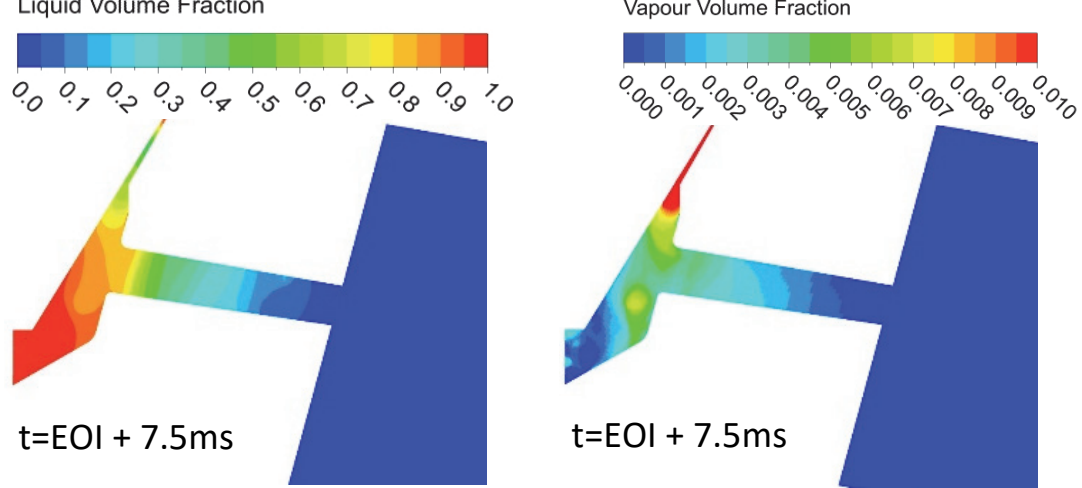

Figure 36. Liquid and vapour volume fraction at late timing AEOI, 900 bar inlet, 35 bar outlet, 353 K (Test Case 4).

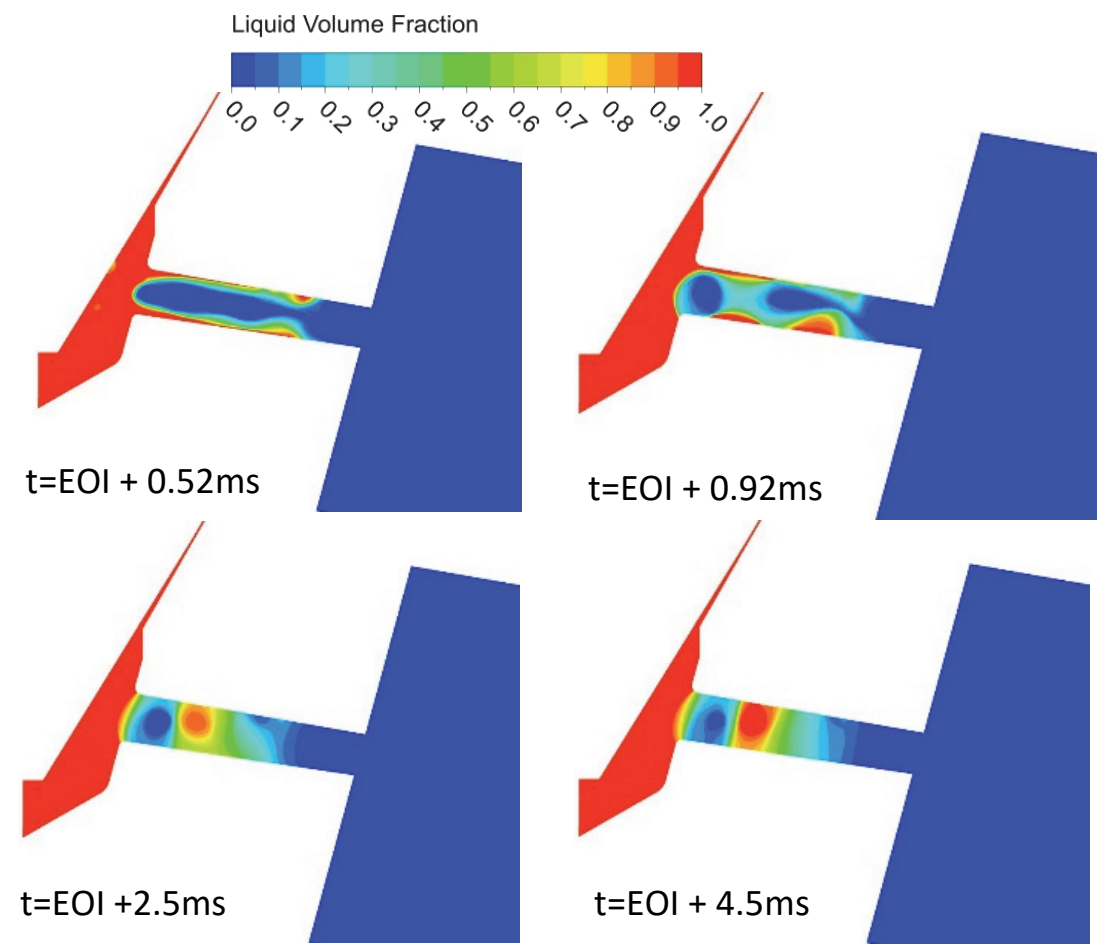

Figure 37. Liquid volume fraction at later timings AEOI, 900 bar inlet at $333 \mathrm{~K}, 35$ bar outlet at $550 \mathrm{~K}$ (Test Case 5). 


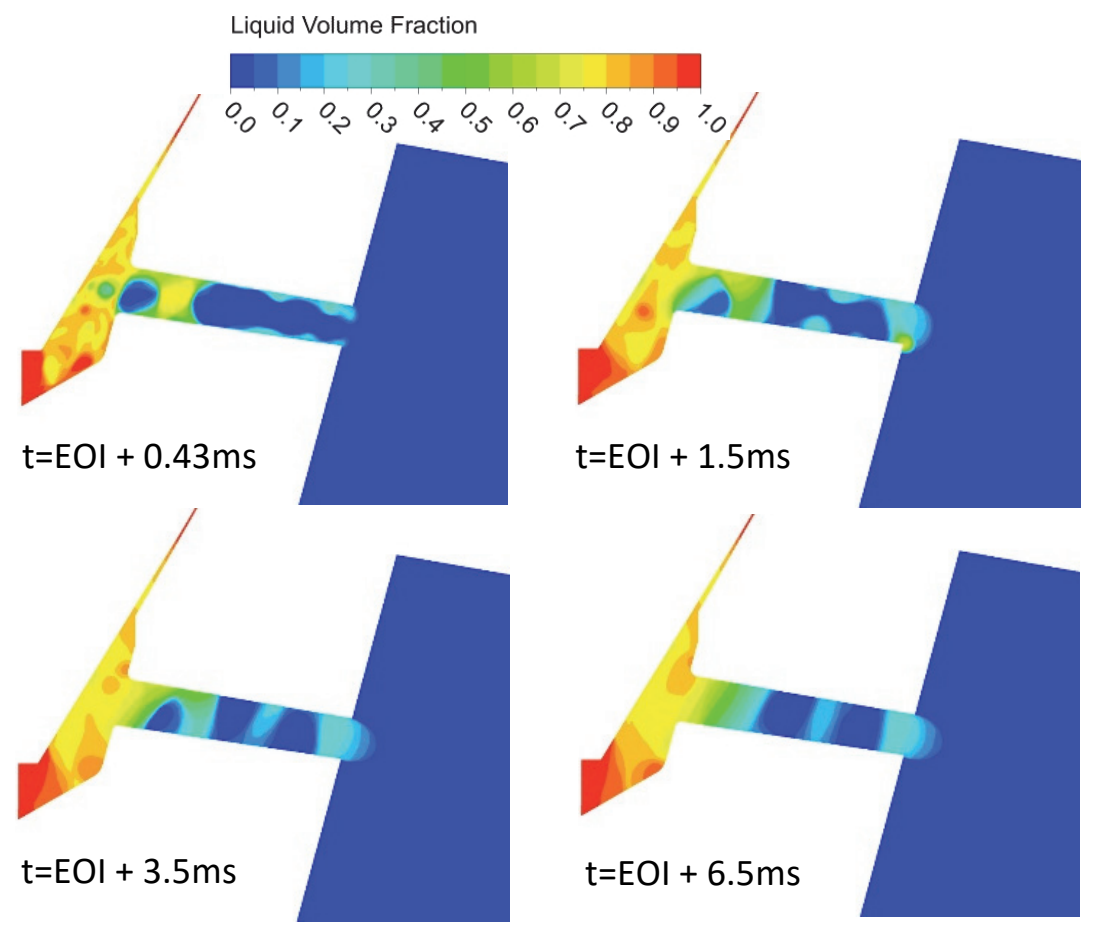

Figure 38. Liquid volume fraction at later timings AEOI, 900 bar $\mathrm{K}$ inlet, 35 bar outlet, $333 \mathrm{~K}$, walls at $473 \mathrm{~K}$ (Test Case 6).

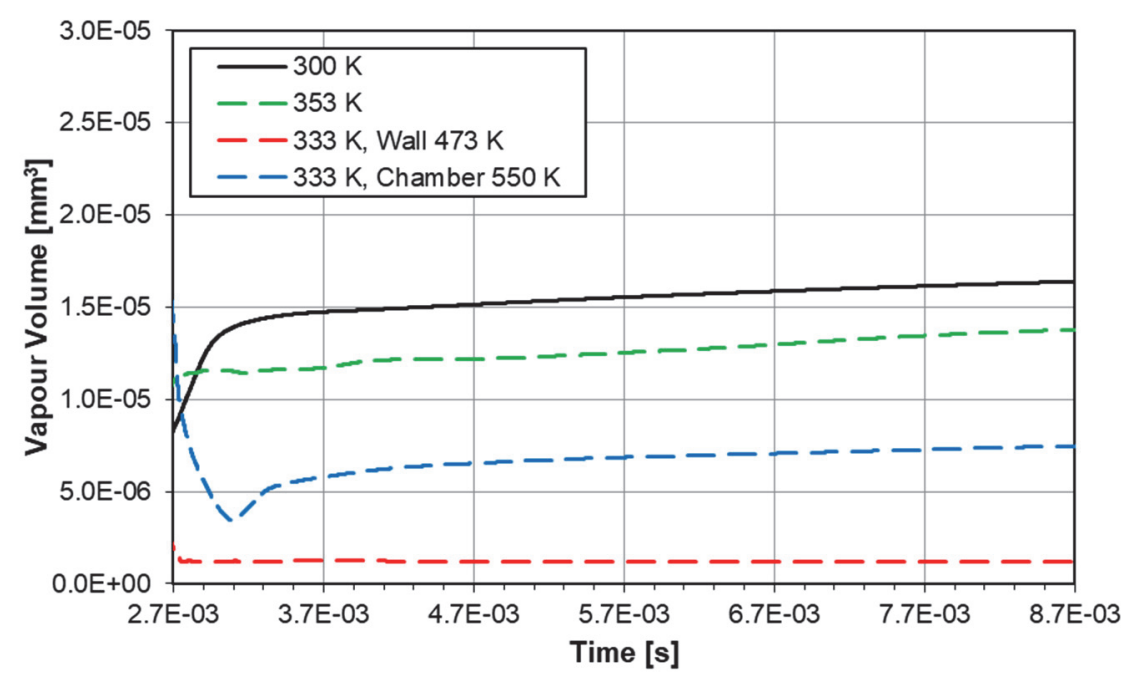

Figure 39. Total volume of vapour in the orifice AEOI, 900 bar.

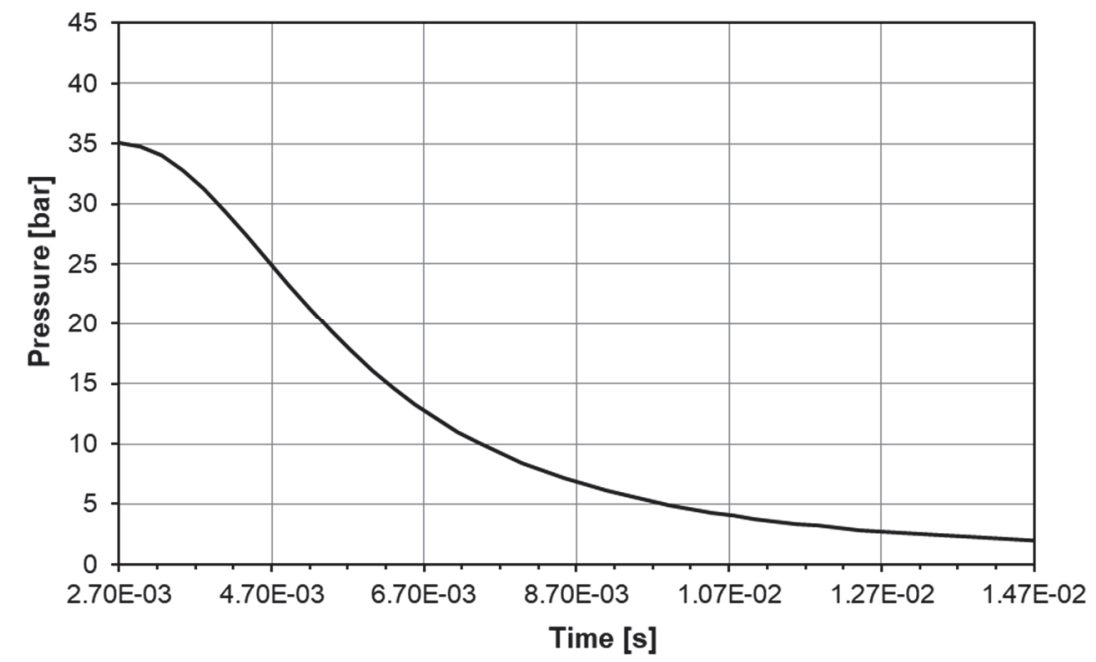

Figure 40. Engine expansion pressure trace used as dynamic outlet boundary condition. 


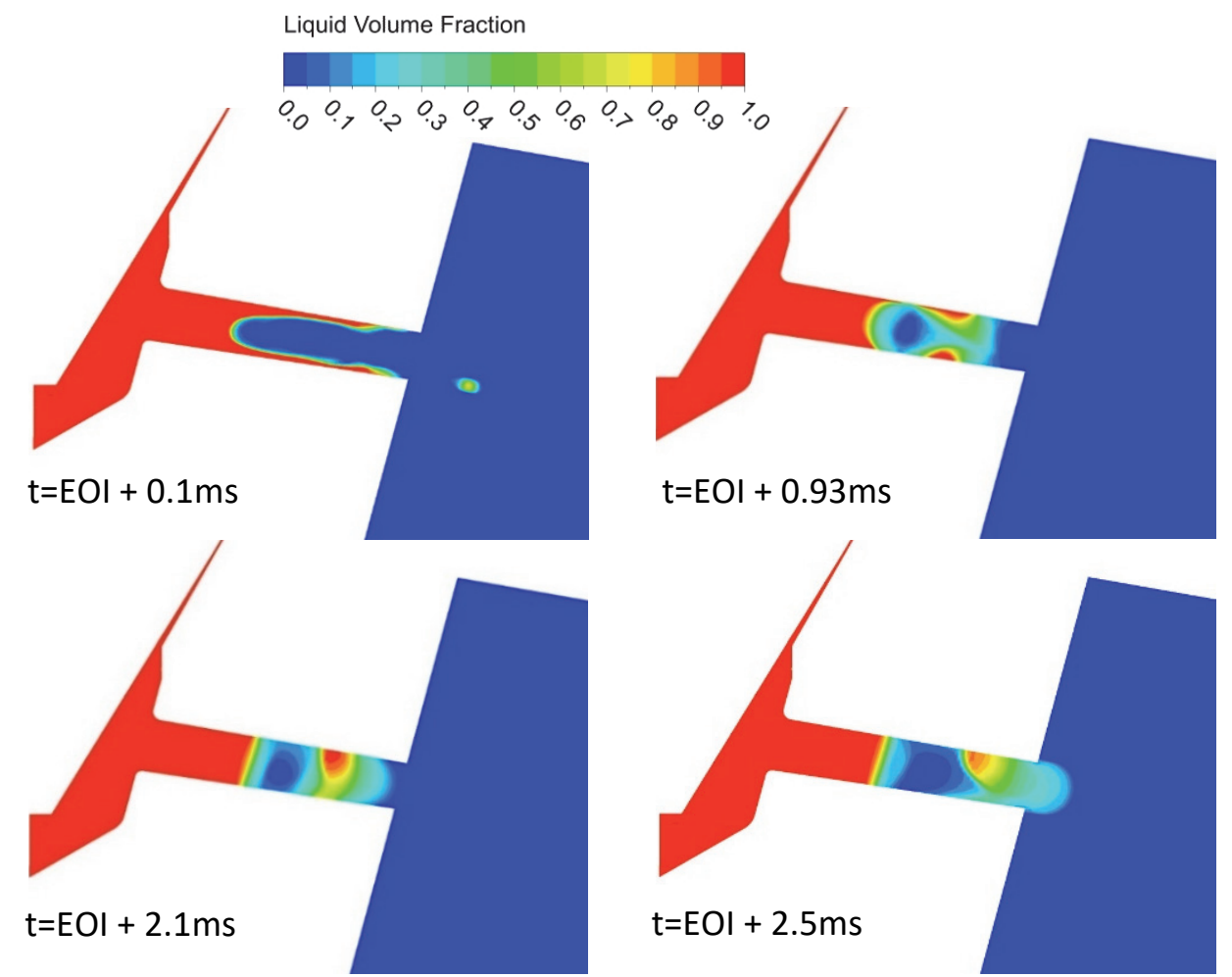

Figure 41. Liquid volume fraction at later timings AEOI with transient pressure outlet boundary, 900 bar inlet, 35 bar outlet, $300 \mathrm{~K}$ (Test Case 7).

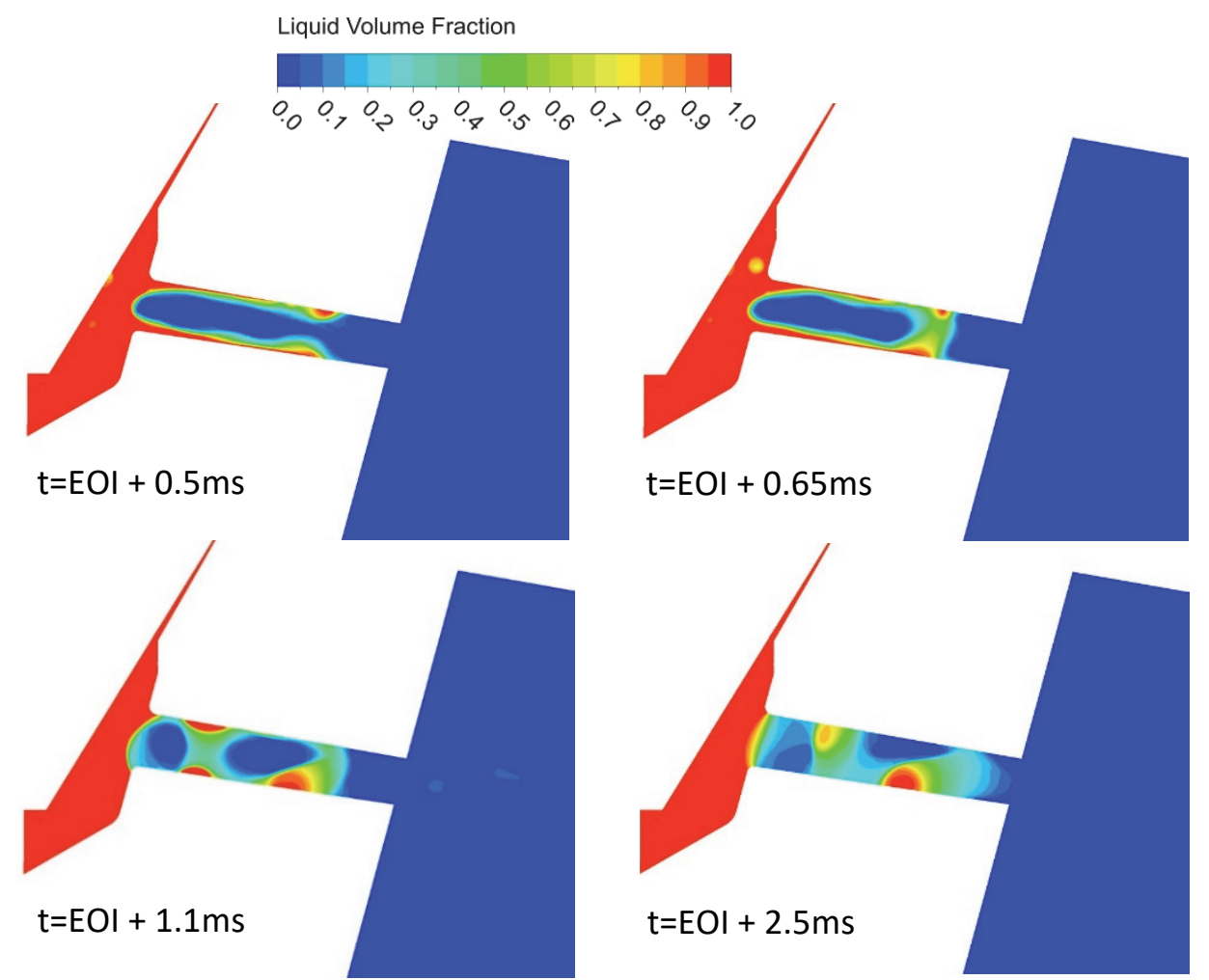

Figure 42. Liquid volume fraction at later timings AEOI with transient pressure outlet boundary, 900 bar inlet at $333 \mathrm{~K}, 35$ bar outlet at $550 \mathrm{~K}$ (Test Case 8). 


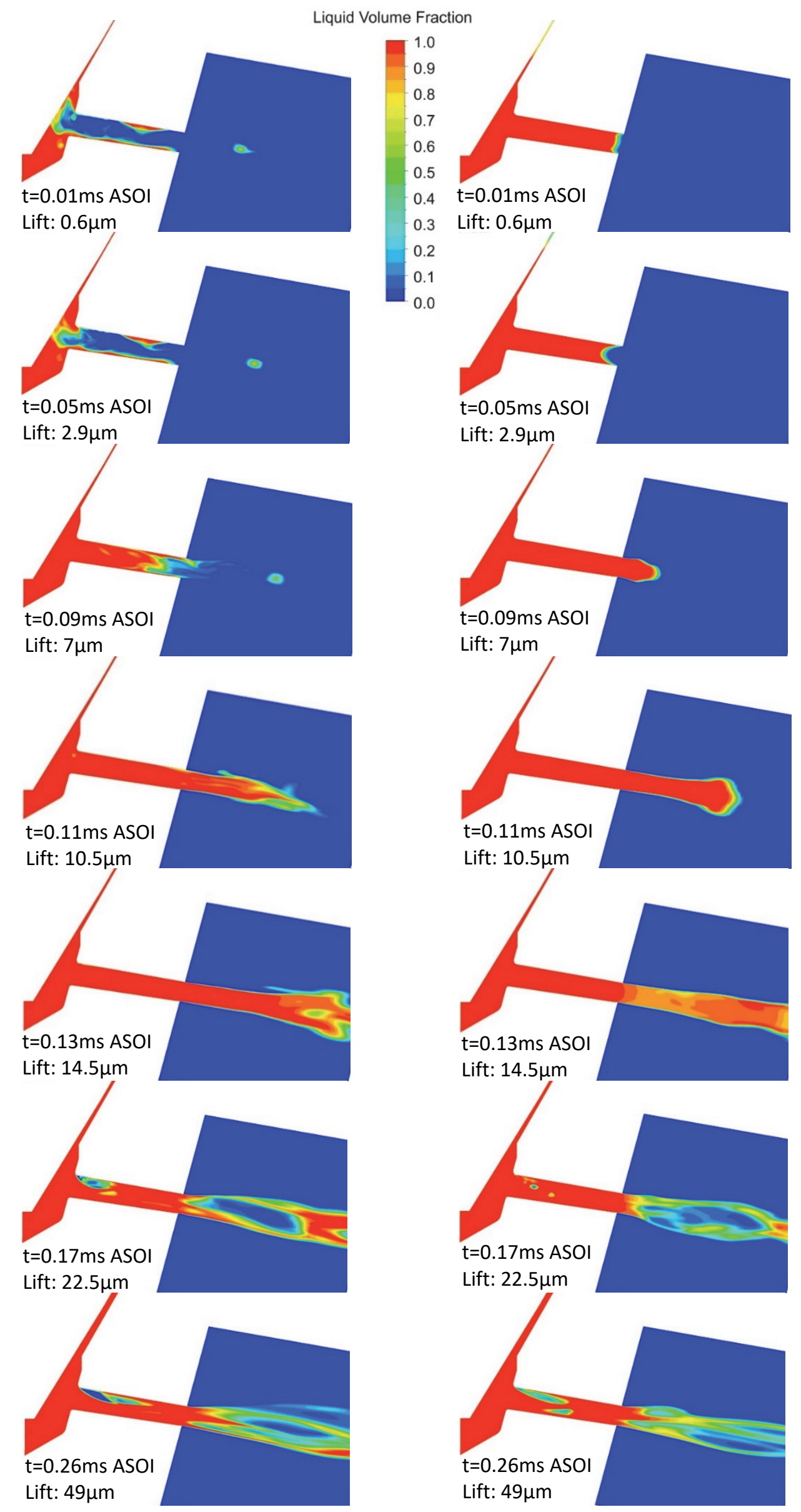

Figure 43. Liquid volume fraction at the beginning of injection by relifting the needle (left, Test Case 9) compared to the original needle lift with nozzle full of liquid fuel (right, Test Case 2). 